\title{
In Situ Monitoring of Mechanochemical Covalent Organic Framework Formation Reveals Templating Effect of Liquid Additive
}

Sebastian Emmerling, Luzia S. Germann, Patrick Julien, Igor Moudrakovski, Martin Etter, Tomislav Friscic, Robert E. Dinnebier, Bettina Lotsch

Submitted date: 22/09/2020 - Posted date: 23/09/2020

Licence: CC BY-NC-ND 4.0

Citation information: Emmerling, Sebastian; Germann, Luzia S.; Julien, Patrick; Moudrakovski, Igor; Etter, Martin; Friscic, Tomislav; et al. (2020): In Situ Monitoring of Mechanochemical Covalent Organic Framework Formation Reveals Templating Effect of Liquid Additive. ChemRxiv. Preprint. https://doi.org/10.26434/chemrxiv.12988829.v1

Covalent organic frameworks (COFs) have emerged as a new class of molecularly precise, porous functional materials characterized by a broad structural and chemical versatility, leading to a diverse range of applications. Despite the increasing popularity of COFs, fundamental aspects of their formation are poorly understood and profound experimental insights into their formation processes are still lacking. Here we use a combination of in situ X-ray powder diffraction and Raman spectroscopy to elucidate the reaction mechanism of mechanochemically synthesized imine COFs, leading to the observation of key reaction intermediates. Real-time monitoring provides experimental evidence of templating effects by the liquid additive for the subsequent pore formation and layer assembly. Moreover, the solid-state catalyst scandium triflate $\mathrm{Sc}(\mathrm{OTf})_{3}$ is revealed to be instrumental in directing the reaction kinetics and mechanism, resulting in products with crystallinity and porosity en par with solvothermally synthesized COFs. This work highlights the potential of mechanochemistry as a green synthetic route towards COF synthesis, and emphasizes the subtle interplay between choice of liquid additives, catalysts, and activation procedure.

File list (2)

Manuscript_COF-Milling_ChemRxiv.pdf (1.55 MiB) view on ChemRxiv • download file ESI_COF-Milling_ChemRxiv.pdf (3.30 MiB) view on ChemRxiv - download file 


\title{
In Situ Monitoring of Mechanochemical Covalent Organic Framework Formation Reveals Templating Effect of Liquid Additive
}

\author{
Sebastian T. Emmerling, ${ }^{a, b, \neq}$ Luzia S. Germann, ${ }^{a, c, \neq,}$ Patrick A. Julien, ${ }^{c}$ Igor Moudrakovski, ${ }^{a}$ Martin Etter, ${ }^{d}$ \\ Tomislav Friščić, ${ }^{c}$ Robert E. Dinnebier, ${ }^{a}$ and Bettina V. Lotsch ${ }^{\mathrm{a}, \mathrm{b}, *}$ \\ a Max-Planck-Institute for Solid State Research, 70569 Stuttgart, Germany, E-mail: b.lotsch@fkf.mpg.de \\ ${ }^{\mathrm{b}}$ Department of Chemistry, Ludwig-Maximilians-Universität (LMU), 81377 Munich, Germany \\ ${ }^{\mathrm{C}}$ Department of Chemistry, McGill University, H3A 0B8, Montreal, Canada. \\ ${ }^{d}$ Deutsches-Elektronen Synchrotron (DESY), 22607 Hamburg, Germany. \\ ${ }^{\ddagger}$ equal contribution
}

\begin{abstract}
Covalent organic frameworks (COFs) have emerged as a new class of molecularly precise, porous functional materials characterized by a broad structural and chemical versatility, leading to a diverse range of applications. Despite the increasing popularity of COFs, fundamental aspects of their formation are poorly understood and profound experimental insights into their formation processes are still lacking. Here we use a combination of in situ X-ray powder diffraction and Raman spectroscopy to elucidate the reaction mechanism of mechanochemically synthesized imine COFs, leading to the observation of key reaction intermediates. Real-time monitoring provides experimental evidence of templating effects by the liquid additive for the subsequent pore formation and layer assembly. Moreover, the solid-state catalyst scandium triflate $\mathrm{Sc}(\mathrm{OTf})_{3}$ is revealed to be instrumental in directing the reaction kinetics and mechanism, resulting in products with crystallinity and porosity en par with solvothermally synthesized COFs. This work highlights the potential of mechanochemistry as a green synthetic route towards COF synthesis, and emphasizes the subtle interplay between choice of liquid additives, catalysts, and activation procedure.
\end{abstract}

\section{Introduction}

Covalent organic frameworks (COFs) are an emerging class of organic solids whose chemical and structural modularity enable remarkable features including a highly tunable, molecularly precise backbone, paired with porosity and crystallinity. ${ }^{[1,2]}$ The reticular assembly of molecular building blocks with inherently different sizes, shapes, and flexibility into two- (2D) or three-dimensional (3D) frameworks of increasingly complex structures and topologies allows for the tailored design of functional materials with targeted properties. The so far proposed applications of COFs are many, including gas storage and separation, ${ }^{[3-5]}$ heterogeneous catalysis, ${ }^{[6-9]}$ waste water treatment, ${ }^{[10-12]}$ fuel cells, ${ }^{[13,14]}$ and sensing. ${ }^{[15-17]}$ COFs are typically synthesized by solution methods, e.g. solvothermally, sonochemically, using microwave irradiation, or in continuous flow, ${ }^{[18]}$ and more recently also by electron beam irradiation, ${ }^{[19]}$ as well as by mechanochemistry. ${ }^{[20-22]}$

Mechanochemistry, i.e. the application of mechanical agitation to conduct and sustain chemical and materials transformations, has recently been established as a cornerstone of green, sustainable solvent-free chemistry. ${ }^{[23-25]}$ Mechanochemistry has successfully been applied to a wide range of 
reactions, including the formation of nanoparticles, ${ }^{[26]}$ molecular cages, ${ }^{[27]}$ small molecules, ${ }^{[28]}$ cocrystals, ${ }^{[29,30]}$ solid electrolytes, ${ }^{[31]}$ coordination polymers, ${ }^{[32]}$ as well as metal-organic frameworks $(\mathrm{MOFs})^{[33]}$ and COFs. ${ }^{[20-22]}$ Mechanochemistry is not only highly efficient for the synthesis of new metastable solid phases, ${ }^{[33]}$ but is also a superior technique to screen and explore the phase landscape for new polymorphs or novel materials. ${ }^{[34,35]}$ Bulk mechanochemical reactions are usually performed by either direct grinding of reactants (neat grinding), or in the presence of grinding additives, as in liquid-assisted grinding (LAG). ${ }^{[36]}$ Recently, mechanistic studies of mechanochemistry have been facilitated by the development of methods for in situ monitoring using synchrotron X-ray powder diffraction (XRPD), ${ }^{[37,38]}$ Raman spectroscopy, ${ }^{[39,40]} \mathrm{X}$-ray absorption spectroscopy, ${ }^{[41]}$ solid-state nuclear magnetic resonance spectroscopy (ssNMR), ${ }^{[42]}$ and/or thermal measurements. ${ }^{[43]}$ This has enabled rapid progress in fundamental understanding of mechanochemical processes and the discovery of new materials. ${ }^{[4]}$

Although COFs are well established, mechanistic and time-resolved formation studies are quite rare. While previous work has mostly focused on characterization, ${ }^{[45-47]}$ post-synthetic modifications and transformations of COFs, ${ }^{[48-50]}$ only a handful of reports so far have investigated the linkage formation, particle growth, and self-assembly process itself. ${ }^{[51,52]}$ This previous work has been done either through solution-based studies (e.g. using turbidity), ${ }^{[33]}$ in situ wide-angle X-ray diffraction, ${ }^{[54]}$ and nuclear magnetic resonance (NMR) measurements, as well as theoretical investigations, ${ }^{[1,55]}$ thus often lacking direct structural information during the COF formation.

Here we report the first real-time mechanistric study of mechanochemical COF formation using time-resolved in situ synchrotron XRPD and Raman spectroscopy. A library of four different 2D hexagonal imine COFs based on $C_{2}$ and $C_{3}$ linkers were chosen as model systems, with only one system (COF-LZU1) previously prepared mechanochemically. ${ }^{[20]}$ The effects of liquid additive and catalyst on reaction kinetics and product formation were investigated, revealing pronounced effects on COF formation, both regarding the reaction kinetics and mechanism as well as crystallinity of the products. The time-resolved in situ experiments led to the observation of crystalline reaction intermediates, with direct evidence of templating effects by the liquid additive, highlighting the role and critical importance of solvent choice during COF synthesis.

\section{Results and discussion}

Real-time in situ XRPD measurements were performed at the Powder Diffraction and Total Scattering beamline P02.1 at the Deutsches Elektronen-Synchrotron (DESY) using a modified Retsch MM400 ball mill operating at a milling frequency of $30 \mathrm{~Hz} \cdot{ }^{[37]}$ The reactions were carried out in custommade $5 \mathrm{~mL}$ volume X-ray transparent poly(methyl methacrylate) (PMMA) milling jars, enabling direct, realtime monitoring of the mechanochemically formed COFs with a time resolution of 10 or $20 \mathrm{~s}$. We used a combination of different $C_{2}$ and $C_{3}$ amine and aldehyde linkers, forming four different hexagonal imine COFs (Figure 1). Reactions were performed with one $7 \mathrm{~mm}$ diameter stainless steel ball (1.38 grams weight), using a 1,4-dioxane/mesitylene mixture (1:1 v/v) as a liquid additive, with either aqueous acetic acid $(\mathrm{AcOH})$ or scandium(III) triflate $\left(\mathrm{Sc}(\mathrm{OTf})_{3}\right)$ as a catalyst. The optimal reaction conditions were extensively screened prior to the beamtime by maximizing the measured diffraction intensities of the assynthesized COFs in laboratory XRPD measurements. This step was crucial to maximize the diffraction signal of the weakly scattering light-element based COFs during in situ monitoring with the given setup (Figure $\mathrm{S} 6$ in Electronic Supporting Information, ESI). 
a

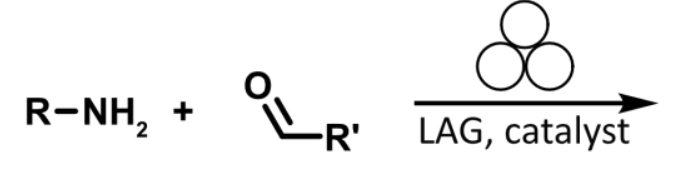

b

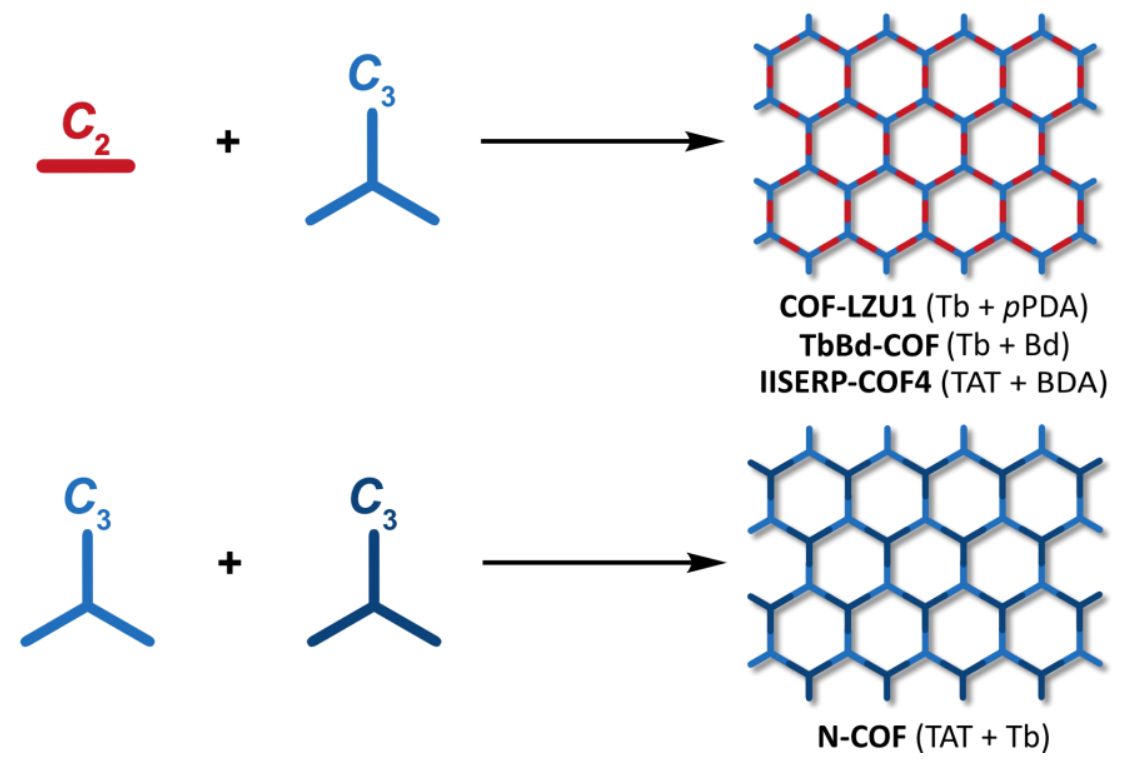

C

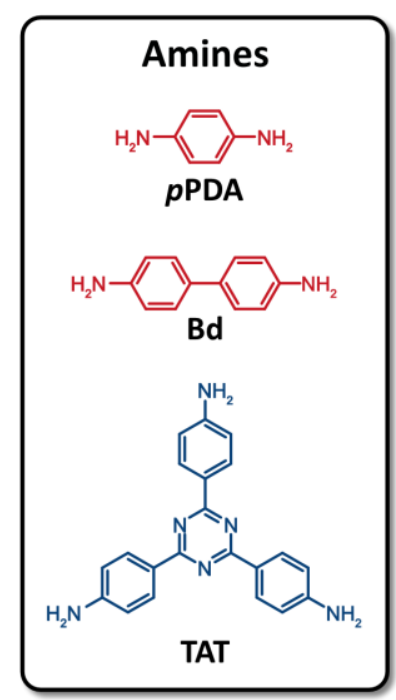

Aldehydes

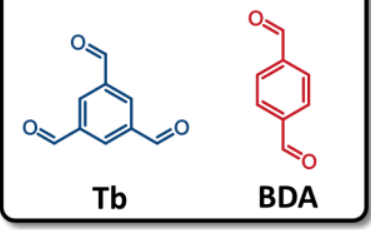

Figure 1. (a) Schematic representation of imine COF synthesis starting from an amine and aldehyde precursor. (b) Combinations of $C_{2}$ and $C_{3}$ as well as $C_{3}$ and $C_{3}$ linkers resulting in reticular 2D hexagonal COF structures. (c) Representation of the amine and aldehyde linkers used throughout this study. Sign for mechanochemistry (three balls) adapted from Rightmire and Hanusa. ${ }^{[56]}$

\section{In situ monitoring of COF formations}

In situ monitoring of mechanochemical COF-LZU1 $1^{[9]}$ formation was performed by milling paraphenylenediamine ( $p$ PDA) with 1,3,5-triformylbenzene (Tb) in the presence of a 1,4-dioxane/mesitylene mixture $(1: 1 \mathrm{v} / \mathrm{v})$ using $\mathrm{AcOH}$ as catalyst with the ratio of liquid additive volume to reactant weight $(\eta$ parameter $)^{[36]}$ of $0.60 \mu \mathrm{L} / \mathrm{mg}$. Unexpectedly, the formation of COF-LZU1 proceeded via a reaction intermediate (1), visible by the appearance of new Bragg reflections at $2.3,2.4,2.5$, and $3.2^{\circ} 2 \theta$ (Figure 2a). This previously unknown phase was later identified and characterized by ex situ diffraction and spectroscopic techniques. The COF formation was readily followed by integrating the most intense COF and intermediate Bragg reflections. The intermediate formed immediately upon grinding, simultaneously with the loss of $p$ PDA signal and only traces of Tb remaining after ca. 3 minutes. The (100) COF X-ray reflection appeared after ca. 3 mins, with an initial fast increase, reaching a slower transformation around ca. $15 \mathrm{~min}$, exhibiting a typical sigmoidal reaction curve. ${ }^{[57]}$ The reaction was found to be complete after ca. 25 min, coinciding with the disappearance of the diffraction signal of 1 (Figure 2b). Measured ex situ XRPD pattern show the formation of COF-LZU1 in accordance with previous reports (Figure S10). ${ }^{[9,58]}$ 
a
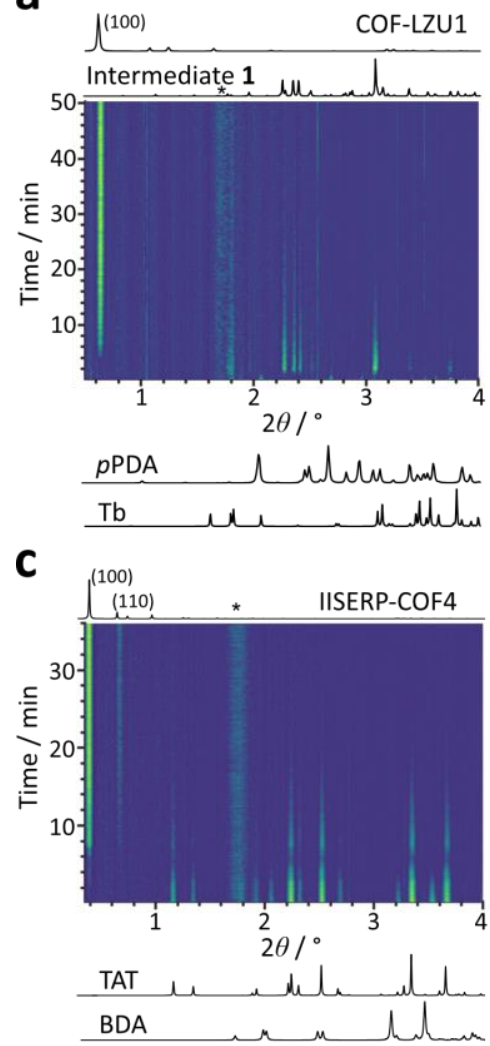

b

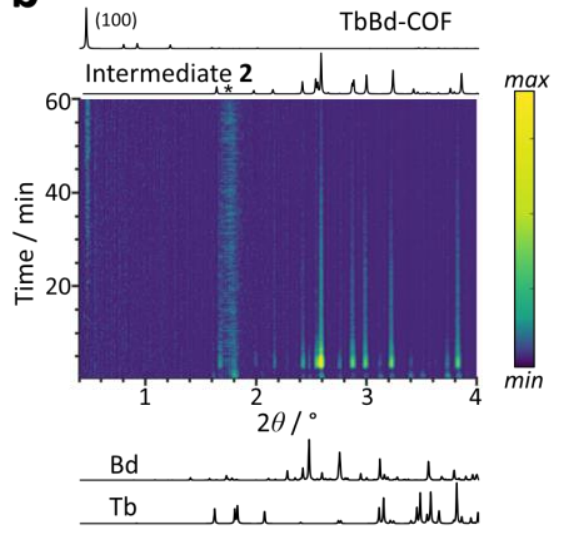

d

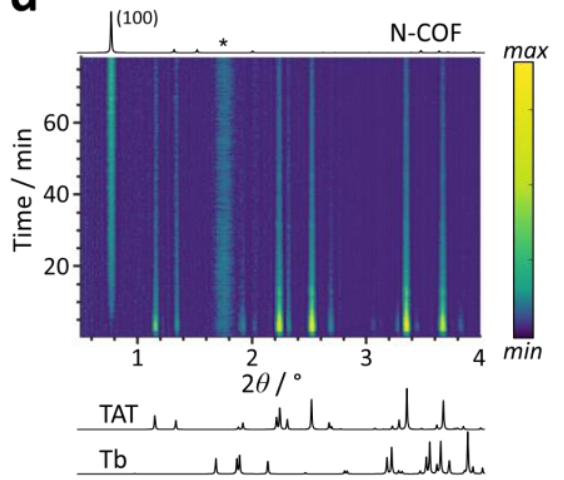

e
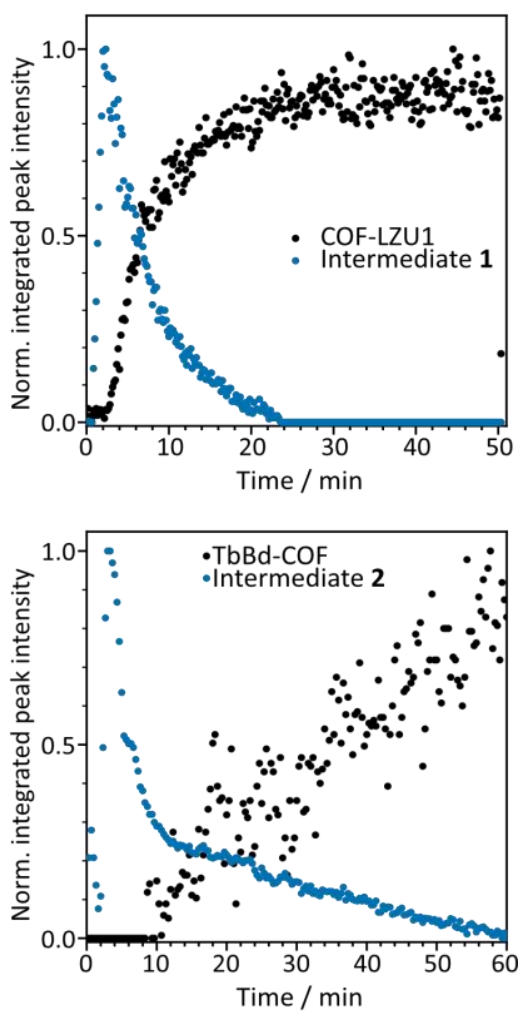

Figure 2. Background subtracted 2D XRPD plots for the mechanochemical reaction of (a) COF-LZU1, (b) TbBd-COF, (c) IISERPCOF4, and (d) N-COF using AcOH as catalyst. Calculated XRPD patterns of reactants, 1, 2, and COFs are shown below and above the $2 \mathrm{D}$ plots $\left(\lambda=0.207 \AA\right.$ ). Diffraction of PMMA is visible by the broad peak around $1.7^{\circ} 2 \theta$, marked by an asterisk. Artefacts from background subtraction appear at ca. 1.1 and $2.6^{\circ} 2 \theta$ in (a) due to background subtraction. (e) Normalized integrated peak intensities of COF-LZU1 and $\mathbf{1}$ (top) and TbBd-COF and $\mathbf{2}$ (bottom).

Next, the isoreticular TbBd-COF ${ }^{[59]}$ was synthesized by milling benzidine (Bd), a similar diamine linker with an extended length of one phenyl group, with Tb. Mechanochemical formation of TbBd-COF was conducted using a 1,4-dioxane/mesitylene $(1: 1, \mathrm{v} / \mathrm{v})$ mixture with $6 \mathrm{M} \mathrm{AcOH}$ as catalyst $(\eta=$ $0.61 \mu \mathrm{L} / \mathrm{mg}$ ). As for COF-LZU1, the COF formation proceeds via a reaction intermediate (2), with corresponding diffraction signals at $2.4,2.6,2.9,3.0,3.2$ and $3.8^{\circ} 2 \theta$ (Figure $2 b$ ). The reaction was readily followed by integrating the most intense Bragg reflections of the intermediate and TbBd-COF. The diffraction signals of the reactants were barely visible after few minutes with the intermediate appearing after ca. 4 min. The COF formation was found to be significantly slower in comparison to COF-LZU1, with signals from the COF only starting to appear after an initial induction time of ca. 10 min and the diffraction signal of the intermediate visible up to 60 min of milling (Figure $2 \mathrm{~b}, \mathrm{e}$ ). The measured ex situ XRPD patterns show the successful formation of TbBd-COF in accordance with previous reports (Figure S10). ${ }^{[59]}$

The third COF in the series of $C_{3}-C_{2}$ linkers, IISERP-COF4, ${ }^{[60]}$ was obtained by milling 2,4,6-tris(4aminophenyl)-1,3,5-triazine (TAT) with terephthaladehyde (BDA) in the presence of 1,4-dioxane/mesitylene (1:1 v/v) using $6 \mathrm{M} \mathrm{AcOH}$ as catalyst $(\eta=0.94 \mu \mathrm{L} / \mathrm{mg}$ ) (Figure 2c). No reaction intermediate was observed in this case and the reaction was readily followed by integrating the most intense Bragg reflections of the reactants and the (100) X-ray reflection of the IISERP-COF4 product (Figures 2c and S9). Notably, the second most intense (110) X-ray reflection was also observed during in 
situ monitoring (Figure 2c). The formation of the COF starts after an induction period of approx. $10 \mathrm{~min}$, with an initially steep growth rate, and is complete after 40 minutes of milling time. Full consumption of TAT was only achieved after around 60 minutes of milling time. Measured ex situ XRPD patterns show the formation of IISERP-COF4 in accordance with literature reports (Figure S10). ${ }^{60]}$

Next, we monitored the mechanochemical formation of $\mathrm{N}-\mathrm{COF}^{[61]}$ by milling the two $\mathrm{C} 3$ linkers TAT and Tb in a 1:1 ratio using a 1,4-dioxane/mesitylene $(1: 1 \mathrm{v} / \mathrm{v})$ with $6 \mathrm{M} \mathrm{AcOH}$ as catalyst $(\eta=0.73$ $\mu \mathrm{L} / \mathrm{mg}$ ) (Figure $2 \mathrm{~d}$ ). The reaction was readily followed by integrating the most intense Bragg reflections of the reactants and the (100) reflection of N-COF. There was no apparent evidence for a crystalline intermediate during the synthesis. The COF formation started after an induction period of ca. 4 minutes, with an initial fast formation rate in the first 20 minutes and subsequently a continuous growth regime (Figures $2 \mathrm{~d}$ and S9). The reaction did not reach completion within the measured time frame of 80 minutes, visible by the remaining diffraction peaks of TAT linker. XRPD patterns measured ex situ confirm the formation of $\mathrm{N}-\mathrm{COF}$ in accordance with previous reports (Figure S10). ${ }^{[61]}$

\section{Structure elucidation of reaction intermediates}

We attempted to separately synthesize and ex situ characterize the first reaction intermediate 1 using reaction conditions identical to those used for the in situ reaction of COF-LZU1. Subsequent analysis of the reaction mixture after 3 min of milling failed due to poor XRPD data quality and time-resolved XRPD measurements of the reaction mixture indicated that the mixture further polymerized into poorly crystalline COF-LZU1 over several hours (Figure S5). In situ Raman monitoring under similar reaction conditions indicated that the first reaction step constitutes an imine condensation reaction, visible by the appearance of the strong Raman band at $1623 \mathrm{~cm}^{-1}$, assigned to the $v_{C=N}$ vibration (Figure S19). Further milling led to an increase in baseline of the Raman spectra, likely caused by fluorescence associated with the assembly of the conjugated $\pi$-system of COF-LZU1 (Figure S18). Since the diffraction signal of the Tb linker coexisted with intermediate 1 during the time-resolved in situ measurement of COF-LZU1 formation, we expected 1 to exhibit a molecular composition of pPDA and substoichiometric Tb. Therefore, a 1 to 3 ratio of Tb:pPDA was milled to prepare the suspected trimeric intermediate 1 . Indeed, the crystal structure of 1 was successfully solved $a b$ initio from ex situ XRPD analysis, revealing the condensation of the trimesaldehyde in the form of a solvate with the presence of 0.5 eq. of 1,4-dioxane per sum formula, which was further confirmed by liquid and solid-state NMR (ssNMR), Fourier-transform infrared (FT-IR) and high-resolution mass spectroscopy, as well as thermal gravimetric analysis measurements (TGA, see ESI).

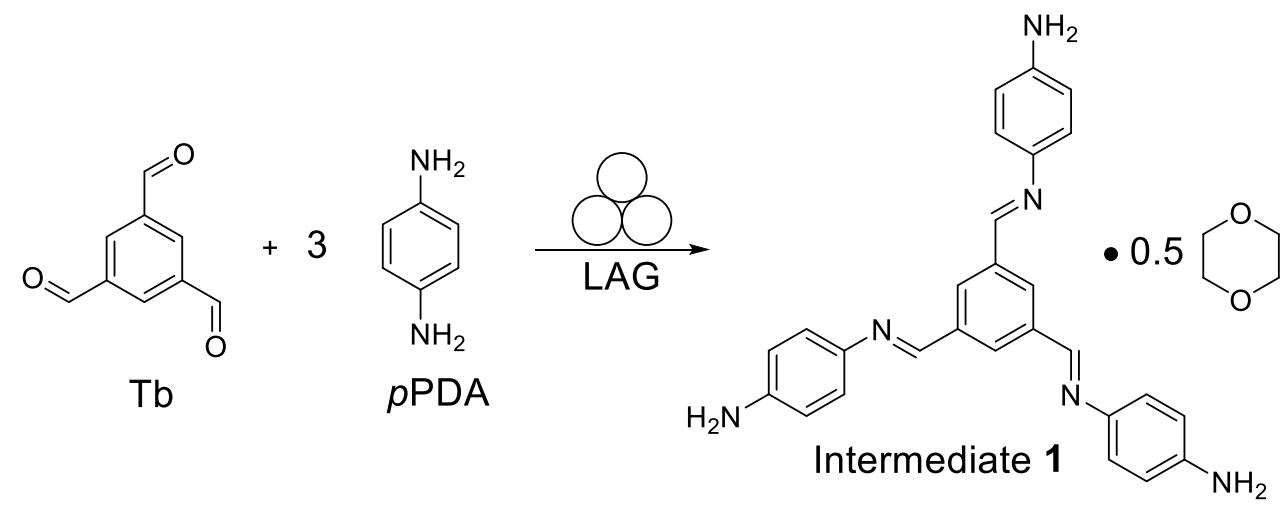

Scheme 1: Mechanochemical formation of intermediate 1 by milling Tb with three eq. pPDA, requiring 1,4-dioxane as liquid additive. 
Intermediate 1 crystallizes in the triclinic space group $P \overline{1}$ with one fully condensed trimer and half a 1,4dioxane in the asymmetric unit. The trimers form a layered hydrogen bonded network whereas two amines interacting with adjacent imines and the third amine forms a weak $\mathrm{N}-\mathrm{H} \cdots \pi$ hydrogen bond (Figure 3a). This is in good agreement with the ${ }^{15} \mathrm{~N}$ ssNMR spectrum, where two peaks for the three crystallographically inequivalent amine were observed (Figure S33). Adjacent hydrogen bonded layers possess an offset with respect to each other of approx. $1 / 2$ of the repeating unit. Prominently, 1,4-dioxane is embedded between two condensed amine dimers forming rhombohedrally shaped cavities (Figure 3a). The intermediate can conceptually be "transformed" into the final COF-LZU1 by rotation and/or translation of the condensed imines within the hydrogend bonded layer, connected through the missing equivalent number of Tb linkers (Figure 4). In this process, 1,4-dioxane acts as a template for the subsequent pore formation during the COF-LZU1 assembly.

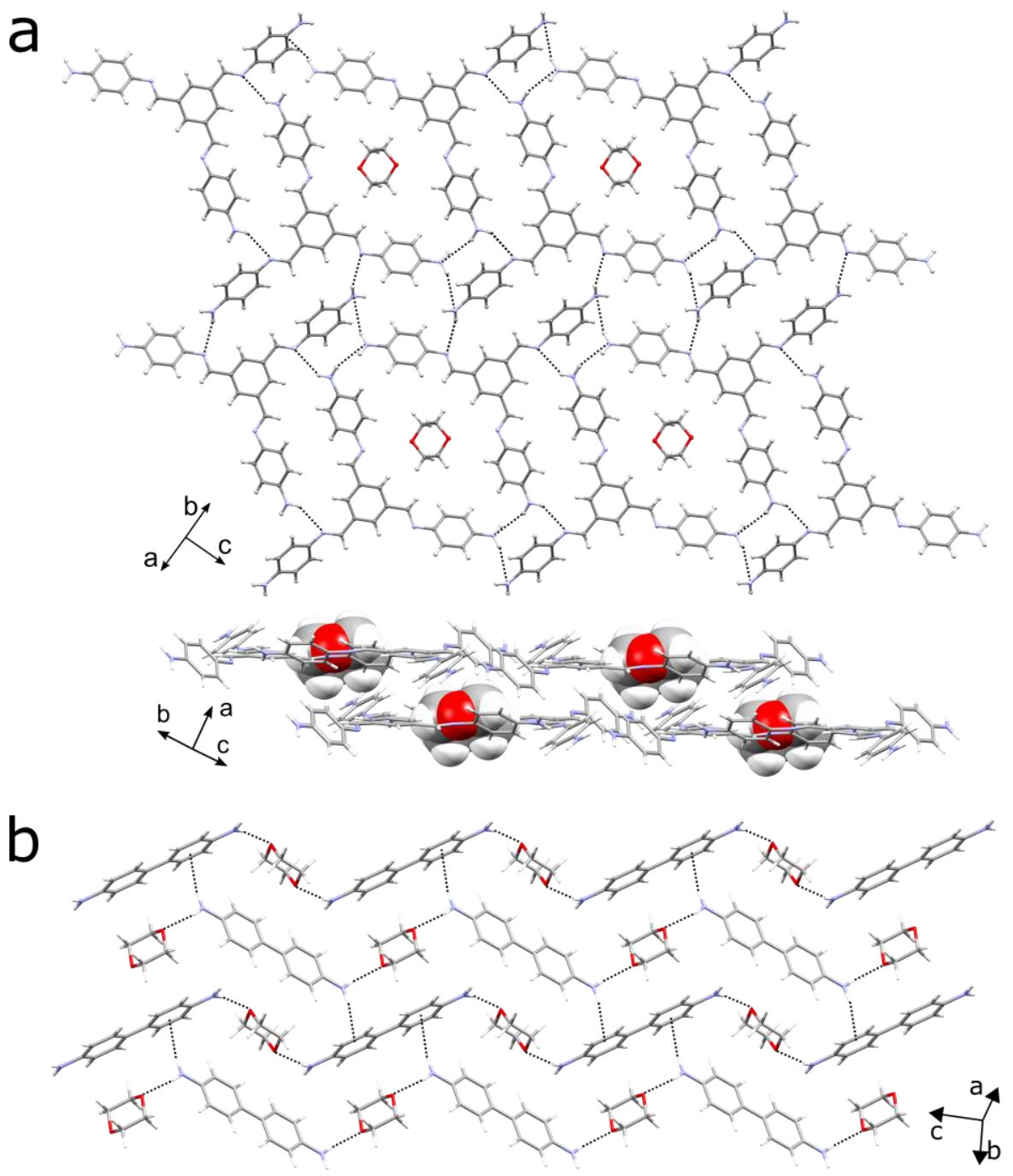

Figure 3. Crystal structures of (a) reaction intermediate 1 with view onto one hydrogen bonded layer (top) and perpendicular to it (bottom), as well as (b) intermediate 2. Hydrogen bonds and $\mathrm{N}-\mathrm{H} \cdots \pi$ interactions are represented by dashed lines.

The imine formation also occurred during neat grinding, i.e. milling without the addition of a liquid additive or catalyst, leading to the formation of a non-solvated imine trimer 1' (Scheme S1). Liquid and ssNMR spectra of the trimers were essentially the same except for the absence of the 1,4-dioxane signals 
in the non-solvated form (Figures S28-36). The crystal structure of the non-solvated trimer could not be determined, due to poor crystallinity in addition to the presence of potentially two polymorphs. ${ }^{13} \mathrm{C}$ and ${ }^{15} \mathrm{~N}$ ssNMR spectra suggest that two phases with identical chemical connectivity but slightly different intermolecular arrangement are present (Figures S35, S36). These differences compared to the solvated intermediate suggest that 1,4-dioxane molecules act as structure-directing agents, with a profound influence on crystallinity.

Different experimental conditions were screened for the synthesis of intermediate $\mathbf{2}$, which was observed during the in situ monitoring of TbBd-COF. Intermediate $\mathbf{2}$ only formed as the main phase by milling solely Bd in the presence of 1,4-dioxane. Different grinding additives lead to different phases; neat grinding or grinding with aqueous $\mathrm{AcOH}$ lead to a polymorphic transition of $\mathrm{Bd}$, with the presence of an additional second (new) phase in case of $\mathrm{AcOH}$, while 2 formed in reactions using 1,4-dioxane as a liquid additive (Figure S17). The formation of different crystalline phases or polymorphs using different liquid additives is a well-known phenomenon in organic mechanochemistry. ${ }^{[34]}$ The crystal structure of $\mathbf{2}$ was $a b$ initio determined from XRPD data, geometry optimized using periodic density functional theory (DFT) calculations, and characterized using liquid- ssNMR and FT-IR spectroscopy (see ESI). Intermediate 2 was found to be a 1,4-dioxane solvate of benzidine, which crystallizes in the monoclinic space group $P 2_{1} / c$ with both $\mathrm{Bd}$ and dioxane molecules lying on a crystallographic center of inversion. The crystal structure is composed of hydrogen-bonded zig-zag chains along the $c$-axis with alternating molecules of $\mathrm{Bd}$ and dioxane, forming amine - ether $\mathrm{N}-\mathrm{H} \cdots \mathrm{O}$ hydrogen bonds $\left(\mathrm{d}_{\mathrm{N}-\ldots \mathrm{O}}=3.02 \AA\right)$. All adjacent chains have a slight offset to each other, introduced through the glide planes, which enables a weak $\mathrm{N}-\mathrm{H} \cdots \pi$ interaction between neighbouring chains. 

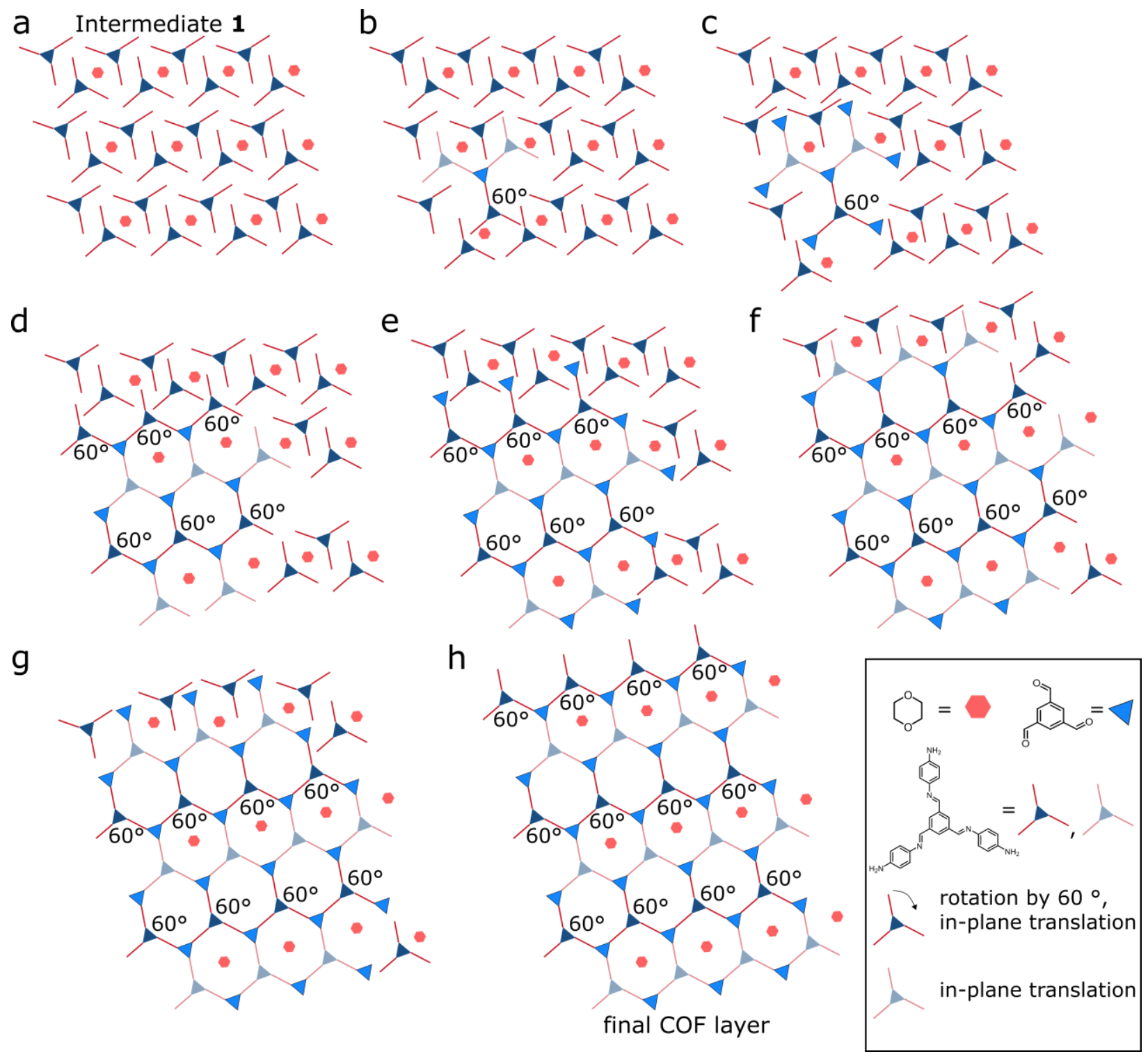

Figure $\mathbf{4}$ Schematic representation of the stepwise transformation from intermediate $\mathbf{1}$ into a layer of COF-LZU1 by molecular rearrangements and addition of remaining Tb linker. (a) Intermediate 1, (b, c, e, g) subsequent addition of Tb linkers, as well as $(\mathbf{b}, \mathbf{d}, \mathbf{f}, \mathbf{h})$ rearrangement of neighbouring trimers. Trimers possess a different color, depending on whether they were rotated by $60^{\circ}$ and translated (dark blue) or solely translated (light blue).

\section{Influence of Liquid Additives}

To further investigate the influence of liquid additive on COF formation and potential templating effects, additional ex situ milling experiments were performed by varying the LAG additive. Specifically, either pure mesitylene, 1,4-dioxane, or their mixture were used as additives while keeping $\eta$ constant $(0.6 \mu \mathrm{L} / \mathrm{mg})$. Notably, the LAG experiments with either mesitylene or 1,4-dioxane as a liquid additive led to the formation of COF-LZU1, as confirmed by XRPD measurements (Figure 5a). However, COF-LZU1 prepared with mesitylene as a liquid additive exhibited a significantly lower crystallinity compared to the materials prepared with 1,4-dioxane, lacking the stacking X-ray reflection (001) around $26^{\circ} 2 \theta$ (Figure 5a), indicating apparent stacking disorder. Morever, it possess a very broad diffraction signal around $21^{\circ} 2 \theta$, typical for materials with an amorphous content. These trends in crystallinity are in good agreement with 
porosity measurements, where the Brunauer-Emmett-Teller surface areas $\left(S_{B E T}\right)$ for the materials synthesized with pure 1,4-dioxane $\left(S_{B E T}=880 \mathrm{~m}^{2} \mathrm{~g}^{-1}\right)$ or a mesitylene/dioxane mixture $\left(\mathrm{S}_{\mathrm{BET}}=757 \mathrm{~m}^{2} \mathrm{~g}^{-1}\right)$ are significantly higher compared to that of the product made using pure mesitylene $\left(S_{\text {BET }}=138 \mathrm{~m}^{2} \mathrm{~g}^{-1}\right)$ as the liquid additive (Figure $5 \mathrm{~b}$ ). The increased crystallinity and surface area in samples prepared in the presence of 1,4-dioxane are attributed to the formation of 1, where the 1,4-dioxane embedded in rhombohedrally shaped cavities can act as template for the COF pore formation. The pre-orientation of the layered hydrogen-bonded trimers facilitates the final condensation step and layer assembly through templating effects and consequently improves the overall crystallinity. Moreover, the displacement of layers prohibits strong $\pi-\pi$ interactions between molecular building blocks. Strong irreversible $\pi-\pi$ interactions in the early stage of COF formation have been identified to prohibit high crystallinity due to the implementation and lock-in of defects. ${ }^{[55,62]}$ While templating effects have been proposed in previous theoretical work, ${ }^{[55]}$ this is to the best of our knowledge the first experimental evidence of solvent templating during COF formation. Notably, our results also suggest that the liquid additive mixture could even be simplified to pure 1,4-dioxane, meaning that complex solvent mixtures are not always necessary for the synthesis of COFs, at least using mechanochemistry.

a

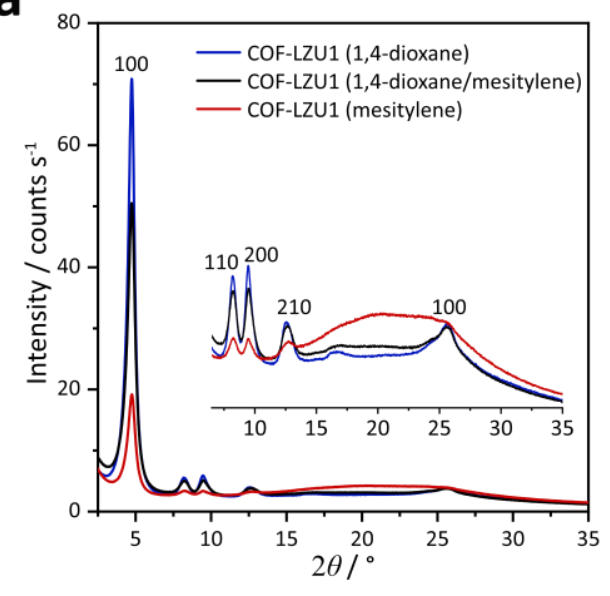

b

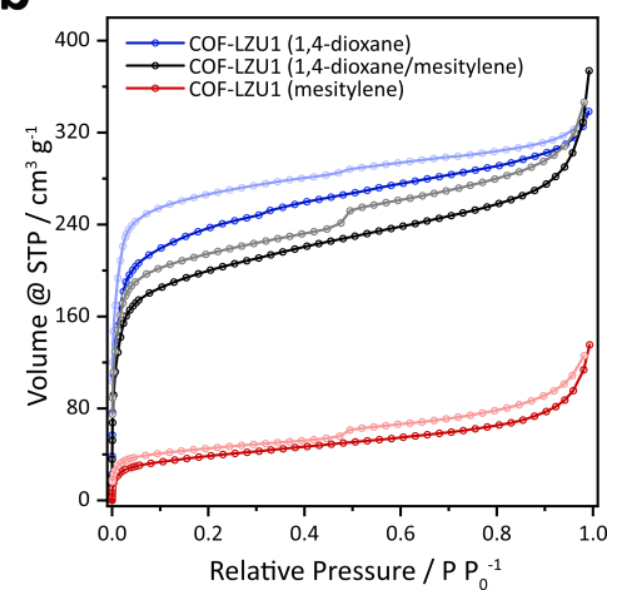

Figure 5. (a) Comparison of measured XRPD $\left(\lambda=1.54 \AA\right.$ ) patterns using different solvent mixtures. (b) $\mathrm{N}_{2}$ isotherms at $77 \mathrm{~K}$ for COF-LZU1 synthesized using either pure 1,4-dioxane (blue curve), a 1,4-dioxane/mesitylene mixture (black curve), or pure mesitylene (red curve) as LAG additives.

\section{Influence of Catalyst}

We further explored the influence of the catalyst on the reaction mechanism and kinetics. To this end, real-time in situ monitoring was extended to milling reactions in which aqueous AcOH was replaced by the solid Lewis acid $\mathrm{Sc}(\mathrm{OTf})_{3}$. Matsumoto et al. reported the use of metal triflates to promote the formation of imine COFs in solution, leading to a significant reduction of reaction time under milder reaction conditions. ${ }^{[63]}$ In all reactions that were monitored in situ, 0.06 eq. Sc(OTf $)_{3}$ were used with respect to the corresponding amine linkers. While the overall reaction pathway was mostly unaffected by the choice of catalyst, the reaction kinetics, as well as crystallinity of the final COFs were increased.

COF-LZU1 was the only investigated COF system where a crystalline intermediate was observed in the presence of $\mathrm{Sc}(\mathrm{OTf})_{3}$ as catalyst. The intermediate $\mathbf{1}$ formed immediately upon milling, with the diffraction signal of the targeted framework COF-LZU1 appearing after ca. one min (Figure 6a). The diffraction signal of 1 completely vanished within $12 \mathrm{~min}$, i.e. in approximately half of the reaction time 
compared to the $\mathrm{AcOH}$ catalysed reaction (ca. $25 \mathrm{~min}$ ). The intensity of the (100) Bragg reflection of COFLZU1 increased throughout the entire experiment, even after the consumption of 1 (Figure $6 \mathrm{~b}$ ). The continuous increase in diffracted intensity might arise from a continued error correction by $\mathrm{Sc}(\mathrm{OTf})_{3}$, acting as an efficient transimination catalyst and resulting in overall improved crystallinity (Figure 6c). ${ }^{[64]}$

The induction times for most other COF systems were significantly reduced, by a factor of two or more (Figures $6 \mathrm{~b}$ and S9). The synthesis of BdTb-COF showed the most pronounced effect, both in reduction of induction time as well as in increase of product formation rate. The TbBd-COF formation started after an induction time of only ca. $3 \mathrm{~min}$ and was found to reach completion after ca. 30 minutes using $\mathrm{Sc}(\mathrm{OTf})_{3}$, while for $\mathrm{AcOH}$ the diffraction signal of COF only appeared after ca. 30 min and still exhibited a weak scattering signal after 60 min with 2 remaining throughout the whole experiment. It is assumed that due to the rapid COF formation rate $\mathrm{Bd}$ is consumed before the solvate is formed and $\mathbf{2}$ was consequently not observed in the $\mathrm{Sc}(\mathrm{OTf})_{3}$ catalysed reaction. These findings demonstrate the unique interplay between thermodynamics and kinetics in COF formation and suggest that different reaction pathways may open up as a function of liquid and catalyst choice.

a

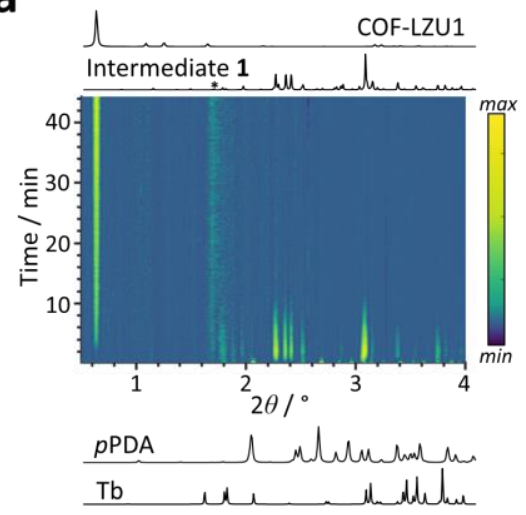

b

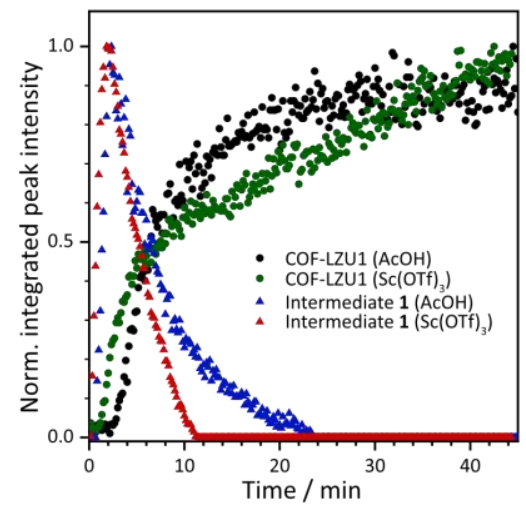

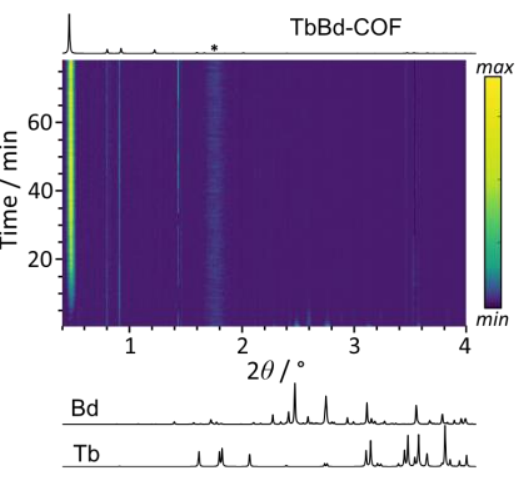

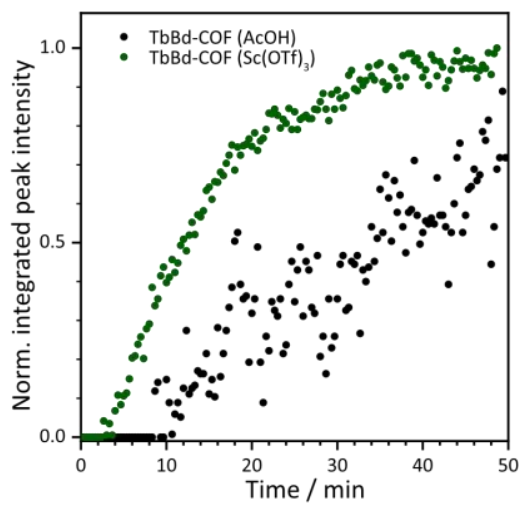

C

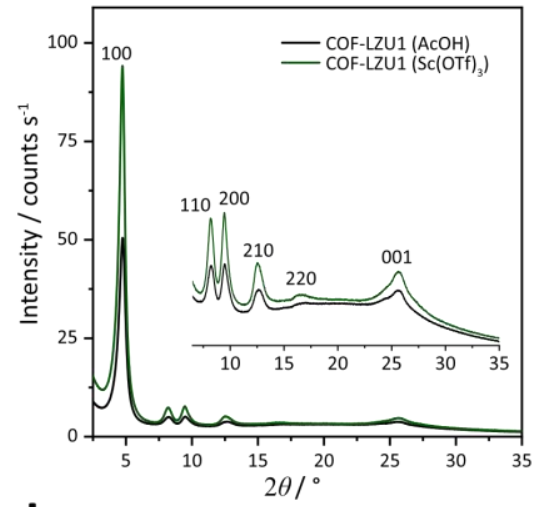

d

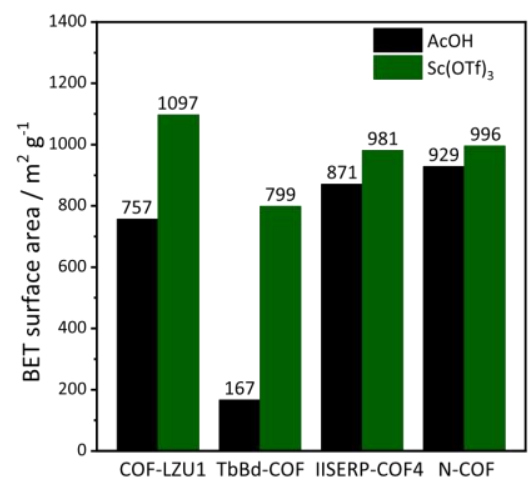

Figure 6: (a) Background subtracted 2D XRPD plots for the mechanochemical reaction of COF-LZU1 (left) and TbBd-COF (right) using $\mathrm{Sc}(\mathrm{OTf})_{3}$ as catalyst. Diffraction of PMMA is visible by the broad peak around $1.7^{\circ} 2 \theta$, marked by an asterisk. Artefacts from background subtraction appear at ca. $0.8,0.9$, and $1.4^{\circ} 2 \theta$ due to background subtraction. (b) Comparison of the normalized integrated peak intensities of 1 and COF-LZU1 (left) derived from the in situ monitoring using AcOH (black and blue) and Sc(OTf) 3 (green and red) as catalyst and of TbBd-COF (right) using AcOH (black) and $\mathrm{Sc}(\mathrm{OTf})_{3}$ (green) as catalyst. (c) Measured ex situ XRPD patterns $(\lambda=1.54 \AA \text { ) of COF-LZU1. (d) Comparison of BET surface areas of COF samples prepared with either AcOH or Sc(OTf) })_{3}$ as catalyst determined by $\mathrm{N}_{2}$ sorption experiments at $77 \mathrm{~K}$. 
Encouraged by our findings of the effects of $\mathrm{Sc}(\mathrm{OTf})_{3}$ on reaction kinetics and mechanism during COF formation we further explored its influence on mechanochemically snythesised COF properties. The direct comparison of separatly mechanochemically synthesized $\mathrm{COFs}$ using $\mathrm{AcOH}$ and $\mathrm{Sc}(\mathrm{OTf})_{3}$ as catalyst shows that not only the crystallinity was significantly improved using $\mathrm{SC}(\mathrm{OTf})_{3}$ (Figure 6c), but also $\mathrm{S}_{\mathrm{BET}}$ was found to be generally larger (Figure $6 \mathrm{~d}$ ). TbBd-COF shows the most pronounced effect with an $\mathrm{S}_{\mathrm{BET}}$ increase of $475 \%$. These results are in good agreement with our in situ studies showing an increased COF formation rate. Interestingly, while previous mechanochemical COF syntheses report a significantly lower crystallinity and porosity $\left(\mathrm{S}_{\mathrm{BET}}<300 \mathrm{~m}^{2} \mathrm{~g}^{-1}\right)$ compared to the respective solvothermal syntheses of the corresponding COF systems, ${ }^{[20-22]}$ the herein presented results show partially the opposite (Table 1). Most notably, the porosity of milled IISERP-COF4 exceeds the solvothermally reported surface area by almost $40 \%$, independent of the catalyst choice. Also, the surface area of COF-LZU1 with Sc(OTf) $)_{3}$ was found to be almost 2.7 times higher $\left(\mathrm{S}_{\mathrm{BET}}=1097 \mathrm{~m}^{2} \mathrm{~g}^{-1}\right)$ than most literature values obtained by classical solvothermal synthesis with $\mathrm{S}_{\mathrm{BET}}=410 \mathrm{~m}^{2} \mathrm{~g}^{-1}{ }^{19]}$ but still slightly lower than other synthetic strategies, where a $\mathrm{S}_{\text {BET }}$ of approx. $1500 \mathrm{~m}^{2} \mathrm{~g}^{-1}$ was reported (Table 1). ${ }^{[65,66]}$ It is noteworthy, however, that the latter required much longer reaction times, up to $48-120 \mathrm{~h}$, whereas the milling reaction was found to be complete within an hour. The increased $\mathrm{S}_{\mathrm{BET}}$ in comparison to previous mechanochemically prepared COFs are attributed to a milder activation process. Activation under harsher conditions, e.g. solvent exchange and heating under vacuum, are known to lead to a collapse of the framework pore structure through the action of capillary forces, and consequently to a reduction or loss of porosity. ${ }^{[67]}$ This strongly depends on the polarity of the used solvent, as well as framework stability. ${ }^{[68]}$ In contrast, $\mathrm{scCO}_{2}$ is considered as a rather mild activation method due to the absence of capillary forces and thus, the structural integrity is retained during the activation process. ${ }^{[67]}$

Table 1: Pore sizes and comparison of surface areas of mechanochemically synthesized COFs with literature values of solvothermally synthesized pendants.

\begin{tabular}{ccccc}
\hline COF system & \multicolumn{3}{c}{ Mechanochemical synthesis } & Reported values \\
& $\begin{array}{c}\text { Pore } \\
\text { size } \\
/ \mathrm{nm}\end{array}$ & $\begin{array}{c}\mathrm{S}_{\mathrm{BET}}(\mathrm{AcOH}) / \\
\mathrm{m}^{2} \mathrm{~g}^{-1}\end{array}$ & $\begin{array}{c}\mathrm{S}_{\mathrm{BET}}\left(\mathrm{Sc}(\mathrm{OTf})_{3}\right) / \\
\mathrm{m}^{2} \mathrm{~g}^{-1}\end{array}$ & $\mathrm{~S}_{\mathrm{BET}} / \mathrm{m}^{2} \mathrm{~g}^{-1}$ \\
\hline COF-LZU1 & 1.9 & 757 & 1097 & $410^{[9]}, 1500^{[65,66]}$ \\
TbBd-COF & 2.2 & 167 & 799 & $1948^{[59]}$ \\
IISERP-COF4 & 3.2 & 871 & 981 & $716^{[60]}$ \\
N-COF & 1.5 & 929 & 996 & $1163^{[61]}$ \\
\hline
\end{tabular}

[a] calculated by DFT.

Overall, $\mathrm{Sc}(\mathrm{OTf})_{3}$ shows advantages in terms of reaction times and measured surface areas in these examples and is consequently an interesting alternative to $\mathrm{AcOH}$ for mechanochemical COF chemistry. Fine-tuning of the reaction conditions as well as $\mathrm{scCO}_{2}$ activation enabled the mechanochemical preparation of COFs that are on an equal footing with solvothermally synthesized COFs, while retaining the benefits of significantly reduced reaction times, milder reaction conditions, and scalability. 


\section{Conclusion}

In conclusion, we report the first in situ monitoring of mechanochemical COF formation, readily followed using real-time in situ XRPD. Our study provides the first direct experimental evidence of templating effects during COF assembly through a crystalline intermediate. Using 1,4-dioxane as a liquid additive let to the observation of reaction intermediates in the form of solvates during both COF-LZU1 and TbBd-COF synthesis. The intermediate for TbBd-COF is the result of a competing reaction, which can occur due to slow imine bond formation and is suppressed by using $\mathrm{Sc}(\mathrm{OTf})_{3}$ as a catalyst. In contrast, in the COF-LZU1 intermediate a solvated, hydrogen-bonded layered trimer is formed with 1,4-dioxane being embedded in rhombohedral cavities, acting as a template for the subsequent pore formation during COF assembly. The quasi layered structural arrangement in the solvate does not only inhibit initial $\pi$ - $\pi$ stacking during the early self-assembly process, an effect that is known to lower the overall crystallite size, ${ }^{[62]}$ but also promotes the self-assembly of the 2D COF sheets. The formation of a discrete trimer could potentially be used for the rational design of mixed-linker COFs, as it has been previously done for mixed-metal MOFs. ${ }^{[69]}$ Moreover, our study reveals pronounced effects of the catalyst choice - AcOH vs Sc(OTf) ${ }_{3}$ - on COF formation, both regarding reaction kinetics, mechanism and crystallinity of the product. Notably, a combination of $\mathrm{Sc}(\mathrm{OTf})_{3}$ as a catalyst and mild activation with supercritical $\mathrm{CO}_{2}$ results in COFs with surface areas that can even exceed those reported for solvothermally synthesized COFs, which generally require higher temperatures, longer reaction times, and the use of bulk-solvents.

Our results highlight the potential of mechanochemical synthesis not only as a material-efficient, green and potentially scalable synthetic route, but reveal the subtle interplay between liquid additives, catalyst choice, and activation procedure in the synthesis of COFs, which often follows standardized procedures owing to the lack of mechanistic insights. Utilizing the power of templated COF synthesis through the targeted formation of intermediates thus enables a more rational design of COFs by utilizing a toolbox of non-covalent interactions and directed self-assembly.

\section{Acknowledgement}

This work has been funded by the Deutsche Forschungsgemeinschaft (DFG, German Research Foundation - project number 358283783 - SFB 1333). Financial support by the Max Planck Society, an ERC Starting Grant (project COFLeaf, grant number 639233) as well as by the Cluster of Excellence e-conversion (EXC 2089) and the Center for Nanoscience (CeNS) is gratefully acknowledged. L. S. G. acknowledges financial support from the Swiss National Science Foundation (Grant P2SKP2_187638). T. F. acknowledges the financial support of the NSERC Discovery Grant (RGPIN-2017-06467) and NSERC Discovery Accelerator award (RGPAS 507837-17). This research was enabled in part by support provided by Calcul Québec (https://www.calculquebec.ca) and Compute Canada (www.computecanada.ca). 


\section{References}

[1] M. S. Lohse, T. Bein, Adv. Funct. Mater. 2018, 28, 1705553.

[2] O. M. Yaghi, ACS Cent. Sci. 2019, 5, 1295-1300.

[3] K. Gottschling, L. Stegbauer, G. Savasci, N. A. Prisco, Z. J. Berkson, C. Ochsenfeld, B. F. Chmelka, B. V. Lotsch, Chem. Mater. 2019, 31, 1946-1955.

[4] H. Furukawa, O. M. Yaghi, J. Am. Chem. Soc. 2009, 131, 8875-8883.

[5] J. T. Yu, Z. Chen, J. Sun, Z. T. Huang, Q. Y. Zheng, J. Mater. Chem. 2012, 22, 5369-5373.

[6] H. Xu, J. Gao, D. Jiang, Nat. Chem. 2015, 7, 905-912.

[7] M. Mu, Y. Wang, Y. Qin, X. Yan, Y. Li, L. Chen, ACS Appl. Mater. Interfaces 2017, 9, 22856-22863.

[8] H. Xu, X. Chen, J. Gao, J. Lin, M. Addicoat, S. Irle, D. Jiang, Chem. Commun. 2014, 50, 1292-1294.

[9] S.-Y. Ding, J. Gao, Q. Wang, Y. Zhang, W.-G. Song, C.-Y. Su, W. Wang, J. Am. Chem. Soc. 2011, 133, 19816-19822.

[10] T. Banerjee, F. Haase, G. Savasci, K. Gottschling, C. Ochsenfeld, B. V. Lotsch, J. Am. Chem. Soc. 2017, 139, 16228-16234.

[11] X. Wang, L. Chen, S. Y. Chong, M. A. Little, Y. Wu, W. H. Zhu, R. Clowes, Y. Yan, M. A. Zwijnenburg, R. S. Sprick, et al., Nat. Chem. 2018, 10, 1180-1189.

[12] B. P. Biswal, H. A. Vignolo-González, T. Banerjee, L. Grunenberg, G. Savasci, K. Gottschling, J. Nuss, C. Ochsenfeld, B. V. Lotsch, J. Am. Chem. Soc. 2019, 141, 11082-11092.

[13] H. B. Aiyappa, J. Thote, D. B. Shinde, R. Banerjee, S. Kurungot, Chem. Mater. 2016, 28, 4375-4379.

[14] C.-Y. Lin, L. Zhang, Z. Zhao, Z. Xia, Adv. Mater. 2017, 29, 1606635.

[15] H. Singh, V. K. Tomer, N. Jena, I. Bala, N. Sharma, D. Nepak, A. De Sarkar, K. Kailasam, S. K. Pal, J. Mater. Chem. A 2017, 5, 21820-21827.

[16] W. Li, C. X. Yang, X. P. Yan, Chem. Commun. 2017, 53, 11469-11471.

[17] Z. Zhou, W. Zhong, K. Cui, Z. Zhuang, L. Li, L. Li, J. Bi, Y. Yu, Chem. Commun. 2018, 54, 9977-9980.

[18] Y. Peng, W. K. Wong, Z. Hu, Y. Cheng, D. Yuan, S. A. Khan, D. Zhao, Chem. Mater. 2016, 28, 50955101.

[19] M. Zhang, J. Chen, S. Zhang, X. Zhou, L. He, M. V. Sheridan, M. Yuan, M. Zhang, L. Chen, X. Dai, et al., J. Am. Chem. Soc. 2020, jacs.0c03941.

[20] B. P. Biswal, S. Chandra, S. Kandambeth, B. Lukose, T. Heine, R. Banerjee, J. Am. Chem. Soc. 2013, 135, 5328-5331.

[21] G. Das, D. Balaji Shinde, S. Kandambeth, B. P. Biswal, R. Banerjee, Chem. Commun. 2014, 50, 12615-12618.

[22] D. B. Shinde, H. B. Aiyappa, M. Bhadra, B. P. Biswal, P. Wadge, S. Kandambeth, B. Garai, T. Kundu, S. Kurungot, R. Banerjee, J. Mater. Chem. A 2016, 4, 2682-2690. 
[23] T. Friščić, C. Mottillo, H. M. Titi, Angew. Chemie Int. Ed. 2020, 59, 1018-1029.

[24] S. L. James, C. J. Adams, C. Bolm, D. Braga, P. Collier, T. Friščić, F. Grepioni, K. D. M. Harris, G. Hyett, W. Jones, et al., Chem. Soc. Rev. 2012, 41, 413-447.

[25] D. DeSantis, J. A. Mason, B. D. James, C. Houchins, J. R. Long, M. Veenstra, Energy and Fuels 2017, 31, 2024-2032.

[26] P. Baláž, M. Achimovicová, M. Baláž, P. Billik, C. Z. Zara, J. M. Criado, F. Delogu, E. Dutková, E. Gaffet, F. J. Gotor, et al., Chem. Soc. Rev. 2013, 42, 7571-7637.

[27] M. Leonardi, M. Villacampa, J. C. Menéndez, Chem. Sci. 2018, 9, 2042-2064.

[28] A. Bruckmann, A. Krebs, C. Bolm, Green Chem. 2008, 10, 1131-1141.

[29] T. Friščič, W. Jones, Cryst. Growth Des. 2009, 9, 1621-1637.

[30] D. Hasa, W. Jones, Adv. Drug Deliv. Rev. 2017, 117, 147-161.

[31] N. V. Kosova, N. F. Uvarov, E. T. Devyatkina, E. G. Avvakumov, Solid State Ionics 2000, 135, 107114.

[32] C. Cappuccino, F. Farinella, D. Braga, L. Maini, Cryst. Growth Des. 2019, 19, 4395-4403.

[33] A. D. Katsenis, A. Puškarić, V. Štrukil, C. Mottillo, P. A. Julien, K. Užarević, M. H. Pham, T. O. Do, S. A. J. Kimber, P. Lazić, et al., Nat. Commun. 2015, 6, 1-8.

[34] D. Hasa, E. Miniussi, W. Jones, Cryst. Growth Des. 2016, 16, 4582-4588.

[35] L. S. Germann, M. Arhangelskis, M. Etter, R. E. Dinnebier, T. Friščić, Chem. Sci. 2020, DOI 10.1039/DOSC03629C.

[36] T. Friščić, S. L. Childs, S. A. A. Rizvi, W. Jones, CrystEngComm 2009, 11, 418-426.

[37] T. Friščić, I. Halasz, P. J. Beldon, A. M. Belenguer, F. Adams, S. A. J. Kimber, V. Honkimäki, R. E. Dinnebier, Nat. Chem. 2013, 5, 66-73.

[38] I. Halasz, S. A. J. Kimber, P. J. Beldon, A. M. Belenguer, F. Adams, V. Honkimäki, R. C. Nightingale, R. E. Dinnebier, T. Friščić, Nat. Protoc. 2013, 8, 1718-1729.

[39] D. Gracin, V. Štrukil, T. Friščić, I. Halasz, K. Užarević, Angew. Chemie Int. Ed. 2014, 53, 6193-6197.

[40] L. Batzdorf, F. Fischer, M. Wilke, K.-J. Wenzel, F. Emmerling, Angew. Chemie Int. Ed. 2015, 54, 17991802.

[41] P. F. M. de Oliveira, A. A. L. Michalchuk, A. G. Buzanich, R. Bienert, R. M. Torresi, P. H. C. Camargo, F. Emmerling, Chem. Commun. 2020, DOI 10.1039/d0cc03862h.

[42] J. G. Schiffmann, F. Emmerling, I. C. B. Martins, L. Van Wüllen, Solid State Nucl. Magn. Reson. 2020, 101687.

[43] K. Užarević, V. Štrukil, C. Mottillo, P. A. Julien, A. Puškarić, T. Friščić, I. Halasz, Cryst. Growth Des. 2016, 16, 2342-2347.

[44] K. Užarević, I. Halasz, T. Friščić, J. Phys. Chem. Lett. 2015, 6, 4129-4140.

[45] F. Haase, K. Gottschling, L. Stegbauer, L. S. Germann, R. Gutzler, V. Duppel, V. S. Vyas, K. Kern, R. 
E. Dinnebier, B. V. Lotsch, Mater. Chem. Front. 2017, 1, 1354-1361.

[46] L. Ascherl, T. Sick, J. T. Margraf, S. H. Lapidus, M. Calik, C. Hettstedt, K. Karaghiosoff, M. Döblinger, T. Clark, K. W. Chapman, et al., Nat. Chem. 2016, 8, 310-316.

[47] Y. B. Zhang, J. Su, H. Furukawa, Y. Yun, F. Gándara, A. Duong, X. Zou, O. M. Yaghi, J. Am. Chem. Soc. 2013, 135, 16336-16339.

[48] F. Haase, E. Troschke, G. Savasci, T. Banerjee, V. Duppel, S. Dörfler, M. M. J. Grundei, A. M. Burow, C. Ochsenfeld, S. Kaskel, et al., Nat. Commun. 2018, 9, 1-10.

[49] T. Jadhav, Y. Fang, C.-H. Liu, A. Dadvand, E. Hamzehpoor, W. Patterson, A. Jonderian, R. S. Stein, D. F. Perepichka, J. Am. Chem. Soc. 2020, 142, 8862-8870.

[50] Y. Du, D. Calabro, B. Wooler, Q. Li, S. Cundy, P. Kamakoti, D. Colmyer, K. Mao, P. Ravikovitch, J. Phys. Chem. C 2014, 118, 399-407.

[51] H. Li, A. D. Chavez, H. Li, H. Li, W. R. Dichtel, J. L. Bredas, J. Am. Chem. Soc. 2017, 139, 16310-16318.

[52] I. Castano, A. M. Evans, H. Li, E. Vitaku, M. J. Strauss, J. L. Brédas, N. C. Gianneschi, W. R. Dichtel, ACS Cent. Sci. 2019, 5, 1892-1899.

[53] B. J. Smith, N. Hwang, A. D. Chavez, J. L. Novotney, W. R. Dichtel, Chem. Commun. 2015, 51, 75327535.

[54] R. L. Li, N. C. Flanders, A. M. Evans, W. Ji, I. Castano, L. X. Chen, N. C. Gianneschi, W. R. Dichtel, Chem. Sci. 2019, 10, 3796-3801.

[55] B. T. Koo, R. F. Heden, P. Clancy, Phys. Chem. Chem. Phys. 2017, 19, 9745-9754.

[56] N. R. Rightmire, T. P. Hanusa, Dalt. Trans. 2016, 45, 2352-2362.

[57] E. Colacino, M. Carta, G. Pia, A. Porcheddu, P. C. Ricci, F. Delogu, ACS Omega 2018, 3, 9196-9209.

[58] T. Shiraki, G. Kim, N. Nakashima, Chem. Lett. 2015, 44, 1488-1490.

[59] M. C. Daugherty, E. Vitaku, R. L. Li, A. M. Evans, A. D. Chavez, W. R. Dichtel, Chem. Commun. 2019, 55, 2680-2683.

[60] R. Gomes, P. Bhanja, A. Bhaumik, Chem. Commun. 2015, 51, 10050-10053.

[61] P. Wang, Q. Xu, Z. Li, W. Jiang, Q. Jiang, D. Jiang, Adv. Mater. 2018, 30, 1801991.

[62] V. Nguyen, M. Grünwald, J. Am. Chem. Soc. 2018, 140, 3306-3311.

[63] M. Matsumoto, R. R. Dasari, W. Ji, C. H. Feriante, T. C. Parker, S. R. Marder, W. R. Dichtel, J. Am. Chem. Soc. 2017, 139, 4999-5002.

[64] N. Giuseppone, J. L. Schmitt, E. Schwartz, J. M. Lehn, J. Am. Chem. Soc. 2005, 127, 5528-5539.

[65] T. Shiraki, G. Kim, N. Nakashima, Chem. Lett. 2015, 44, 1488-1490.

[66] Y. Liao, J. Li, A. Thomas, ACS Macro Lett. 2017, 6, 1444-1450.

[67] C. H. Feriante, S. Jhulki, A. M. Evans, R. R. Dasari, K. Slicker, W. R. Dichtel, S. R. Marder, Adv. Mater. 2020, 32, 1905776. 
[68] G. Ayoub, T. Islamoglu, S. Goswami, T. Friščić, O. K. Farha, ACS Appl. Mater. Interfaces 2019, 11, 15788-15794.

[69] G. Ayoub, B. Karadeniz, A. J. Howarth, O. K. Farha, I. Lilović, L. S. Germann, R. E. Dinnebier, K. Užarević, T. Friščić, Chem. Mater. 2019, 31, 5494-5501. 


\section{In Situ Monitoring of Mechanochemical Covalent Organic Framework Formation Reveals Templating Effect of Liquid Additive}

Sebastian T. Emmerling, ${ }^{a, b, \ddagger}$ Luzia S. Germann, ${ }^{a, c, \neq,}$, Patrick A. Julien, ${ }^{c}$ Igor Moudrakovski, ${ }^{a}$ Martin Etter, ${ }^{d}$ Tomislav Friščić, ${ }^{c}$ Robert E. Dinnebier, ${ }^{a}$ and Bettina V. Lotsch ${ }^{a, b}$

${ }^{a}$ Max-Planck-Institute for Solid State Research, 70569 Stuttgart, Germany

${ }^{b}$ Department of Chemistry, Ludwig-Maximilians-Universität (LMU), 81377 Munich, Germany

${ }^{\mathrm{c}}$ Department of Chemistry, McGill University, H3A 0B8, Montreal, Canada.

${ }^{d}$ Deutsches-Elektronen Synchrotron (DESY), 22607 Hamburg, Germany.

${ }^{\ddagger}$ equal contribution

\section{Table of Contents}

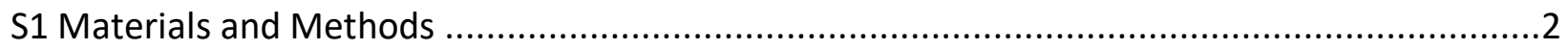

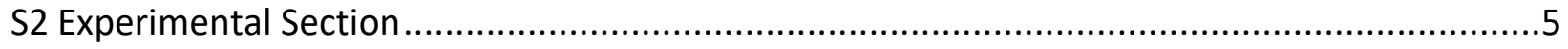

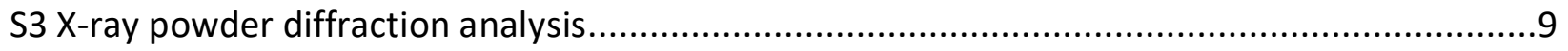

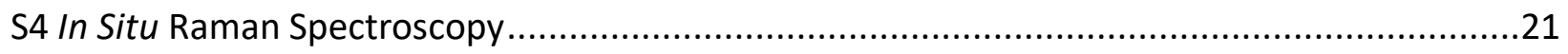

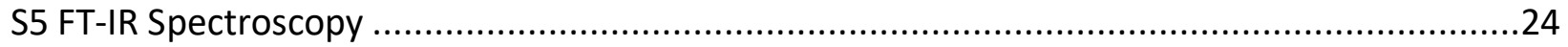

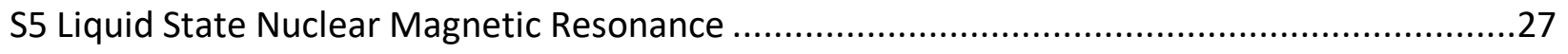

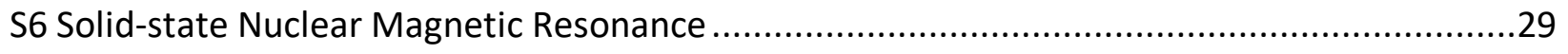

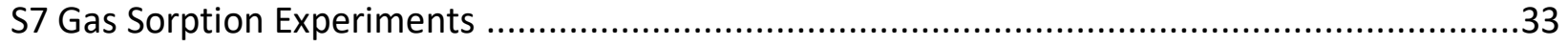

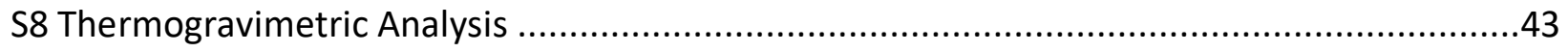

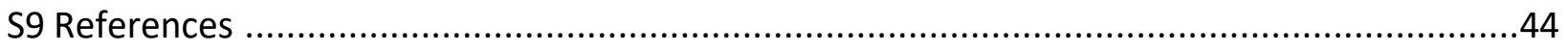




\section{S1 Materials and Methods}

Chemicals. All starting materials, unless otherwise specified, were obtained from Sigma-Aldrich Chemicals, and used without further purification. All solvents, unless otherwise specified, were obtained from Acros Organics, and used without further purification. $p$-Phenylenediamine was obtained from TCl Europe N.V. and purified by sublimation before use. 2,4,6-Tris(4aminophenyl)-1,3,5-triazine was prepared according to a literature procedure. ${ }^{[1]}$

Since the in situ synthesized COFs could not be washed and dried on site at the beamline, selected analytical measurements (e. g. sorption measurements) were performed on separately synthesized materials under identical condition as in situ synthesized materials with a fixed milling time of $60 \mathrm{~min}$. This enables the comparison of analytical measurements and properties of the mechanochemically synthesized COFs that are potentially compromised by storing wetted samples for multiple days.

\section{Ex situ milling}

All laboratory, ex situ mechanochemical syntheses were performed in custom made $5 \mathrm{~mL}$ poly(methylmethacrylate) (PMMA) milling jars using a MM400 Retsch shaker mill operating at $30 \mathrm{~Hz}$.

Ex situ X-ray powder diffraction. Ex situ X-ray powder diffraction (XRPD) measurements for phase analysis and crystal structure determination of 1 were performed on a Stoe Transmission

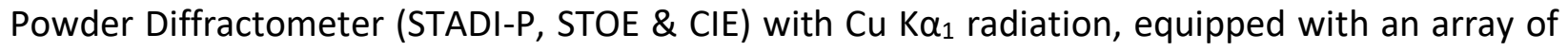
three MYTHEN $1 \mathrm{~K}$ detectors (Dectris Ltd.), and a Ge(111) Johann-type monochromator (STOE \&

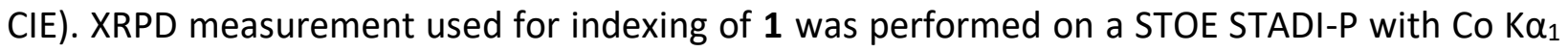
radiation, equipped with a MYTHEN $1 \mathrm{~K}$ detector (Dectris Ltd.), and a Ge(111) Johann-type monochromator (STOE \& CIE). All further XRPD measurements for phase analysis of reactants and COF products were measured on a STOE STADI-P equipped with $\mathrm{Cu} \mathrm{K}$. For consistency samples were separately synthesized using the experimental descriptions below with an identical milling time of $60 \mathrm{~min}$. For better particle statistics all samples were spun during data collection.

FT-IR Spectroscopy. Infrared spectra were measured in attenuated total reflection (ATR) geometry on a PerkinElmer UATR Two equipped with a diamond crystal. The spectra were background corrected.

Liquid State Nuclear Magnetic Resonance. All liquid state nuclear magnetic resonance (NMR) measurements were performed on a JEOL ECZ $400 \mathrm{~S} 400 \mathrm{MHz}$ spectrometer (magnetic field 9.4 T). ${ }^{1} \mathrm{H},{ }^{13} \mathrm{C}$ and ${ }^{15} \mathrm{~N}$ measurements were performed in $5 \mathrm{~mm}$ NMR tubes using deuterium field lock.

Solid-State Nuclear Magnetic Resonance. Solid-state NMR (ssNMR) spectra were recorded on a Bruker Avance III $400 \mathrm{MHz}$ spectrometer (magnetic field 9.4 T). For ssNMR spectroscopy, the samples were packed in $4 \mathrm{~mm} \mathrm{ZrO}_{2}$ rotors, which were spun in a Bruker WVT BL4 double 
resonance MAS probe. Chemical shift was referenced relative to tetramethylsilane $\left({ }^{13} \mathrm{C}\right)$, and $\mathrm{CH}_{3} \mathrm{NO}_{2}\left({ }^{15} \mathrm{~N}\right)$. The spinning rate was $12-14 \mathrm{kHz}$ for ${ }^{13} \mathrm{C}$ and $8 \mathrm{kHz}$ for ${ }^{15} \mathrm{~N}$ measurements. A standard cross-polarization sequence with a $2 \mathrm{~ms}$ ramped contact pulse was used for ${ }^{13} \mathrm{C}$ and a total of 4096-8192 scans were routinely accumulated. ${ }^{15} \mathrm{~N}$ ssNMR spectra were obtained with ramped cross-polarization and contact pulses of 3-8 ms optimized for the best signal. Both ${ }^{13} \mathrm{C}$ and ${ }^{15} \mathrm{~N}$ measurements were performed in conditions of high-power broadband proton decoupling (SPINAL 64) with the spectral conditions being optimized for the shortest relaxation delay by measuring ${ }^{1} \mathrm{H}$ T1 relaxation time.

Sorption Measurements. Sorption measurements were performed on a Quantachrome Instruments Autosorb iQ 3 with nitrogen at $77 \mathrm{~K}$. The pore size distribution was determined from nitrogen adsorption isotherms using the QSDFT (cylindrical pores, adsorption branch) kernel in carbon for nitrogen at $77 \mathrm{~K}$ implemented in the ASiQwin software v 3.01. Samples were activated in high vacuum at $120^{\circ} \mathrm{C}$ for $12 \mathrm{~h}$ before measurement.

\section{Elemental Microanalyses (EA).}

The elemental analyses were performed on a UNICUBE - Micro Combustion Analyzer.

\section{Mass Spectrometry}

Electrospray ionization (ESI) mass spectrometry was performed on a Thermo Finnigan LTQ FT in positive and negative mode. Samples were dissolved in an acetonitrile/water mixture.

\section{Thermogravimetric analysis}

Thermogravimetric analysis (TGA) measurements were performed on a STA 409 CD machine (Netzsch Co., Germany). Intermediates 1, 1', and 2 were filled into $\mathrm{Al}_{2} \mathrm{O}_{3}$ crucibles. The experiments were conducted from $40-450{ }^{\circ} \mathrm{C}$ with a heating rate of $5^{\circ} \mathrm{C} / \mathrm{min}$ under a protective Ar flow.

In situ X-ray powder diffraction. All 2D XRPD patterns were collected at the P02.1 Powder Diffraction and Total Scattering beamline at the Deutsches Elektronen-Synchrotron (DESY) in Hamburg, Germany. The beamline is equipped with a modified MM400 Retsch shaker mill[2] and a PerkinElmer 2D area detector. The wavelength was determined with the NIST NSR 660a ( $\operatorname{LaB}_{6}$ ) standard, using two different detector positions to be $0.20736 \AA$ (59.78 keV) and $0.20747 \AA$ $(59.78 \mathrm{keV})$. All 2D XRPD patterns were integrated using either Fit2D or Dioptas. ${ }^{[3,4]} \mathrm{A}$ custom made Matlab script was used to subtract background and plot the time-resolved XRPD patterns in a 2D plot. Background subtraction was only performed for visual presentation. 


\section{In situ Raman spectroscopy}

All Raman spectra were collected on RamanRxn1 $1^{\mathrm{TM}}$ analyzer equipped with a $785 \mathrm{~nm}$ laser by Kaiser Optical Systems Inc. Real-time Raman monitoring was conducted in an approximately 8 $\mathrm{mL}$ sapphire milling jar with spectra acquired at 10 second intervals as a sum of 7 spectra with 10 ms acquisition time. A Retsch MM400 mill was operated at $30 \mathrm{~Hz}$ and a single $7 \mathrm{~mm}$ stainless steel ball. The Holograms ${ }^{\circledR}$ software package Spectra was used to dark and intensity correct the data. Subsequent baseline correction was performed using the Sonneveld and Visser algorithm ${ }^{[5]}$ and vector normalization (L2 Norm).

\section{Density Function Theory calculation}

Density function theory (DFT) calculations with periodic boundary conditions were performed for intermediate 1 and 2 using the plane wave DFT code CASTEP 19.11. ${ }^{[6]}$ Both crystal structures of $\mathbf{1}$ and $\mathbf{2}$ were geometry-optimized and $\mathbf{1}$ subsequently used for NMR calculations.

The CASTEP input file was prepared from the corresponding crystallographic information file (CIF) using the program cif2cell. ${ }^{[7]}$ Geometry optimization was performed using the $\mathrm{PBE}^{[8]}$ functional combined with the Grimme-D2 dispersion correction. ${ }^{[9]}$ The plane wave basis set was truncated at $700 \mathrm{eV}$ cutoff and norm-conserving pseudopotentials were used to describe the core regions of electron density. The electronic Brillouin zone was sampled with a $0.07 \AA^{-1}$ Monkhorst-Pack kpoint grid. Geometry optimization involved full relaxation of atom coordinates and unit cell parameters, subject to symmetry constraints of the corresponding space groups. Calculation were deemed finished after the following convergence criteria had been satisfied: $\Delta E /$ atom $<$ $2 \cdot 10^{-5} \mathrm{eV}$, maximum atom displacement $<0.001 \AA$, maximum force on atom $<0.05 \mathrm{eV} \AA^{-1}$ and maximum residual stress $<0.1 \mathrm{GPa}$.

The optimized crystal structures were used for NMR calculations with Gauge Including Projector Augmented Waves (GIPAW) method. ${ }^{[10]}$ Calculations were performed with a PBE functional, the plane-wave cutoff was increased to $900 \mathrm{eV}$, and on-the-fly generated ultrasoft pseudopotentials were used for modelling the core part of the Coulomb potential. The NMR calculation provided isotropic chemical shieldings $\left(\sigma_{\text {iso }}\right)$ for ${ }^{15} \mathrm{~N}$ nuclei, which were converted to isotropic chemical shifts $\left(\delta_{\text {iso }}\right)$ using the equation:

$$
\delta_{\text {iso }}=-\sigma_{\text {iso }}-\delta_{\text {ref }}
$$

where $\delta_{\text {ref }}$ value was fitted as a single to find the best match between calculated and experimental spectra. Calculated ssNMR spectrum was plotted using MagresView 1.6.2. ${ }^{[11]}$ 


\section{S2 Experimental Section}

\section{In situ syntheses}

COF LZU-1. 1,3,5-Triformylbenzene (Tb, $100 \mathrm{mg}, 0.598 \mathrm{mmol}$ ) and p-phenylenediamine ( $p$ PDA, $100 \mathrm{mg}, 0.897 \mathrm{mmol}$ ) were placed into a $5 \mathrm{~mL}$ PMMA reaction jar and a $7 \mathrm{~mm}$ steel ball (1.38 $\mathrm{g}$ weight) was added. Either 1,4-dioxane $(40 \mu \mathrm{L})$, mesitylene $(40 \mu \mathrm{L})$ and $6 \mathrm{M}$ acetic acid $(40 \mu \mathrm{L}$, $\eta=0.60 \mu \mathrm{L} / \mathrm{mg})$ or 1,4-dioxane $(80 \mu \mathrm{L})$, mesitylene $(20 \mu \mathrm{L})$ with $\mathrm{Sc}(\mathrm{OTf})_{3}(17.7 \mathrm{mg}, 0.036 \mathrm{mmol}$, $\eta=0.50 \mu \mathrm{L} / \mathrm{mg}$ ) were added, respectively. The mixture was milled at $30 \mathrm{~Hz}$ until no further change in the in situ XPRD data was visible. The resulting solid was washed with acetone, DMF, dichloromethane, methanol, and a $12 \mathrm{~h}$ Soxhlet extraction with $\mathrm{MeOH}$. The wet sample was then activated by supercritical $\mathrm{CO}_{2}$ drying and further drying under high vacuum for $24 \mathrm{~h}$. Yield: $150.7 \mathrm{mg}$ (93\%) for $\mathrm{AcOH}$ as catalyst and $151.1 \mathrm{mg}$ (93\%) for $\mathrm{Sc}(\mathrm{OTf})_{3}$ as catalyst. Elemental Analysis, calc.: C, 79.98; H, 4.47; N, 15.55; found for AcOH: C, 76.92; H, 4.97; N, 14.46; found for $\mathrm{Sc}(\mathrm{OTf})_{3}$ : C, 75.84; $\mathrm{H}, 4.97 ; \mathrm{N}, 13.69$.

TbBd-COF. 1,3,5-Triformylbenzene (Tb, $76.2 \mathrm{mg}, 0.47 \mathrm{mmol}$ ) and benzidine (Bd, $130 \mathrm{mg}, 0.706$ mmol) were placed into a $5 \mathrm{~mL}$ PMMA reaction jar and a $7 \mathrm{~mm}$ steel ball (1.38 g weight) was added. 1,4-Dioxane $(62.5 \mu \mathrm{L})$, mesitylene $(62.5 \mu \mathrm{L})$ and as catalyst $6 \mathrm{M}$ acetic acid $(25 \mu \mathrm{L}$, $\eta=0.73 \mu \mathrm{L} / \mathrm{mg})$ or $\mathrm{Sc}(\mathrm{OTf})_{3}(13.9 \mathrm{mg}, 0.028 \mathrm{mmol}, \eta=0.61 \mu \mathrm{L} / \mathrm{mg})$ were added, respectively. The mixture was milled at $30 \mathrm{~Hz}$ until no further change in the in situ XRPD data was visible. The resulting solid was washed with acetone, DMF, dichloromethane, methanol, and a $12 \mathrm{~h}$ Soxhlet extraction with $\mathrm{MeOH}$. The wet sample was then activated by supercritical $\mathrm{CO}_{2}$ drying and further drying under high vacuum for $24 \mathrm{~h}$. Yield: $156 \mathrm{mg}$ (86\%) for $\mathrm{AcOH}$ as catalyst and $161 \mathrm{mg}(89 \%)$ for $\mathrm{Sc}(\mathrm{OTf})_{3}$ as catalyst. Elemental Analysis, calc.: $\mathrm{C}, 84.35 ; \mathrm{H}, 4.72 ; \mathrm{N}, 10.93$; found for $\mathrm{AcOH}$ : $\mathrm{C}$, 81.46; H, 4.98; N, 10.35; found for Sc(OTf) 3 : C, 81.64; H, 5.01; N, 10.16.

IISERP-COF4. 2,4,6-Tris(4-aminophenyl)-1,3,5-triazine (TAT, $126 \mathrm{mg}, 0.356 \mathrm{mmol}$ ) and terephthalaldehyde (BDA, $73.1 \mathrm{mg}, 0.534 \mathrm{mmol}$ ) were placed into a $5 \mathrm{~mL}$ PMMA reaction jar and a $7 \mathrm{~mm}$ steel ball (1.38 g weight) was added. 1,4-Dioxane (75 $\mu \mathrm{L})$, mesitylene $(75 \mu \mathrm{L})$ and as catalyst $6 \mathrm{M}$ acetic acid $(37.5 \mu \mathrm{L}, \eta=0.94 \mu \mathrm{L} / \mathrm{mg})$ or $\mathrm{Sc}(\mathrm{OTf})_{3}(10.5 \mathrm{mg}, 0.021 \mathrm{mmol}$, $\eta=0.75 \mu \mathrm{L} / \mathrm{mg}$ ) were added, respectively. The mixture was milled at $30 \mathrm{~Hz}$ until no further change in the in situ XRPD data was visible. The resulting solid was washed with acetone, DMF, dichloromethane, methanol, and a $12 \mathrm{~h}$ Soxhlet extraction with $\mathrm{MeOH}$. The wet sample was then activated by supercritical $\mathrm{CO}_{2}$ drying and further drying under high vacuum for $24 \mathrm{~h}$. Yield: $149.2 \mathrm{mg}$ (83\%) for $\mathrm{AcOH}$ as catalyst and $153.0 \mathrm{mg}$ (86\%) for $\mathrm{Sc}(\mathrm{OTf})_{3}$ as catalyst. Elemental Analysis, calc.: C, 79.02; H, 4.22; N, 16.76; found for AcOH: C, 76.95; H, 4.44; N, 15.87; found for $\mathrm{Sc}(\mathrm{OTf})_{3}$ : C, 77.42; H, 4.45; N, 15.80.

N-COF. 1,3,5-Triformylbenzene (Tb, $60 \mathrm{mg}, 0.37 \mathrm{mmol}$ ) and 2,4,6-tris(4-aminophenyl)-1,3,5triazine (TAT, $131 \mathrm{mg}, 0.37 \mathrm{mmol}$ ) were placed into a $5 \mathrm{~mL}$ PMMA reaction jar and a $7 \mathrm{~mm}$ steel 
ball (1.38 g weight) was added. 1,4-Dioxane (50 $\mu \mathrm{L})$, mesitylene $(50 \mu \mathrm{L})$ and as catalyst $6 \mathrm{M}$ acetic acid $(40 \mu \mathrm{L}, \eta=0.73 \mu \mathrm{L} / \mathrm{mg})$ or Sc(OTf) $3(10.9 \mathrm{mg}, 0.022 \mathrm{mmol}, \eta=0.52 \mu \mathrm{L} / \mathrm{mg})$ were added, respectively. The mixture was milled at $30 \mathrm{~Hz}$ until no further change in the in situ XRPD data was visible. The resulting solid was washed with acetone, DMF, dichloromethane, methanol, and a $12 \mathrm{~h}$ Soxhlet extraction with $\mathrm{MeOH}$. The wet sample was then activated by supercritical $\mathrm{CO}_{2}$ drying and further drying under high vacuum for $24 \mathrm{~h}$. Yield: $152.0 \mathrm{mg}$ (89\%) for AcOH as catalyst and $159.4 \mathrm{mg}$ (93\%) for $\mathrm{Sc}(\mathrm{OTf})_{3}$ as catalyst. Elemental Analysis, calc.: C, 77.91; H, 3.92; N, 18.17; found for $\mathrm{AcOH}$ : C, 74.83; H, 4.28; N, 16.84; found for Sc(OTf) 3 : C, 74.54; H, 4.30; N, 16.82 .

\section{In situ Raman spectroscopy synthesis}

Tb (100 mg, $0.598 \mathrm{mmol}$ ) were milled with pPDA (100 mg, $0.897 \mathrm{mmol})$, along with $62 \mu \mathrm{L}$ of 1,4-dioxane, $62 \mu \mathrm{L}$ mesitylene, and $25 \mu \mathrm{L}$ of $6 \mathrm{M} \mathrm{AcOH}(\eta=0.745 \mu \mathrm{L} / \mathrm{mg})$ in a ca. $8 \mathrm{~mL}$ sapphire milling jar using a single $7 \mathrm{~mm}$ stainless steel ball (1.38 g weight) at a milling frequency of $30 \mathrm{~Hz}$.

\section{Ex situ Syntheses}

3<smiles>Nc1ccc(N)cc1</smiles>

1<smiles>O=Cc1cc(C=O)cc(C=O)c1</smiles>

mesitylene/1,4-dioxane $\mathrm{AcOH}$

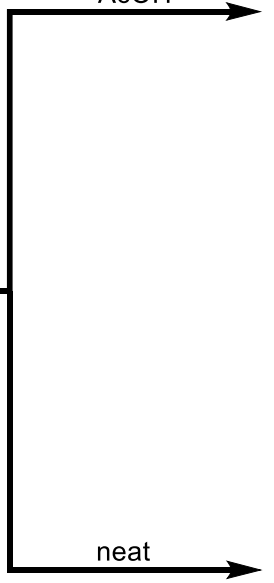

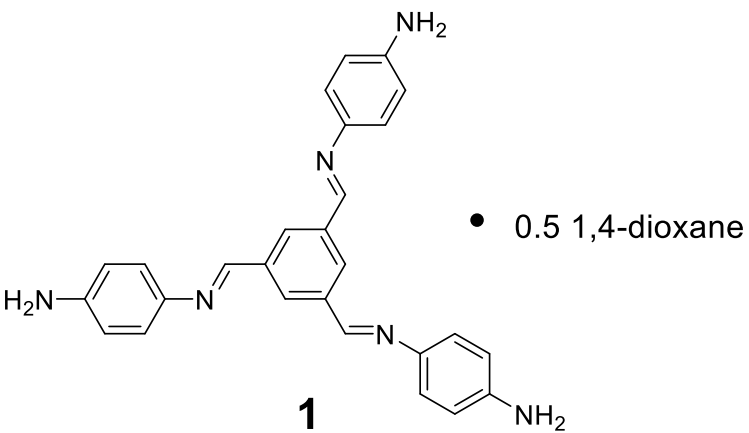

1

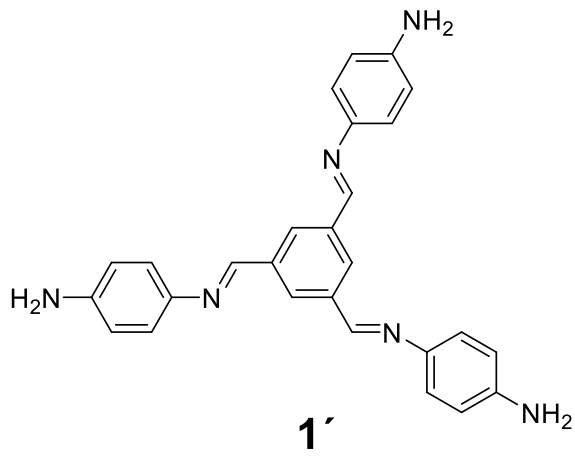

Scheme S1. Reaction scheme for the synthesis of the intermediate $\mathbf{1}$ trimer and its non-solvated form $\mathbf{1}^{\prime}$.

4,4',4"-(((1E,1'E,1'E)-benzene-1,3,5-triyltris(methaneylylidene))tris(azaneyl-ylidene))trianiline 0.5 1,4-dioxane (1). 1,3,5-Triformylbenzene (Tb, $50 \mathrm{mg}, 0.299 \mathrm{mmol}$ ) and $p$ phenylenediamine ( $p$ PDA, $100 \mathrm{mg}, 0.897 \mathrm{mmol}$ ) were placed into a $5 \mathrm{~mL}$ PMMA reaction jar and 
a $7 \mathrm{~mm}$ steel ball was added. 1,4-Dioxane $(31.5 \mu \mathrm{L})$, mesitylene $(31.5 \mu \mathrm{L})$ and as catalyst $6 \mathrm{M}$ acetic acid ( $12.5 \mu \mathrm{L}, \eta=0.50 \mu \mathrm{L} / \mathrm{mg}$ ) was added. The mixture was milled at $30 \mathrm{~Hz}$ for $30 \mathrm{~min}$. The resulting solid was dried under high vacuum for $24 \mathrm{~h}$ to remove remaining solvents and analyzed without further purification. IR $v_{\max } / \mathrm{cm}^{-1} 3455,3434,3407,3352,3326,3219,3032,2908,2882$, $2853,1628,1602,1584,1507,1284,1255,1171,1141,1117,1082,964,872,830,682,562,522$, 494, 470, 418; ${ }^{1} \mathrm{H}$ NMR (400 MHz, DMSO- $\left.d_{6}\right) \delta 8.76(\mathrm{~s}, 3 \mathrm{H}), 8.40(\mathrm{~s}, 3 \mathrm{H}), 7.22$ (d, J = $\left.7.4 \mathrm{~Hz}, 6 \mathrm{H}\right)$, $6.63(\mathrm{~d}, \mathrm{~J}=7.4 \mathrm{~Hz}, 6 \mathrm{H}), 5.30(\mathrm{~s}, 6 \mathrm{H}), 3.57(\mathrm{~s}, 4 \mathrm{H}) ;{ }^{13} \mathrm{C}$ NMR $\left(101 \mathrm{MHz}, \mathrm{DMSO}-d_{6}\right) \delta 153.27,148.33$, $139.08,137.80,128.60,122.75,114.09,66.34$; HRMS (ESI) exact mass calculated for [M+H]+ (C27H26N6) requires $\mathrm{m} / \mathrm{z} 433.21352$, found $\mathrm{m} / \mathrm{z} 433.21385$.

\section{4,4',4"-(((1E,1'E,1"E)-benzene-1,3,5-triyltris(methaneylylidene))tris(azaneyl-ylidene))triani-}

line (1'). 1,3,5-Triformylbenzene (TB, $50 \mathrm{mg}, 0.299 \mathrm{mmol}$ ) and $p$-phenylenediamine ( $p$ PDA, $100 \mathrm{mg}, 0.897 \mathrm{mmol}$ ) were placed into a $5 \mathrm{~mL}$ PMMA reaction jar and a $7 \mathrm{~mm}$ steel ball was added $(\eta=0 \mu \mathrm{L} / \mathrm{mg}$ ). The mixture was milled at $30 \mathrm{~Hz}$ for $30 \mathrm{~min}$. The resulting solid was dried under high vacuum for $24 \mathrm{~h}$ to remove remaining solvents and analyzed without further purification. IR $v_{\max } / \mathrm{cm}^{-1} 3435,3337,3208,3032,3002,2882,2856,1622,1599,1578,1505$, $1282,1167,1137,1083,970,873,828,681,643,583,523,493,474,410 ;{ }^{1} \mathrm{H}$ NMR $(400 \mathrm{MHz}$, DMSO- $\left.d_{6}\right) \delta 8.76(\mathrm{~s}, 3 \mathrm{H}), 8.40(\mathrm{~s}, 3 \mathrm{H}), 7.22(\mathrm{~d}, \mathrm{~J}=7.4 \mathrm{~Hz}, 6 \mathrm{H}), 6.63(\mathrm{~d}, \mathrm{~J}=7.4 \mathrm{~Hz}, 6 \mathrm{H}), 5.30(\mathrm{~s}, 6 \mathrm{H})$, $3.57(\mathrm{~s}, 4 \mathrm{H}) ;{ }^{13} \mathrm{C}$ NMR $\left(101 \mathrm{MHz}, \mathrm{DMSO}-d_{6}\right) \delta 153.27,148.33,139.08,137.80,128.60,122.75$, 114.09, 66.34; HRMS (ESI) exact mass calculated for $[\mathrm{M}+\mathrm{H}]^{+}\left(\mathrm{C}_{27} \mathrm{H}{ }_{2}{ }_{6} \mathrm{~N}_{6}\right)$ requires $\mathrm{m} / \mathrm{z} 433.21352$, found $\mathrm{m} / \mathrm{z} 433.21385$.

Benzidine•1,4-dioxane (2). Benzidine ( $\mathrm{Bd}, 100 \mathrm{mg}, 0.543 \mathrm{mmol}$ ) and 1,4-dioxane (46.5 $\mathrm{hL}$ ) were placed into a $5 \mathrm{~mL}$ PMMA reaction jar and a $7 \mathrm{~mm}$ steel ball was added ( $\eta=0.47 \mu \mathrm{L} / \mathrm{mg}$ ). The mixture was milled at $30 \mathrm{~Hz}$ for $10 \mathrm{~min}$. The resulting solid was immediately analyzed without further purification. IR $v_{\max } / \mathrm{cm}^{-1} 3450,3403,3356,3328,3207,3025,2953,2859,1632,1607$, $1498,1289,1264,1175,1112,1079,868,817,748,702,615,526,506 ;{ }^{1} \mathrm{H}$ NMR (400 MHz, Chloroform-d) $\delta 7.34(\mathrm{~d}, J=7.9 \mathrm{~Hz}, 4 \mathrm{H}), 6.72(\mathrm{~d}, J=7.9 \mathrm{~Hz}, 4 \mathrm{H}), 3.70(\mathrm{~s}, 8 \mathrm{H}), 3.65(\mathrm{~s}, 4 \mathrm{H}) ;{ }^{13} \mathrm{C} \mathrm{NMR}$ (101 MHz, Chloroform-d) $\delta 145.07,131.92,127.39,115.54,67.19$; HRMS (ESI) exact mass calculated for $[\mathrm{M}+\mathrm{H}]^{+}\left(\mathrm{C}_{27} \mathrm{H}_{2}{ }_{6} \mathrm{~N}_{6}\right)$ requires $\mathrm{m} / \mathrm{z} 184.10005$, found $\mathrm{m} / \mathrm{z}$.

\section{Solvent study:}

Mechanosynthesis of COF LZU-1 using pure mesitylene as a liquid additive. 1,3,5Triformylbenzene (TB, $100 \mathrm{mg}, 0.598 \mathrm{mmol}$ ) and $p$-phenylenediamine ( $p$ PDA, $100 \mathrm{mg}$, $0.897 \mathrm{mmol}$ ) were placed into a $10 \mathrm{~mL}$ steel reaction jar with the addition of $80 \mu \mathrm{L}$ of mesitylene and $6 \mathrm{M}$ acetic acid $(40 \mu \mathrm{L}, \eta=0.60 \mu \mathrm{L} / \mathrm{mg})$ as catalyst, and a $7 \mathrm{~mm}$ steel ball was added. The mixture was milled at $30 \mathrm{~Hz}$ for $1 \mathrm{~h}$. The resulting solid was washed with acetone, DMF, dichloromethane, methanol, and a $12 \mathrm{~h}$ Soxhlet extraction with $\mathrm{MeOH}$. The wet sample was activated by supercritical $\mathrm{CO}_{2}$ drying and further drying under high vacuum for $24 \mathrm{~h}$. Yield: 
146.6 mg (91\%). Elemental Analysis, calc.: C, 79.98; H, 4.47; N, 15.55; found C, 76.36; H, 4.91; N, 14.76.

Mechanosynthesis of COF LZU-1 using pure 1,4-dioxane as a liquid additive. 1,3,5Triformylbenzene (TB, $100 \mathrm{mg}, 0.598 \mathrm{mmol}$ ) and $p$-phenylenediamine ( $p$ PDA, $100 \mathrm{mg}$, $0.897 \mathrm{mmol}$ ) were placed into a $10 \mathrm{~mL}$ steel reaction jar with $80 \mu \mathrm{L}$ 1,4-dioxane, $6 \mathrm{M}$ acetic acid ( $40 \mu \mathrm{L}, \eta=0.60 \mu \mathrm{L} / \mathrm{mg}$ ) as catalyst, and a $7 \mathrm{~mm}$ steel ball was added. The mixture was milled at $30 \mathrm{~Hz}$ for $1 \mathrm{~h}$. The resulting solid was washed with acetone, DMF, dichloromethane, methanol, and a $12 \mathrm{~h}$ Soxhlet extraction with $\mathrm{MeOH}$. The wet sample was then activated by supercritical $\mathrm{CO}_{2}$ drying and further drying under high vacuum for $24 \mathrm{~h}$. Yield: $151.0 \mathrm{mg}$ (93\%). Elemental Analysis, calc.: C, 79.98; H, 4.47; N, 15.55; C, 77.56; H, 4.76; N, 14.92. 


\section{S3 X-ray powder diffraction analysis}

Crystal structure determination of intermediate 1

Indexing of the intermediate (1) was carried out by an iterative use of singular value decomposition leading to a triclinic space group $(P \overline{1})$ with the lattice parameters listed in Table S1. The peak profile was determined by a Pawley refinement using the fundamental parameter approach (FPA) as implemented in TOPAS. The background was modeled by a Chebychev polynomial of $13^{\text {th }}$ order. The crystal structure of the intermediate was determined using the global optimization method of simulated annealing (SA). The intermediate was decomposed into four different rigid bodies during the $a b$ initio structure solution process and for the consequent Rietveld refinement. The central part of the molecule (1,3,5-trimethylbenzene) and three 1,4diamine molecules were described using rigid bodies in z-matrix notation with idealized bond lengths and bond angles, taken from related COF structures. The three imine bond distances (N11 - C11, N21 - C21, N31 - C31) were restraint to be 1.28 A. 1,4-Dioxane was described by a rigid body in z-matrix notation including a dummy atom in the center of the ring, which was placed on a center of inversion $(0,0,0)$. For the final Rietveld refinement, the background, lattice parameters, microstructure in form of microstrain (Gaussian and Lorentzian component), most translations and rotations of the rigid bodies were refined without any constraint for the final refinement. Only the translational components of 1,4-dioxane were constraint, so that a center of inversion is in the center of the molecule.

Crystal structure determination of benzidine solvate intermediate (2)

Indexing of the benzidine dioxane solvate intermediate (2) was performed by an iterative use of singular value decomposition using a XRPD pattern collected with Co-radiation. Indexing lead to a monoclinic space group $\left(P 2_{1} / c\right)$ with the lattice parameters listed in Table $S 1$. The peak profile was determined by a Pawley refinement using FPA in TOPAS V6. The background was modeled by a Chebychev polynomial of $13^{\text {th }}$ order. The crystal structure of $\mathbf{2}$ was determined using the global optimization method of SA. 1,4-Dioxane and benzidine were described using rigid bodies in z-matrix notation, with only half of each molecule in the rigid bodies, as they are both doubled by a center of inversion. A dummy atom was used to place both rigid bodies on the center of inversion, Wyckoff site $2 a(0,0,0)$ for benzidine and $2 d(0.5,0,0.5)$ for 1 ,4-dioxane. Initial bond lengths and angles were taken from related crystal structures found in the Cambridge Structural Database (CSD) and subsequently modified according to the bond lengths and angles obtained after DFT structure optimization. An overall isotropic thermal displacement parameter for each molecular moiety was refined using an $U_{\text {iso }}=1.2$ with respect to parent atoms for all hydrogen atoms. For the final Rietveld refinement background, lattice parameters, microstructure in the form of microstrain and crystallite size (Gaussian and Lorentzian component), and rotations of both rigid bodies were freely refined. 
Table 1: Crystallographic information of the Rietveld refinements of the intermediate solvate (1) and benzidine dioxane solvate (2) with selected refinement information.

\begin{tabular}{|c|c|c|}
\hline Name & 1 & Benzidine dioxane solvate (2) \\
\hline Formula & $\mathrm{C}_{29} \mathrm{H}_{28} \mathrm{~N}_{6} \mathrm{O}_{1}$ & $\mathrm{C}_{16} \mathrm{H}_{20} \mathrm{~N}_{2} \mathrm{O}_{2}$ \\
\hline MW / g mol-1 & 476.57 & 272.34 \\
\hline Crystal system & Triclinic & Monoclinic \\
\hline Space group & $P \overline{1}$ & $P 2_{1} / c$ \\
\hline a / $\AA$ & $8.6884(3)$ & $5.94994(13)$ \\
\hline$b / \AA$ & $10.4970(4)$ & $8.61502(17)$ \\
\hline$c / \AA$ & $14.2634(6)$ & $14.1939(4)$ \\
\hline$\alpha /^{\circ}$ & $93.855(3)$ & 90 \\
\hline$B /^{\circ}$ & $101.0341(19)$ & $92.0849(14)$ \\
\hline$v /^{\circ}$ & $96.487(3)$ & 90 \\
\hline$V / \AA^{3}$ & $1263.36(9)$ & $727.08(3)$ \\
\hline$T / \mathrm{K}$ & 295 & 295 \\
\hline$\lambda / \AA$ & 1.540596 & 1.540596 \\
\hline Z & 2 & 2 \\
\hline$D_{\text {calc }} / \mathrm{mg} \mathrm{cm}^{-3}$ & 1.253 & 1.244 \\
\hline$\mu / \mathrm{mm}^{-1}$ & 0.6271 & 0.6612 \\
\hline$R_{\mathrm{wp}} / \%{ }^{[\mathrm{a}]}$ & 5.23 & 4.50 \\
\hline$R_{\mathrm{p}} / \%^{[\mathrm{a}]}$ & 4.07 & 3.35 \\
\hline
\end{tabular}



$R_{\exp } / \%^{[a]}$
0.83
$\mathrm{R}_{\text {Bragg }}{ }^{[a]}$
Starting angle $/{ }^{\circ} 2 \theta$
Final angle $/{ }^{\circ} 2 \theta$
85
89.9
Step width $/{ }^{\circ} 2 \theta$
0.0075
0.0075
Time per scan / h
8
8
No. of variables
52
38

${ }^{\text {[a] }} \mathbf{R}_{\text {wp }}, \mathbf{R}_{\mathrm{p}}, \mathbf{R}_{\text {exp }}, \mathbf{R}_{\text {Bragg }}$ as defined in TOPAS.

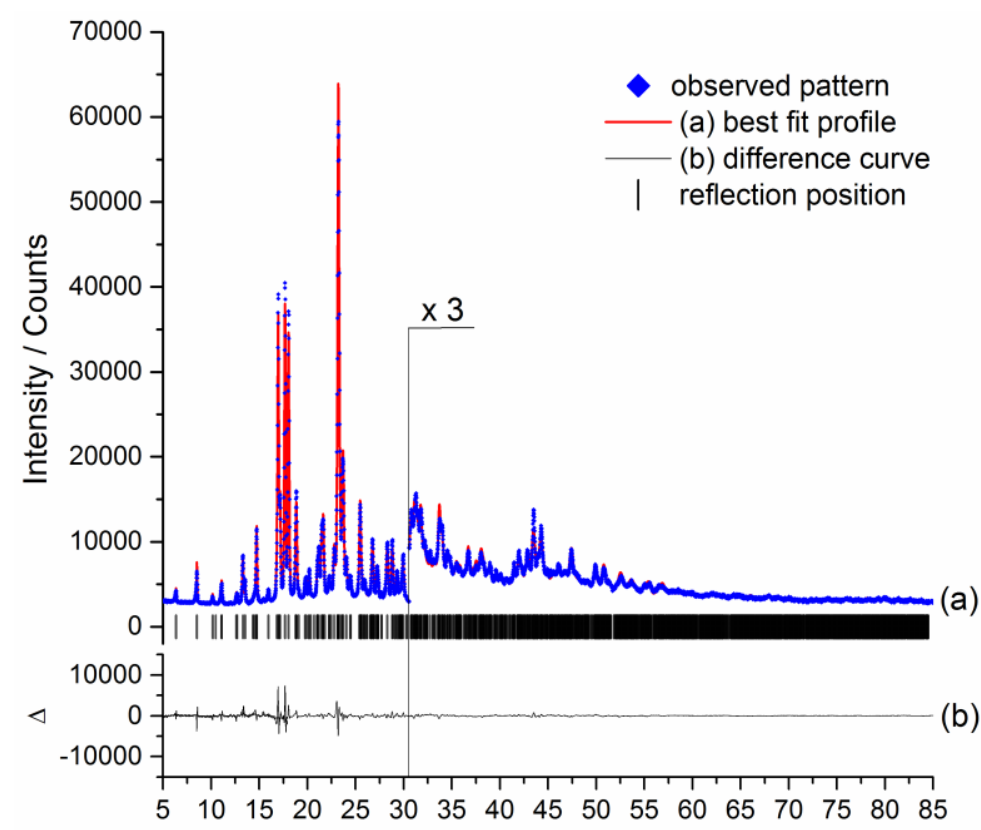

Figure S1. Rietveld refinement plot of $1\left(\lambda=\mathrm{Cu} \mathrm{K} \alpha_{1}\right)$ with the observed pattern (blue diamonds), calculated pattern (red line), calculated peak positions (dashes), and the difference curve (black line). The higher scattering region $\left(2 \theta>30.5^{\circ}\right)$ was enlarged by a factor of 3 for better visualization. 


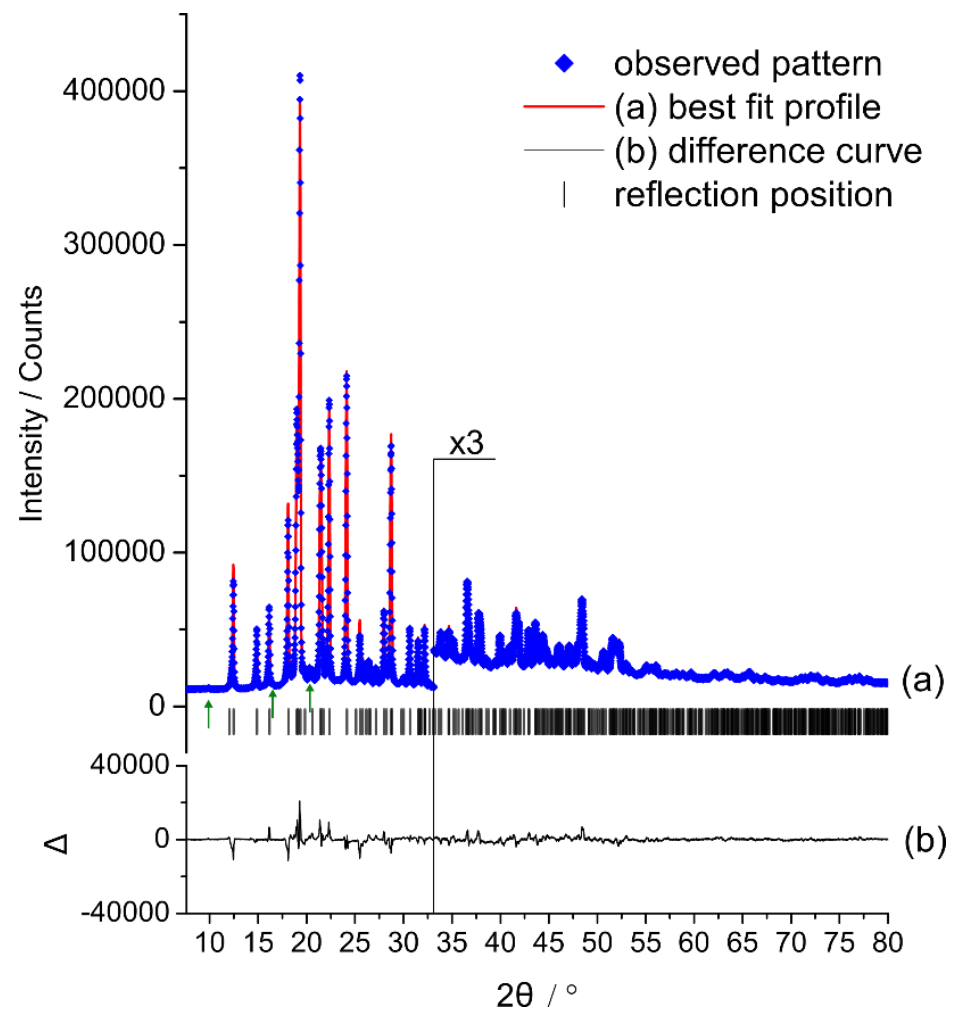

Figure S2. Rietveld refinement plot of $\mathbf{2}\left(\lambda=\mathrm{Cu} \mathrm{K} \alpha_{1}\right)$ with the observed pattern (blue diamonds), calculated pattern (red line), calculated peak positions (dashes), and the difference curve (black line). The higher scattering region $\left(2 \theta>33^{\circ}\right)$ was enlarged by a factor of 3 for better visualization. The sample contains a benzidine polymorph as minor side phase (CSD refcode BENZIE04), relevant weak diffraction peaks are marked with green arrows at $9.8,16.5$, and $20.3^{\circ} 2 \theta$.

a

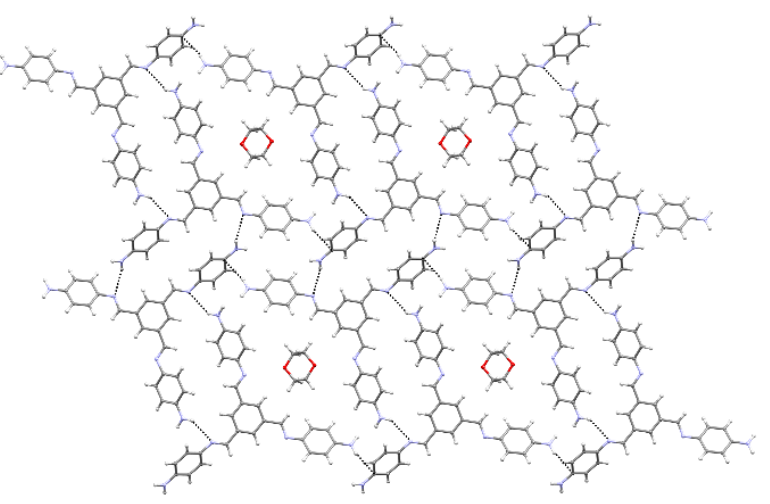

b

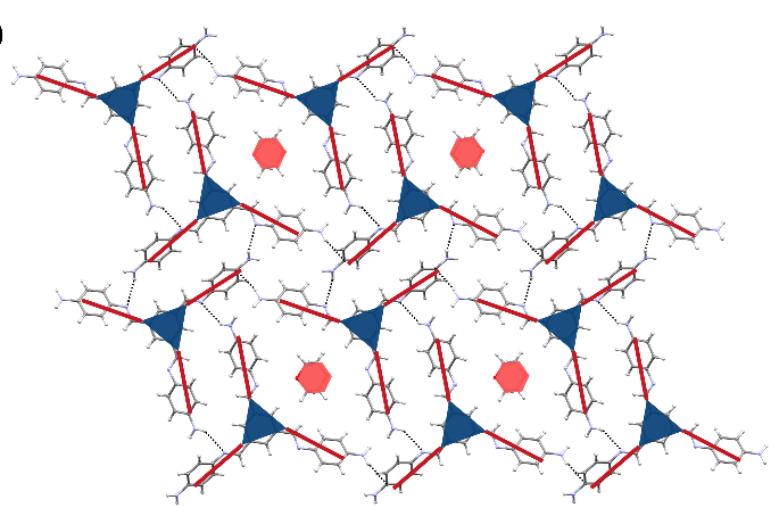

Figure S3. (a) Excerpt of the crystal structure of intermediate 1 with view on top of the layer and (b) schematic representation of trimer and 1,4-dioxane orientation, used for Figure 4 in the main text. 


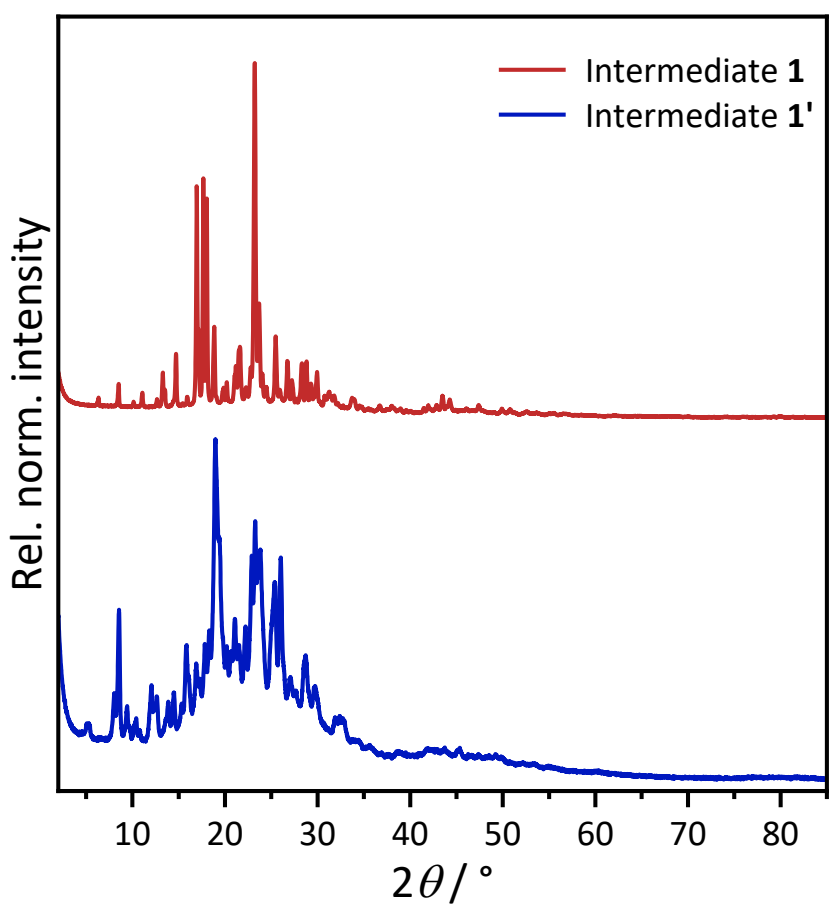

Figure S4. Comparison of measured ex situ XRPD patterns $(\lambda=1.54056 \AA)$ of intermediate solvate 1 and $\mathbf{1}^{\prime}$.

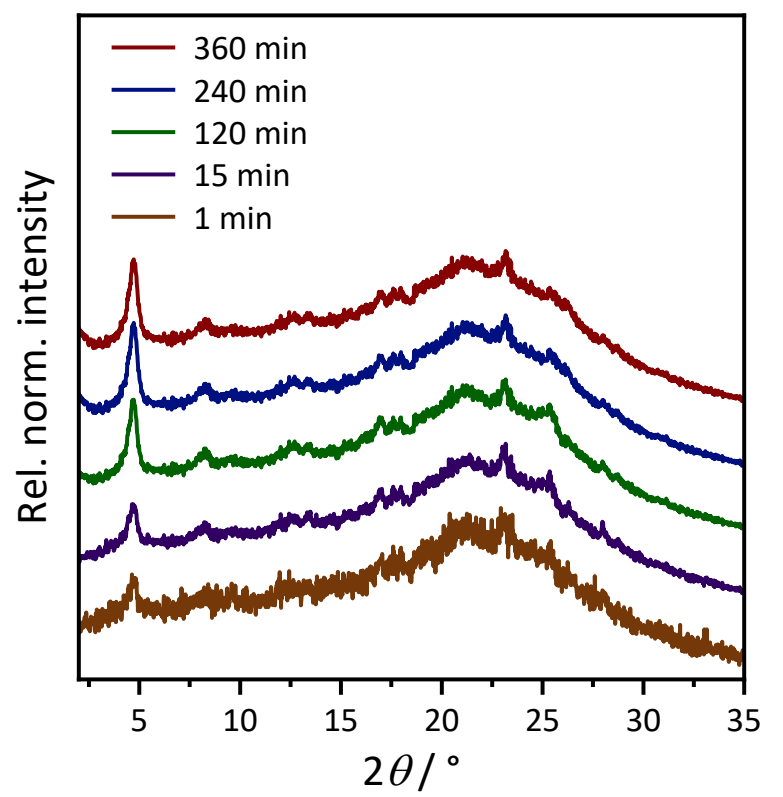

Figure S5. XRPD patterns of the reaction mixture during synthesis of COF-LZU1, stopped after 3 min of milling, with the attempt to capture the intermediate $\mathbf{1}$, showing the continuation of the polymerization and self-assembly of COF-LZU1 over time. 


\section{In situ XRPD measurements and sequential refinement}

Sequential Rietveld refinements were performed using TOPAS V5. A LaB 6 standard measurement was used to describe the instrumental profile function (IPF) by applying equivalent conditions (same milling frequency and exposure time). The IPF was described using a modified ThompsonCox-Hasting pseudo-Voight function as implemented in TOPAS. The diffraction signals of the COFs and the reaction intermediate (1) were modelled by single peak phases with fixed peak positions and peak widths. Reactants were modelled. Those reactants, whose crystal structures were known from the database were modelled by sequential Rietveld refinements

(a)

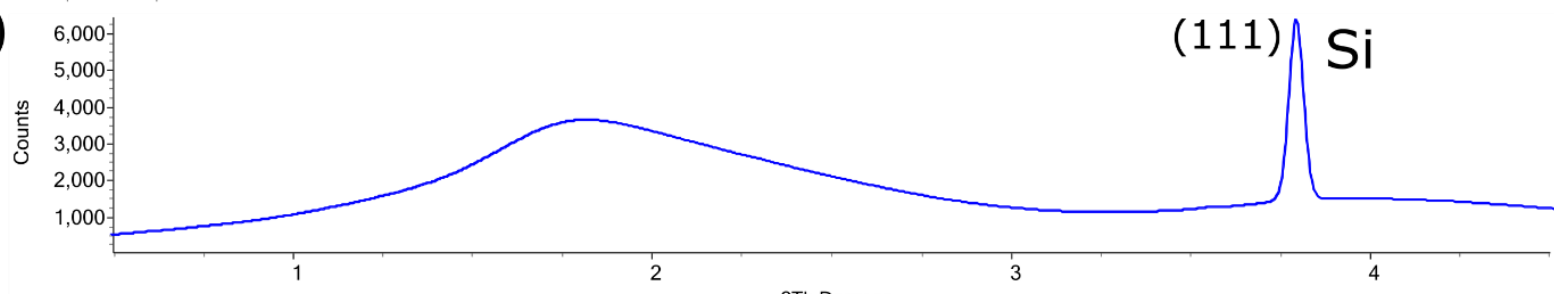

(b)

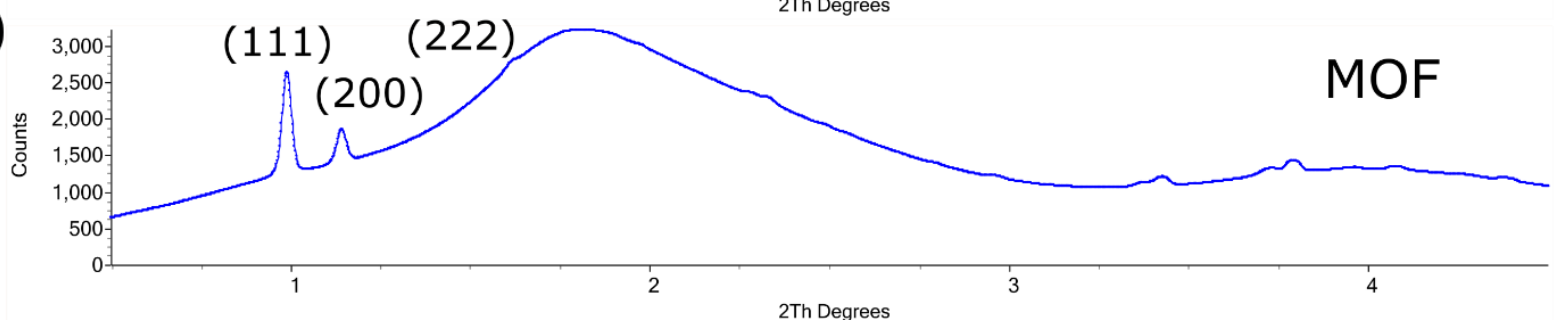

(c)

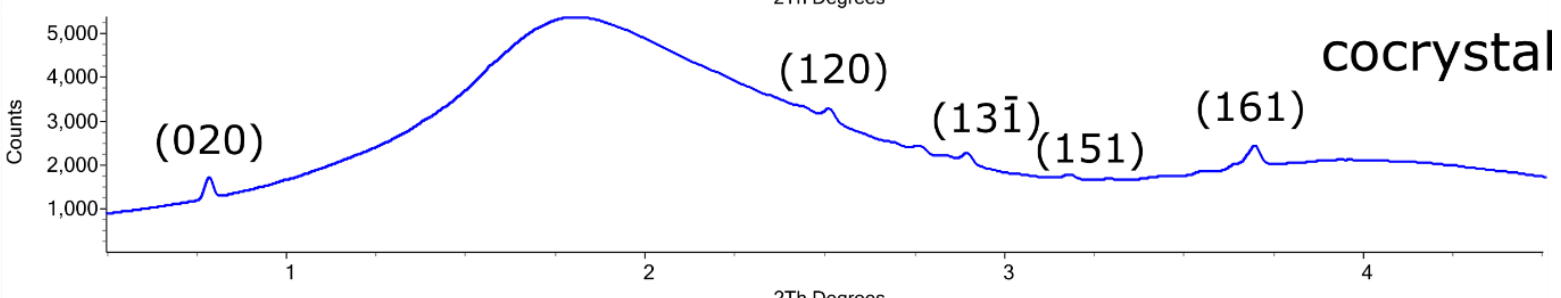

(d)

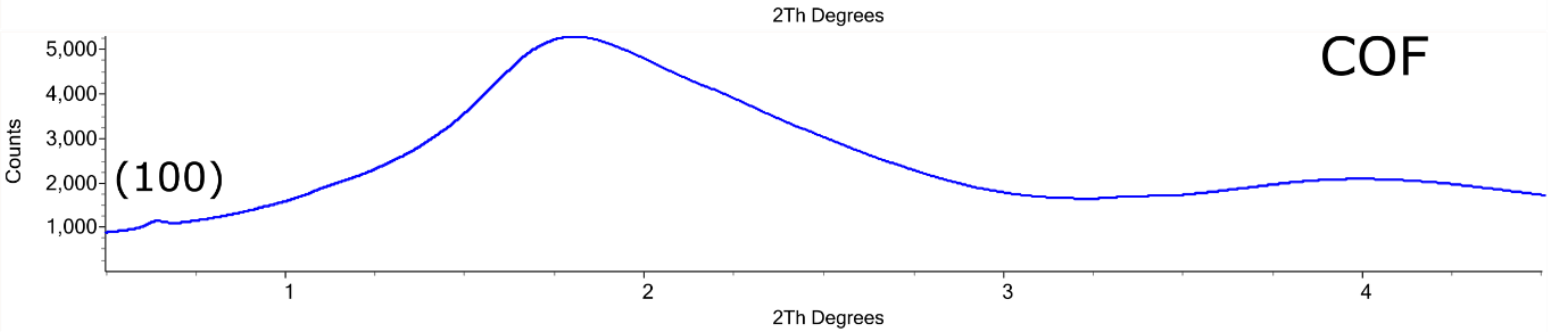

Figure S6. Comparison of measured in situ XRPD patterns of different material classes in PMMA jars during their mechanochemical synthesis at P02.1 Powder Diffraction and Total Scattering beamline with (a) a silicon standard (15 mL PMMA jar), (b) mechanosynthesis of UiO-66 (15 mL PMMA jars),, ${ }^{[12]}$ (c) (nic) •(adi) cocrystals (15 mL PMMA jars), ${ }^{[13]}$ and (d) COF-LZU1 system in $5 \mathrm{~mL}$ PMMA jars from this study. Diffraction signal of the most intense (100) COF reflection is visible at $0.64{ }^{\circ} 2 \theta$. Wavelength in all cases approx. 0.207 $\AA$. 


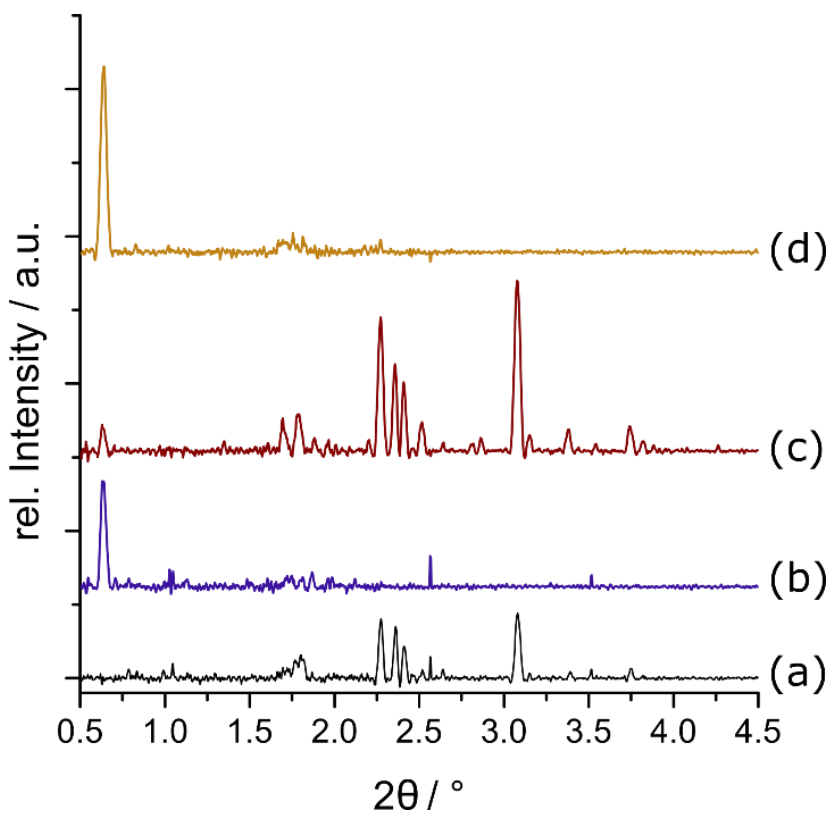

Figure S7. Comparison of measured, background subtracted in situ XRPD patterns during the mechanochemical synthesis of COFLZU1 using either (a, b) AcOH after (a) $3.3 \mathrm{~min}$ and (b) ca. 50 min of milling, and (c,d) Sc(OTf) 3 as catalyst, after (c) 3.3 min and (d) ca. 45 min of milling.
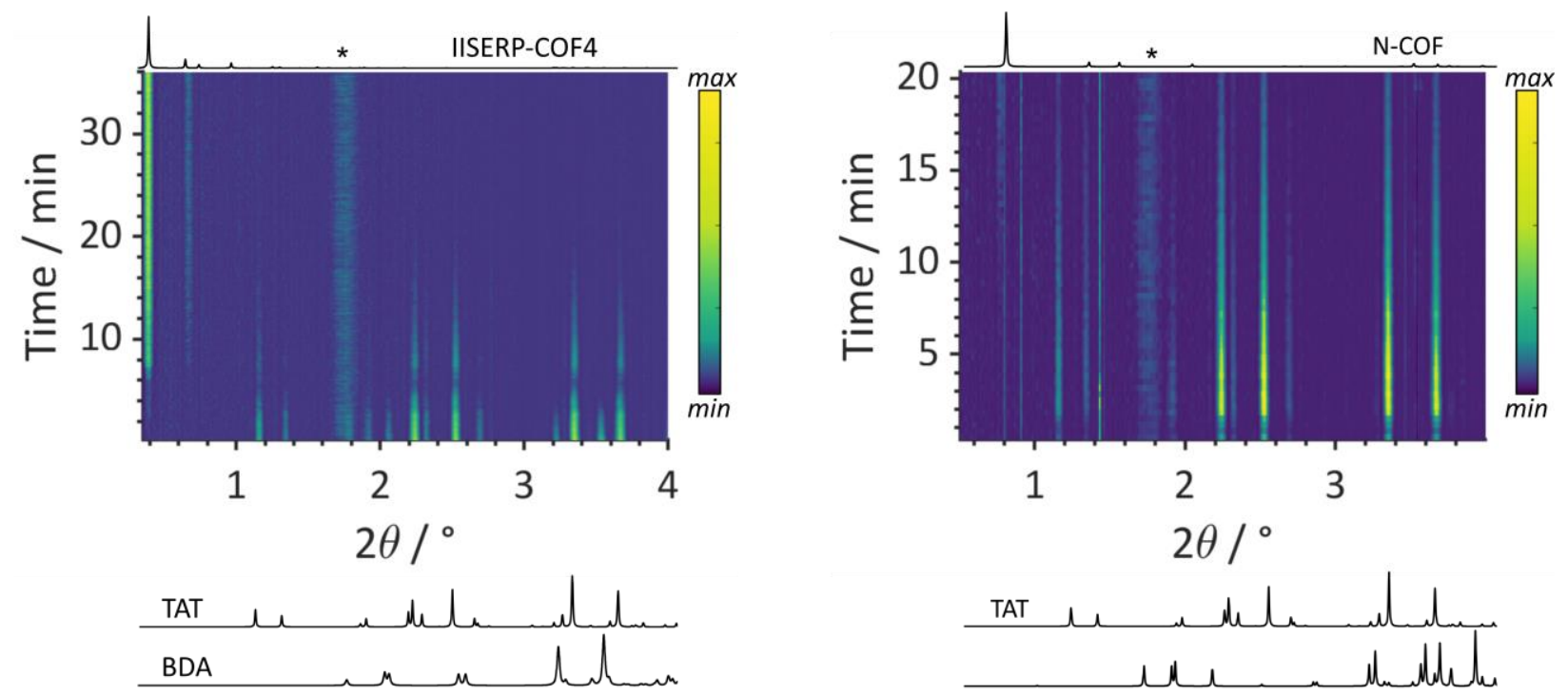

Figure S8. Background subtracted 2D XRPD plots of the mechanochemical synthesis of IISERP-COF (left) and N-COF (right) using $\mathrm{Sc}(\mathrm{OTf})_{3}$ as catalyst. Calculated XRPD patterns of reactants and COFs are shown below and above the 2D plot, respectively, $\lambda=0.207 \AA$. 
a

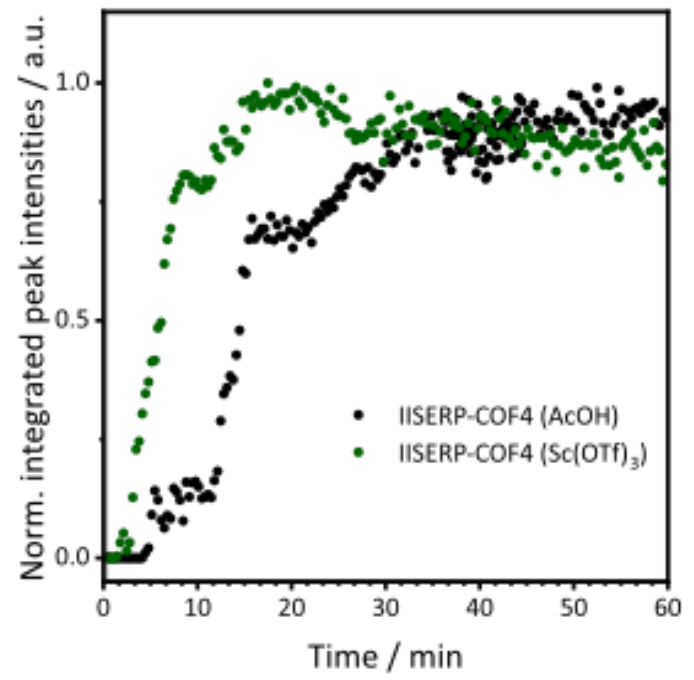

b

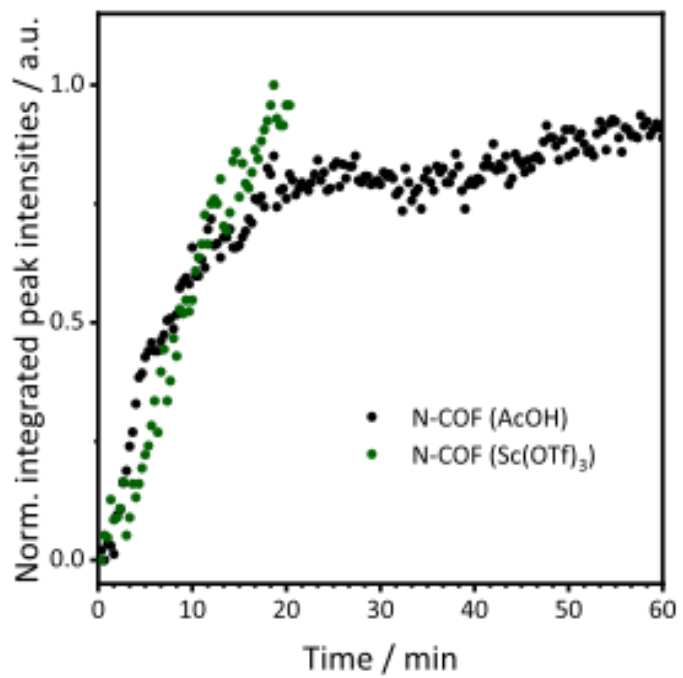

Figure 59. Comparison of the formation kinetics of IISERP-COF4 (a) and N-COF (b) using AcOH or Sc(OTf) ${ }_{3}$ as catalyst. Data collection of $\mathrm{N}-\mathrm{COF}\left(\mathrm{Sc}(\mathrm{OTf})_{3}\right)$ ends after 20 min due to beam dump.

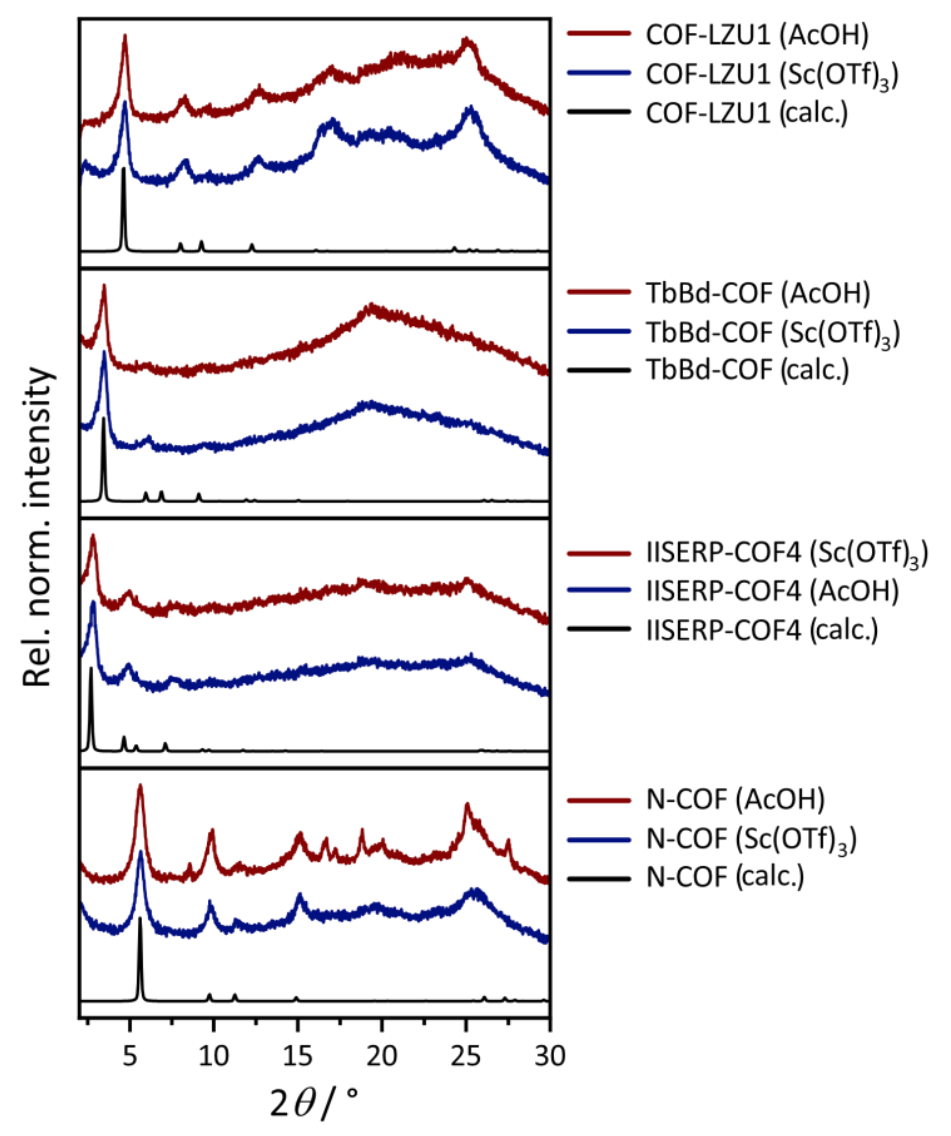

Figure S10. Ex situ XRPD patterns $(\lambda=1.54 \AA$ ) of as-synthesized COF samples obtained during in situ monitoring. From top to bottom: COF-LZU1, TbBD-COF, IISERP-COF4, and N-COF with AcOH and Sc(OTf $)_{3}$ as catalysts, as well as calculated XRPD patterns of the respective COF system. 


\section{Ex situ X-ray powder diffraction}

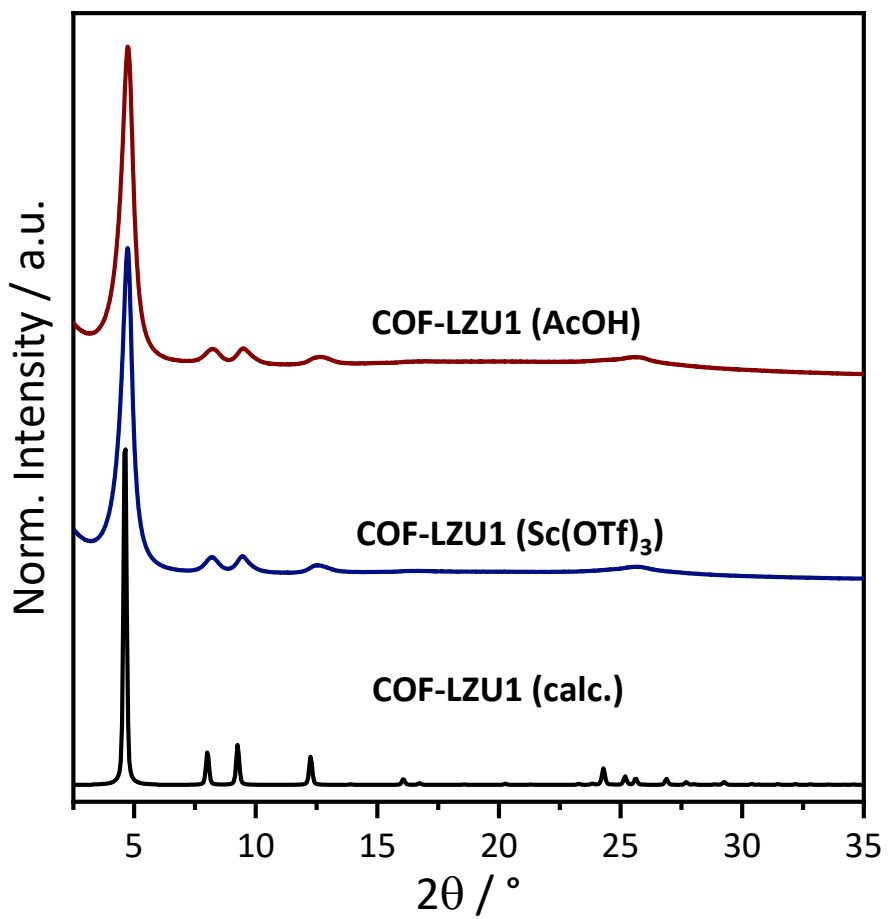

Figure S11. Comparison of measured ex situ XRPD patterns $(\lambda=1.54 \AA ̊ \AA)$ : COF-LZU1 (AcOH), COF-LZU1 $\left(\mathrm{Sc}(\mathrm{OTf})_{3}\right)$ and the calculated pattern of COF-LZU1.

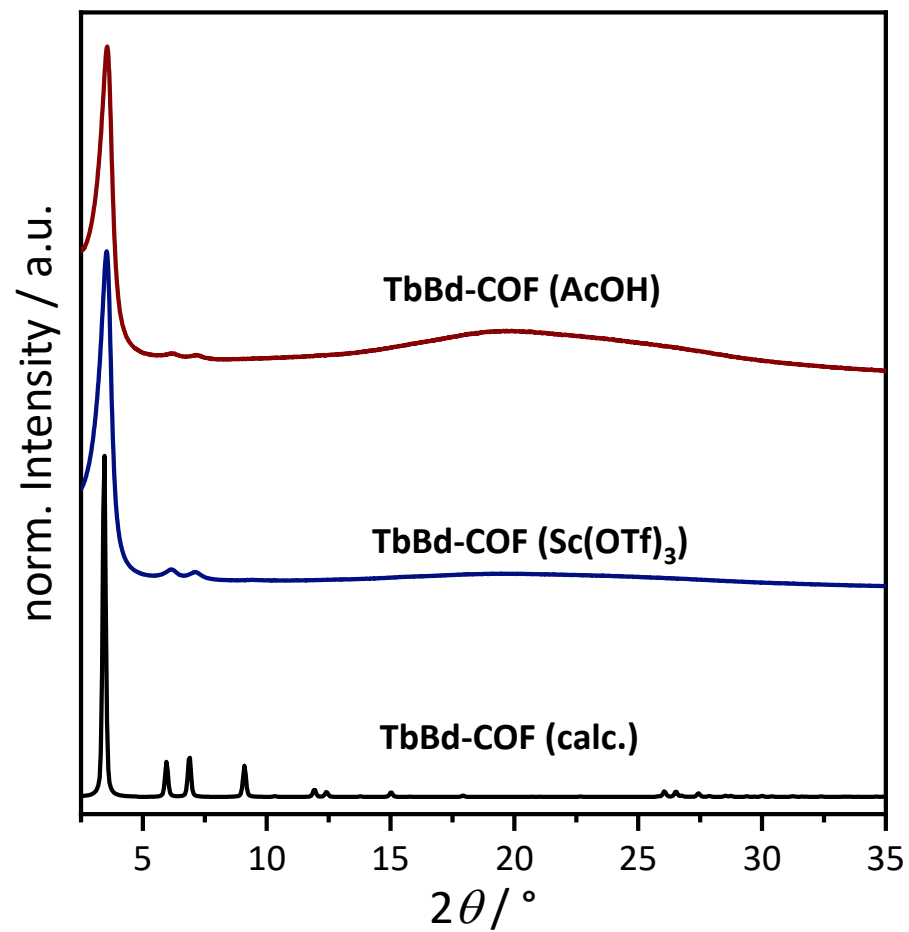

Figure S12. Comparison of measured ex situ XRPD patterns $(\lambda=1.54 \AA)$ : TbBd-COF $(\mathrm{AcOH}), \operatorname{TbBd}-\mathrm{COF}\left(\mathrm{Sc}(\mathrm{OTf})_{3}\right)$ and the calculated pattern of TbBd-COF. 


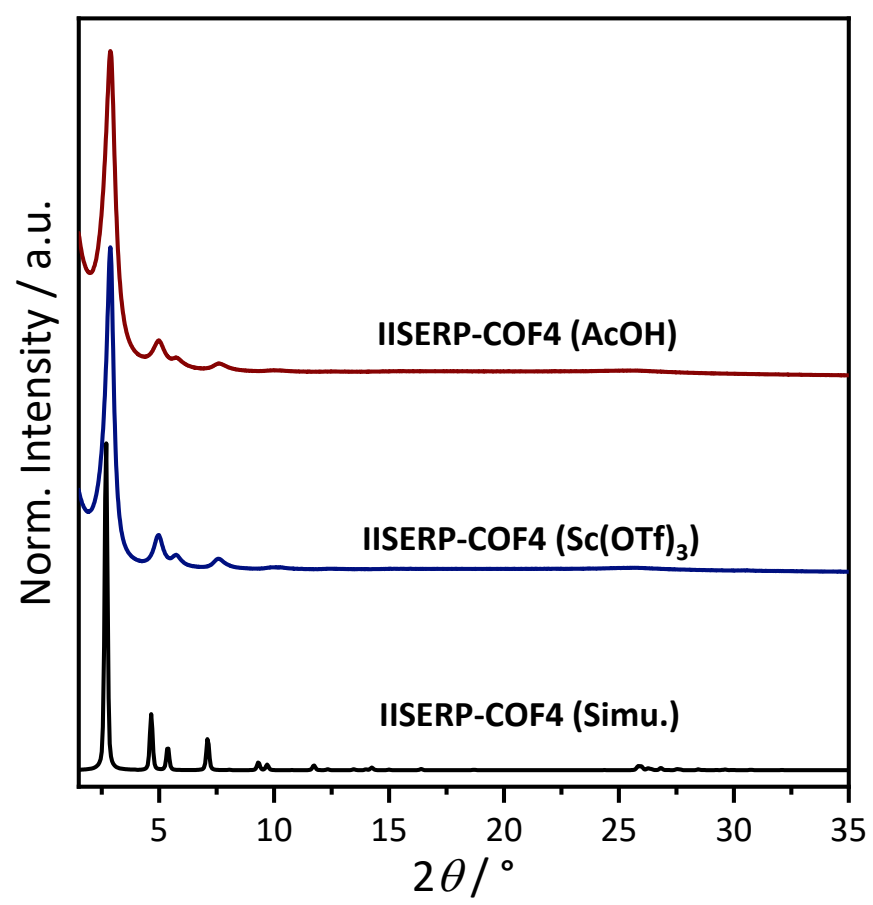

Figure S13. Comparison of measured ex situ XRPD patterns $(\lambda=1.54 \AA$ ) : IISERP-COF4 (AcOH), IISERP-COF4 (Sc(OTf) 3 ) and the calculated pattern of IISERP-COF4.

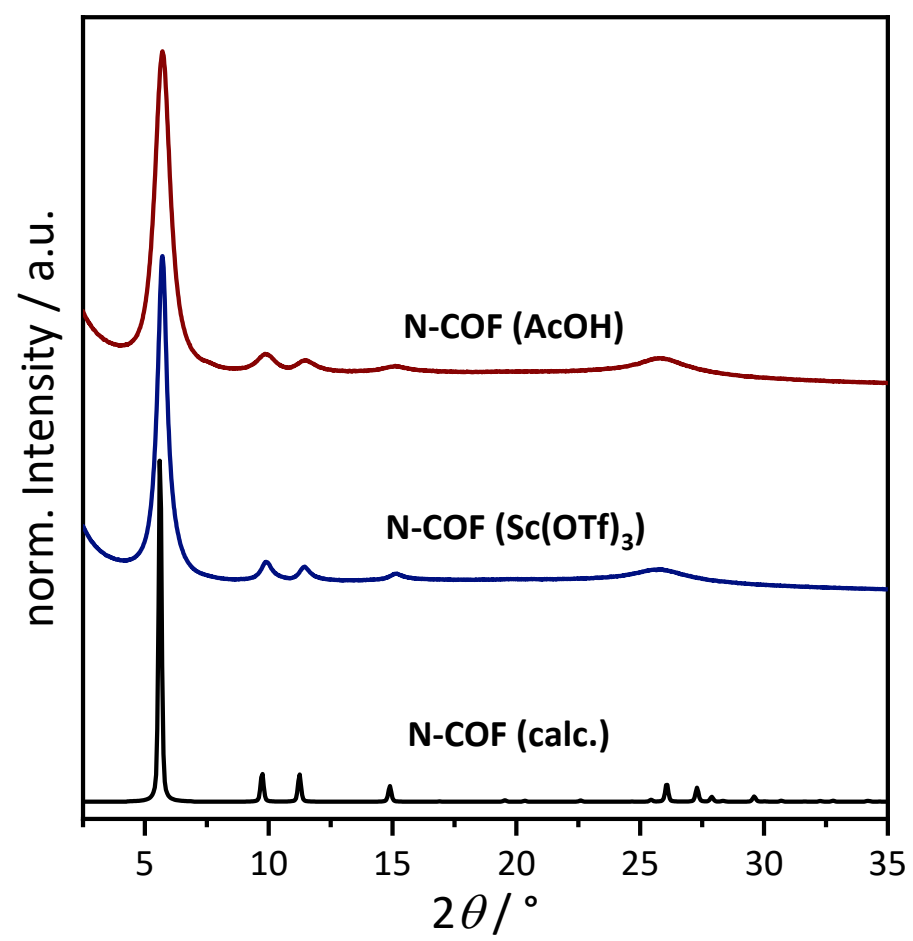

Figure S14. Comparison of measured ex situ XRPD patterns $\left(\lambda=1.54 \AA\right.$ ) : N-COF $(\mathrm{AcOH}), \mathbf{N}-\mathrm{COF}\left(\mathrm{Sc}(\mathrm{OTf})_{3}\right)$ and the calculated pattern of N-COF. 


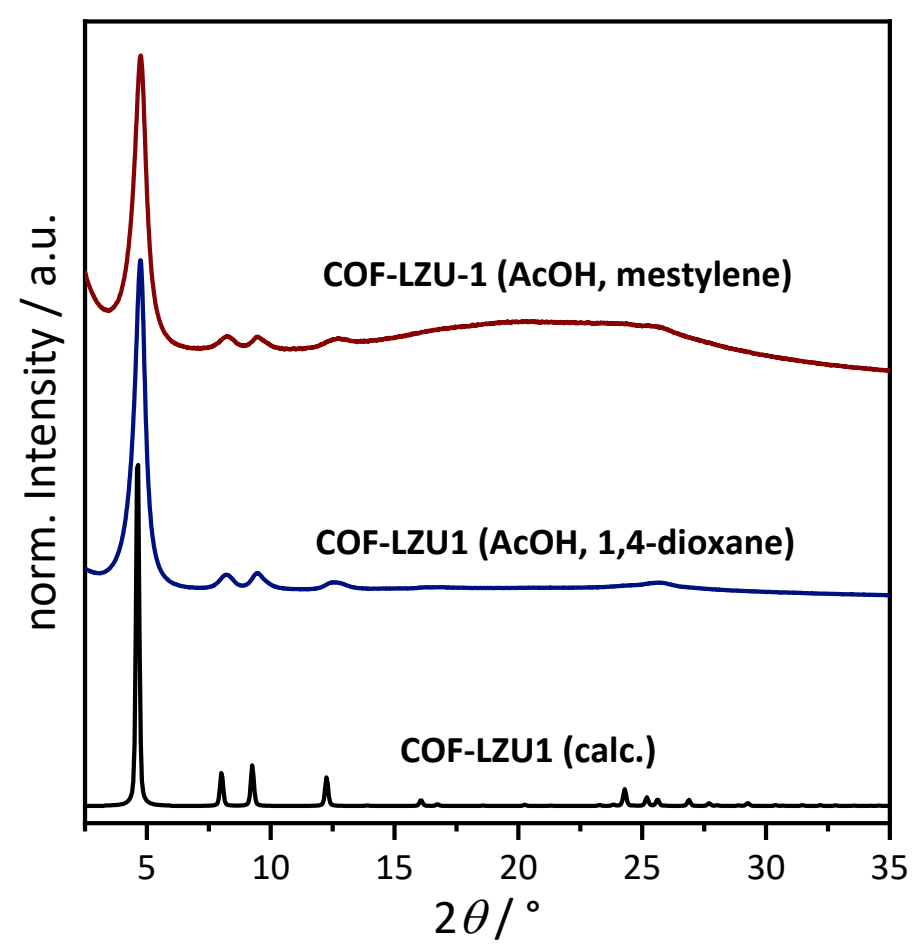

Figure S15. Comparison of ex situ XRPD patterns $(\lambda=1.54 \AA$ A): COF-LZU1 (AcOH, mesitylene), COF-LZU1 (AcOH, 1,4 dioxane) and the calculated pattern of COF-LZU1.

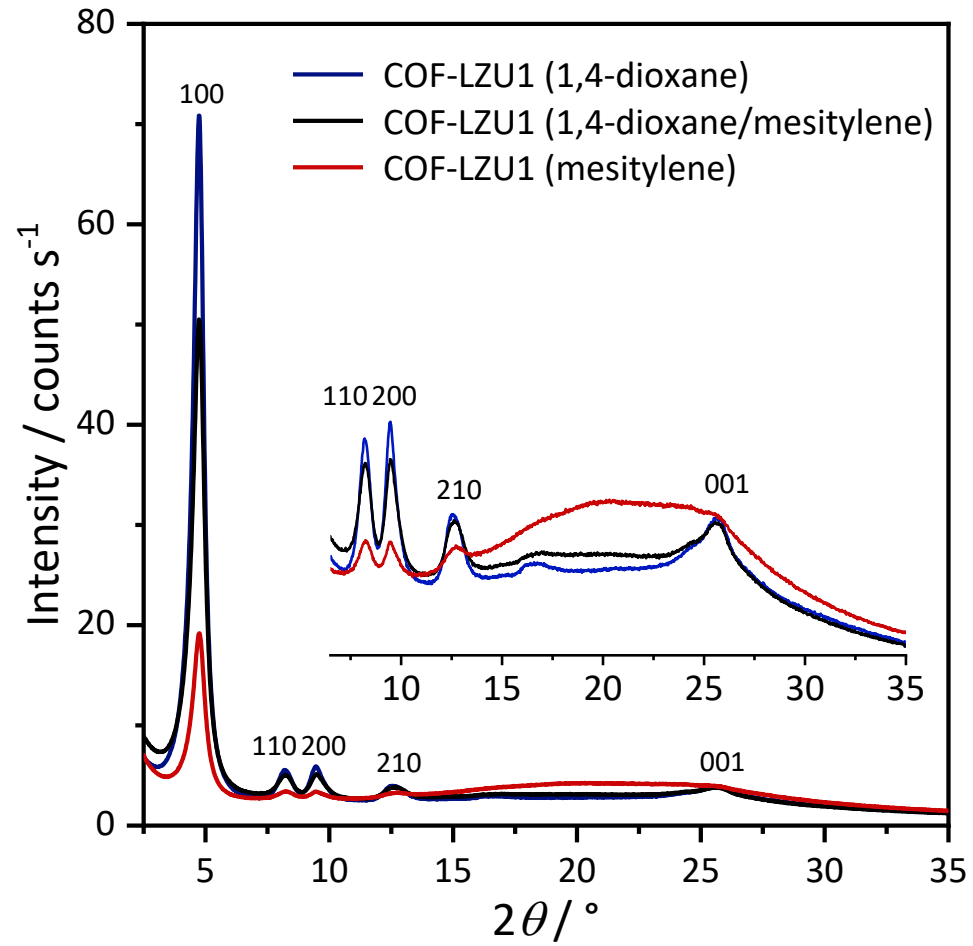

Figure S16. Direct comparison of ex situ XRPD patterns ( $\lambda=1.54 \AA ̊$ ): COF-LZU1 (red: AcOH, mesitylene), COF-LZU1 (black: AcOH, mesitylene:1,4-dioxane) and COF-LZU1 (blue: $\mathrm{AcOH}, 1,4$-dioxane). 


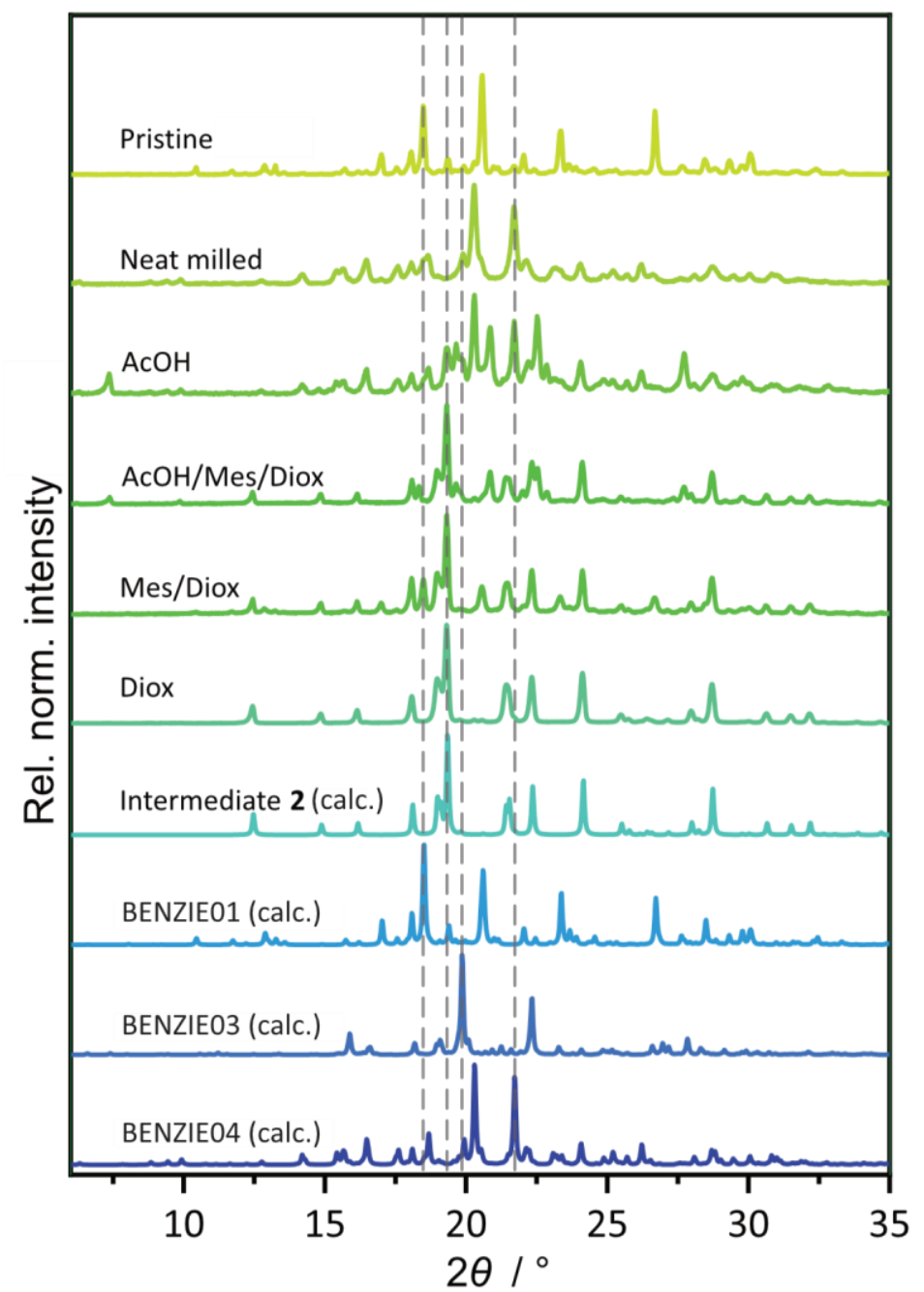

Figure S17. Comparison of XRPD-patterns for milling benzidine with different grinding additives. From top to bottom: pristine benzidine, neat grinding of benzidine, grinding benzidine in presence of $\mathrm{AcOH}, \mathrm{AcOH} / \mathrm{mes} / \mathrm{diox}$, mes/diox, and diox as liquid additives, calculated XRPD patterns of intermediate 2, and different benzidine polymorphs with CCDC refCodes BENZIE01, BENZIEO3, and BENZIE04. 


\section{S4 In Situ Raman Spectroscopy}

Real-time Raman monitoring of the reaction between 1,3,5-triformylbenzene and $p$ phenylenediamine revealed fluorescence along with a strong Raman signal of the condensation product under excitation of the $785 \mathrm{~nm}$ laser (Figure 18).

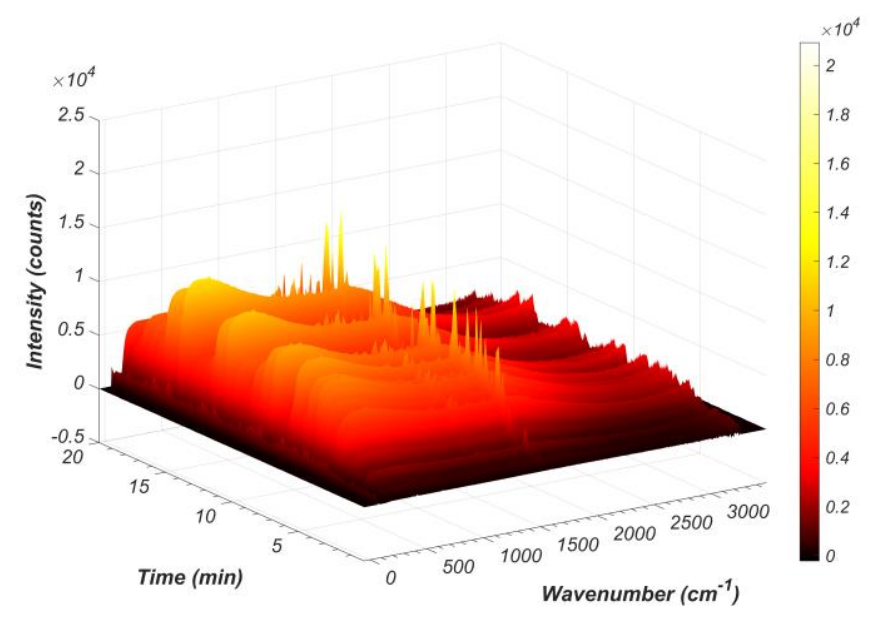

Figure S18: Raw signal of COF-LZU1 formation, monitored in situ by real-time Raman spectroscopy. The appearance of the fluorescence caused by the assembly of COF-LZU1 and consequently the formation of the conjugated $\pi$-system is visible after approx. 5 minutes.

Removal of the fluorescence signal via baseline subtraction and vector normalization reveals only a single set of Raman peaks with a minor component of the Raman signal from the sapphire milling jar (Figure 19). The Raman spectra of the trialdehyde and diamine starting materials were not observed in the reaction (Figure S20) and the characteristic peaks observed at $1574 \mathrm{~cm}^{-1}$ and $1625 \mathrm{~cm}^{-1}$ correspond well with $v_{\mathrm{C}=\mathrm{N}}$ and $v_{\mathrm{C}-\mathrm{N}}$ stretching bands of imines suggesting that imine formation is extremely rapid. ${ }^{[14]}$ 


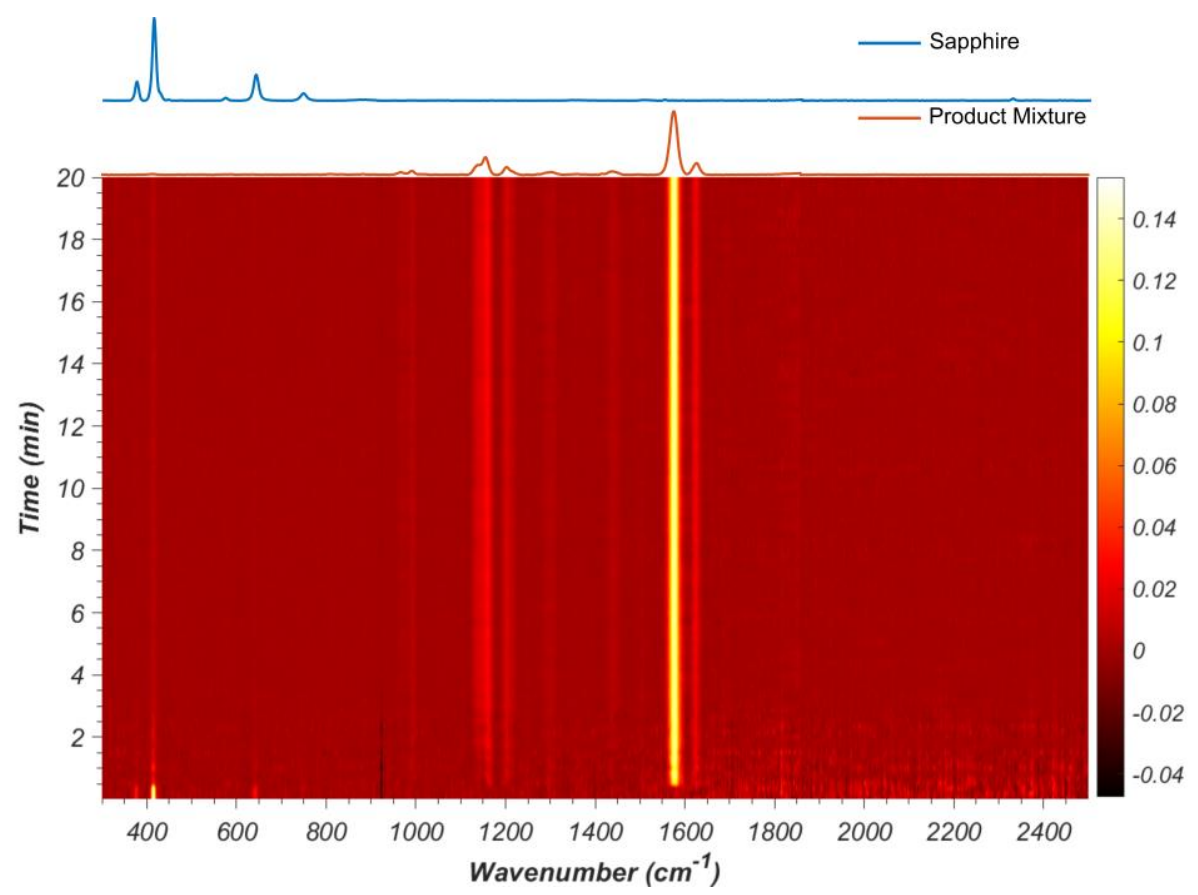

ָֻ

Figure S19: Real time Raman monitoring of the COF-LZU1 formation with the vector normalized, background subtracted Raman signal over time with the signal of the product mixture shown above the $2 \mathrm{D}$ plot.

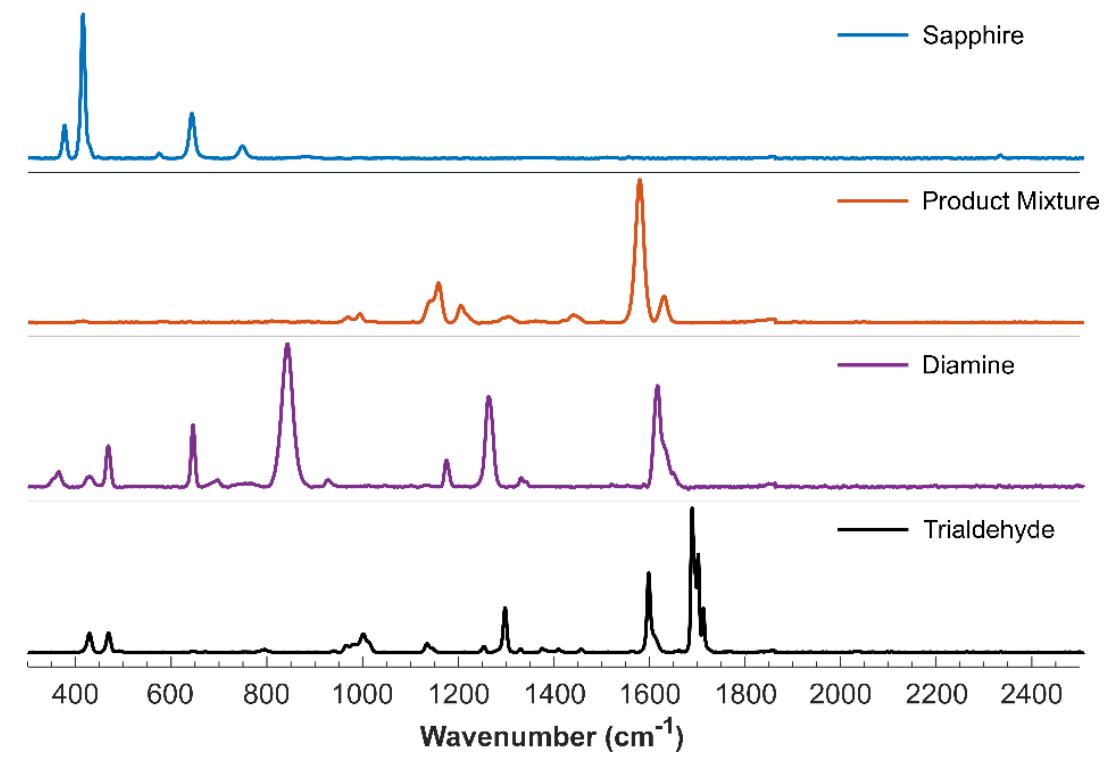

Figure S20: Baseline subtracted Raman spectra of the sapphire jar (blue), the reaction product mixture (red), pure $p$ phenylenediamine (purple), and 1,3,5-triformylbenzene (black).

The product of the reaction after in situ Raman monitoring was characterized using XRPD revealing a mixture of intermediate 1 and COF-LZU1 (Figure S21). This is most likely due to the lower catalyst loading ( $25 \mu \mathrm{L}$ vs. $40 \mu \mathrm{L} \mathrm{AcOH})$, and increased $\eta$ value, which were selected trying to slow the reaction in order to better observe the fast imine formation, although differences in jar geometry (i. e. PMMA vs sapphire jars) affecting both, mixing and impact may also play a role. 


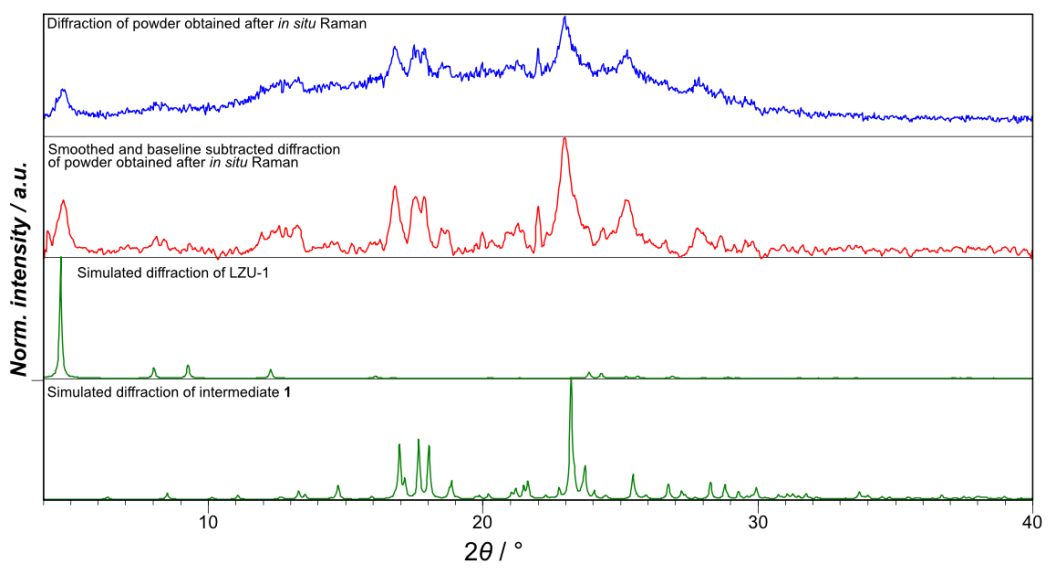

Figure S21: XRPD patterns $(\lambda=1.54 \AA$ ) of product after real time Raman monitoring (blue) was processed for visual clarity using baseline subtraction and cubic polynomial smoothing with a convolution range of 9 data points (red). The diffraction of the product is consistent with a mixture of intermediate $\mathbf{1}$ and COF-LZU1 as evidenced by the powder diffraction patterns of these phases as simulated from their respective crystal structures.

Neither starting materials were observed in Raman monitoring, and no distinct Raman peaks differentiate intermediate 1 from COF-LZU1, however a notable increase in baseline was observed between samples containing only COF-LZU1 and a mixture of COF-LZU1 and intermediate 1 as determined by XRPD (Figure 22).

(a) Raman Spectra

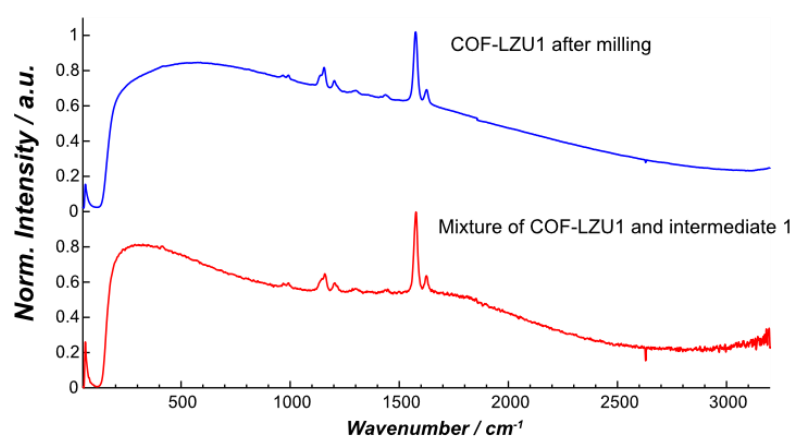

(b) X-ray Powder Diffraction

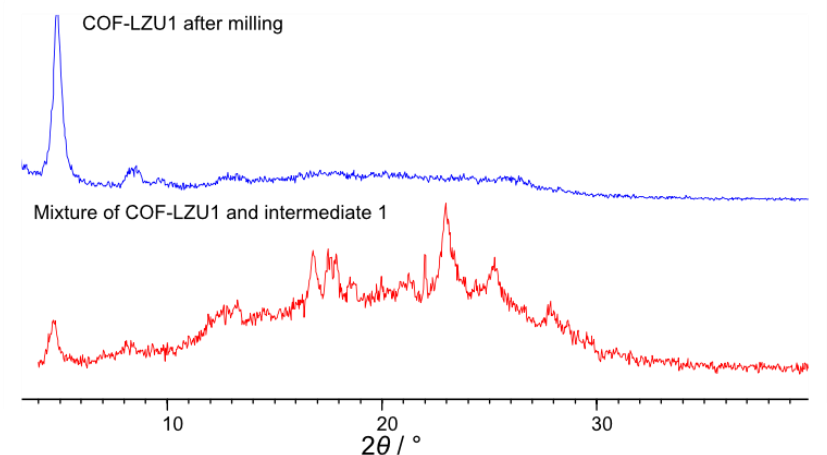

Figure S22: Comparisons of (a) Raman spectra and (b) X-ray powder diffraction patterns $(\lambda=1.54 \AA$ ) of reaction product mixtures containing either only COF-LZU1 after milling or a mixture of COF-LZU1 and intermediate $\mathbf{1}$ as identified by XRPD. The Raman spectra of both samples contain the same Raman peaks, however the presence of COF-LZU1 appears to increase the fluorescence baseline. 


\section{S5 FT-IR Spectroscopy}

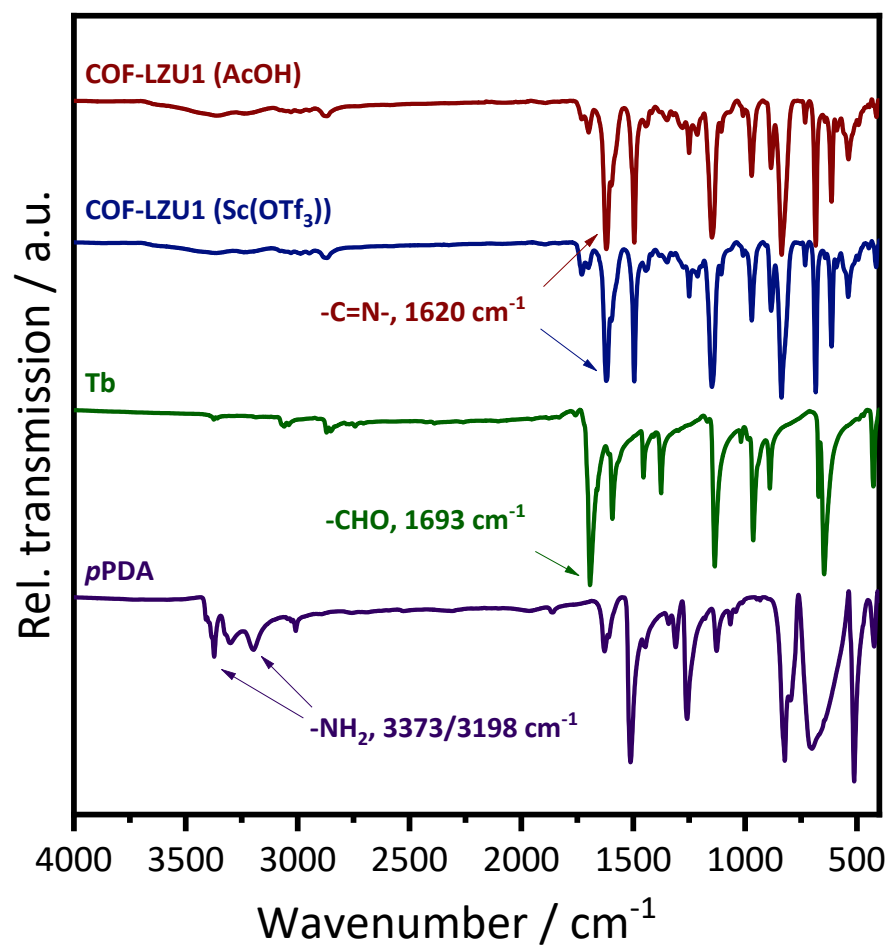

Figure S23. FT-IR comparison of COF-LZU1 ( $\mathrm{AcOH})$, COF-LZU1 $\left(\mathrm{Sc}(\mathrm{OTf})_{3}\right)$ and the starting materials Tb and $p$ PDA.

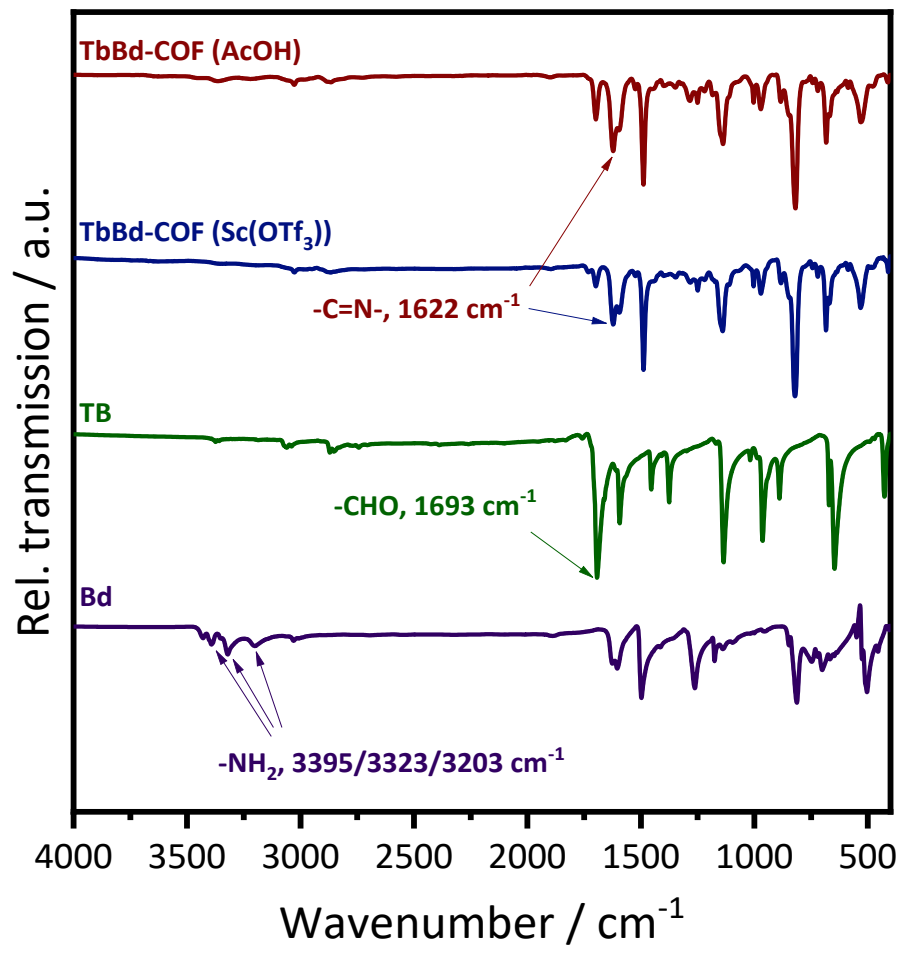

Figure S24. FT-IR comparison of TbBd-COF $(\mathrm{AcOH})$, TbBd-COF $\left(\mathrm{Sc}(\mathrm{OTf})_{3}\right)$ and the starting materials TB and Bd. 


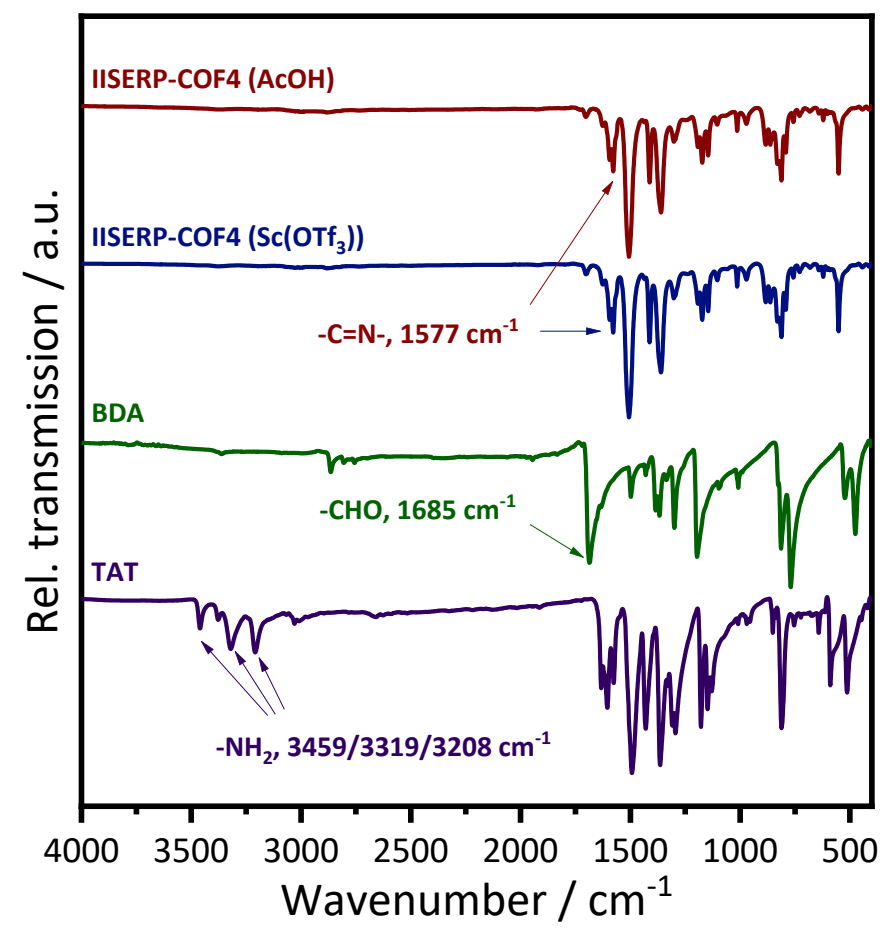

Figure S25. FT-IR comparison of ISERP-COF4 ( $\mathrm{AcOH})$, IISERP-COF4 (Sc(OTf) $\left.)_{3}\right)$ and the starting materials BDA and TAT.

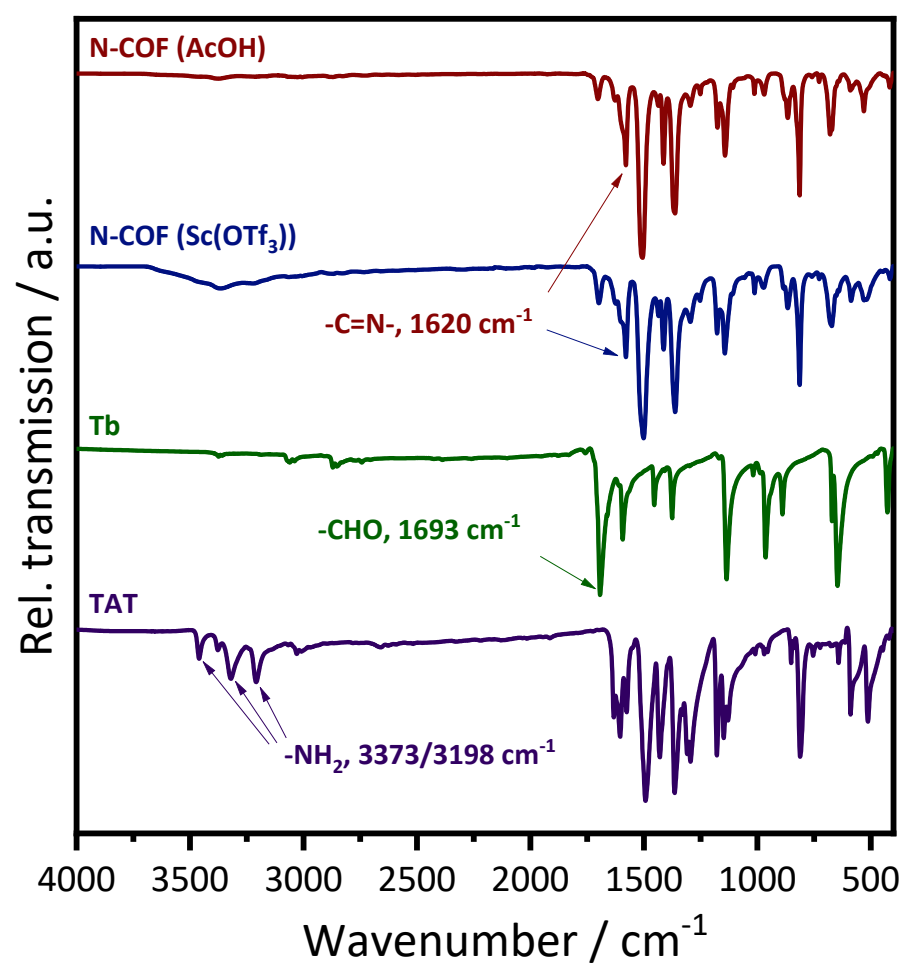

Figure S26. FT-IR comparison of N-COF $(\mathrm{AcOH}), \mathbf{N}-\mathrm{COF}\left(\mathrm{Sc}(\mathrm{OTf})_{3}\right)$ and the starting materials Tb and TAT. 


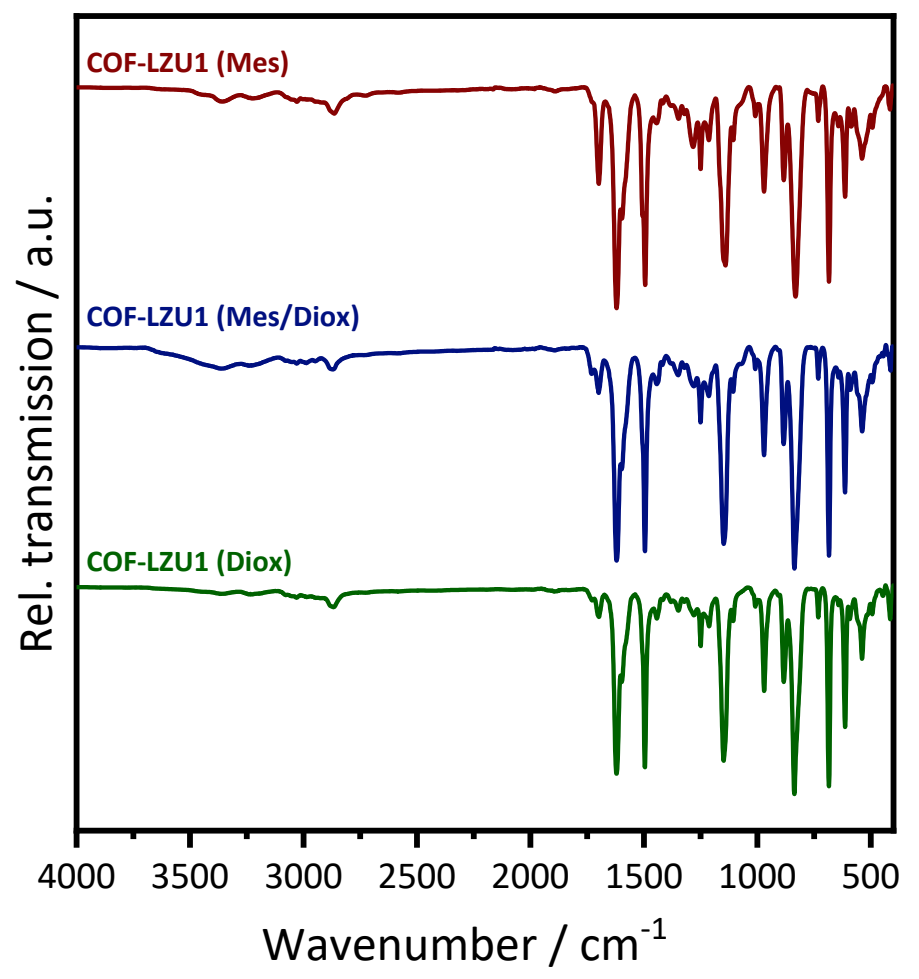

Figure S27. FT-IR comparison of COF-LZU1 (mesitylene), COF-LZU1 (mesitylene/1,4-dioxane) and COF-LZU1 (1,4-dioxane). 


\section{S5 Liquid State Nuclear Magnetic Resonance}

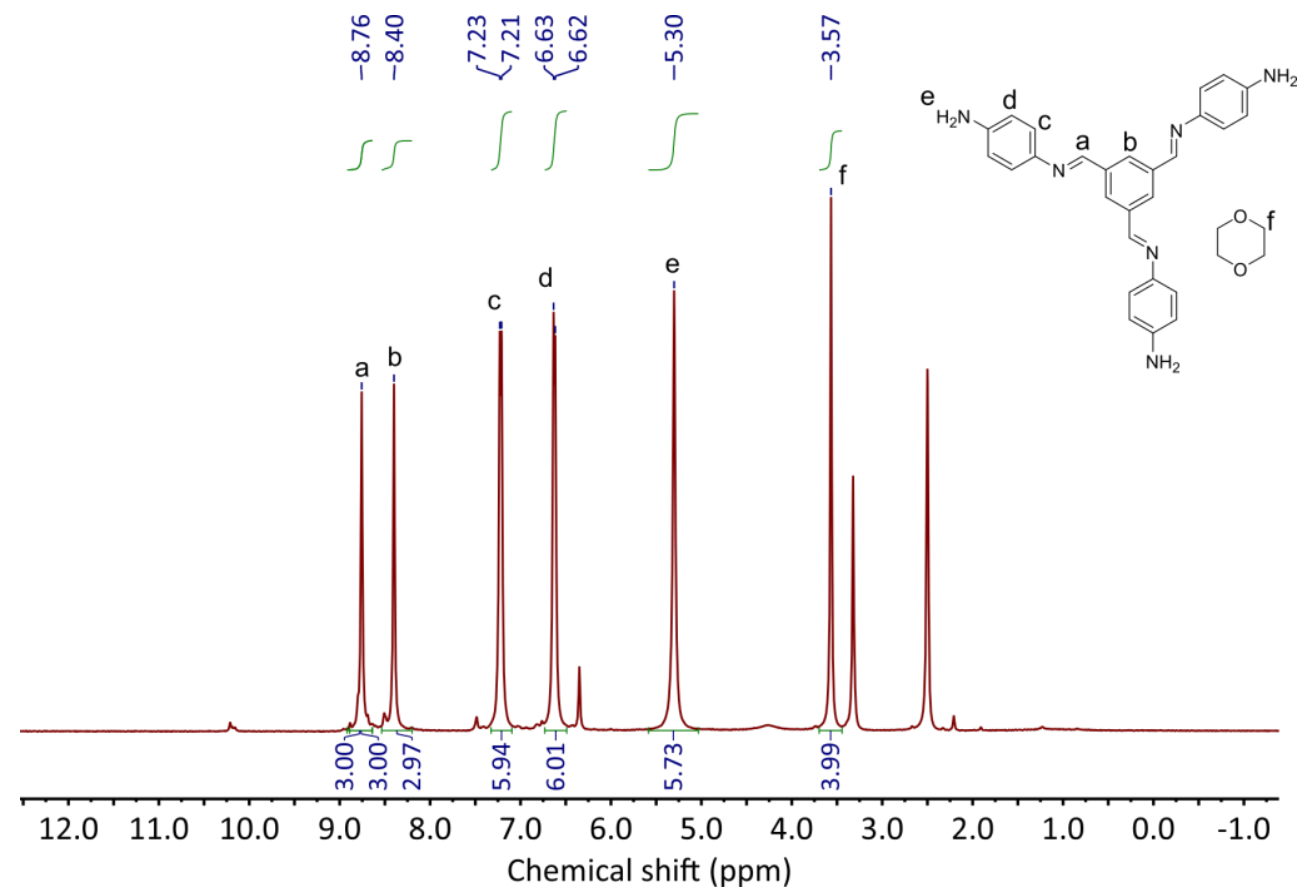

Figure S28. Measured liquid ${ }^{1} \mathrm{H}$ NMR spectrum of 1.

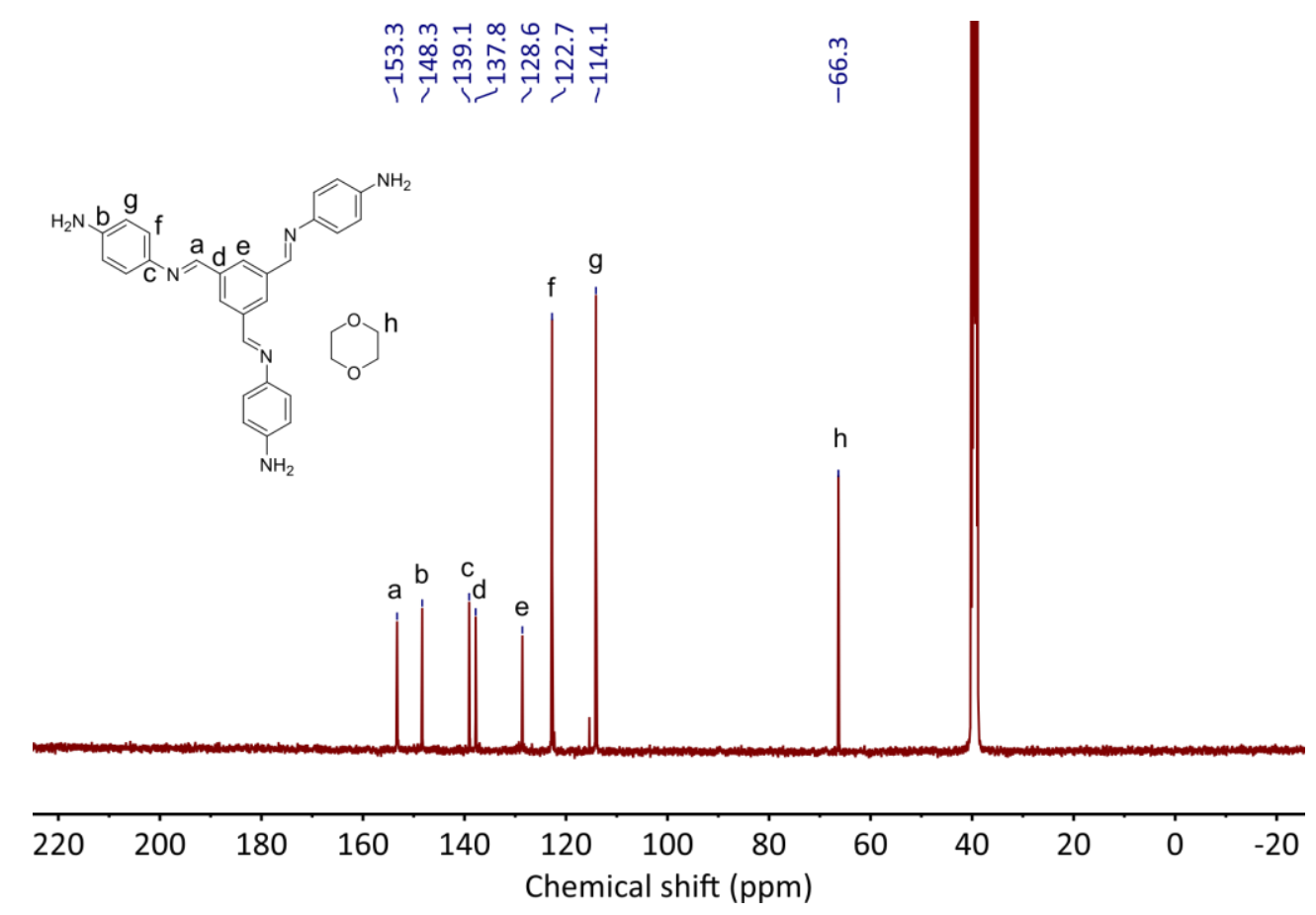

Figure S29. Measured liquid ${ }^{13} \mathrm{C}$ NMR spectrum of 1. 


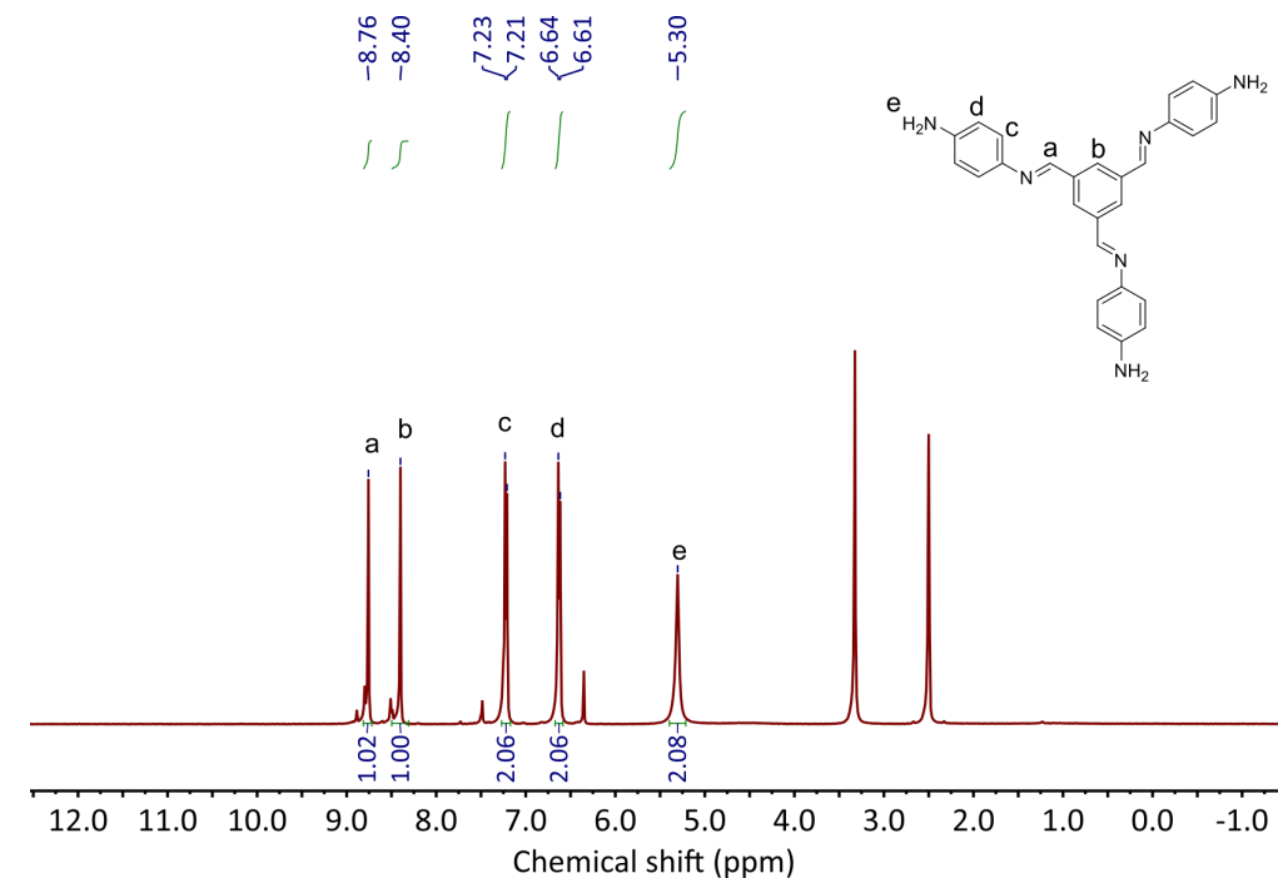

Figure S30. Measured liquid ${ }^{1} \mathrm{H}$ NMR spectrum of $\mathbf{1}^{\prime}$.

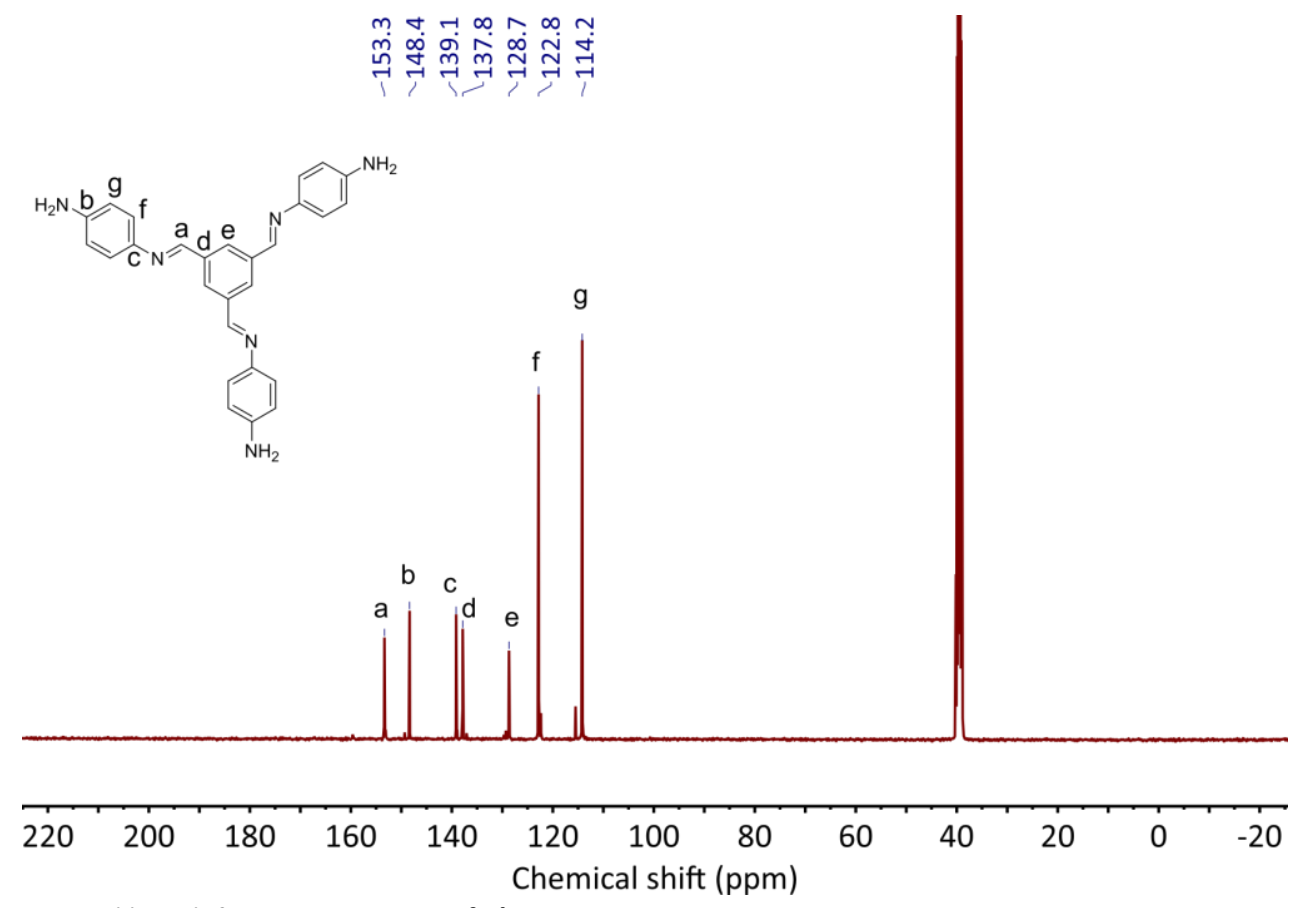

Figure S31. Measured liquid ${ }^{13} \mathrm{C}$ NMR spectrum of $\mathbf{1}^{\prime}$. 


\section{S6 Solid-state Nuclear Magnetic Resonance}

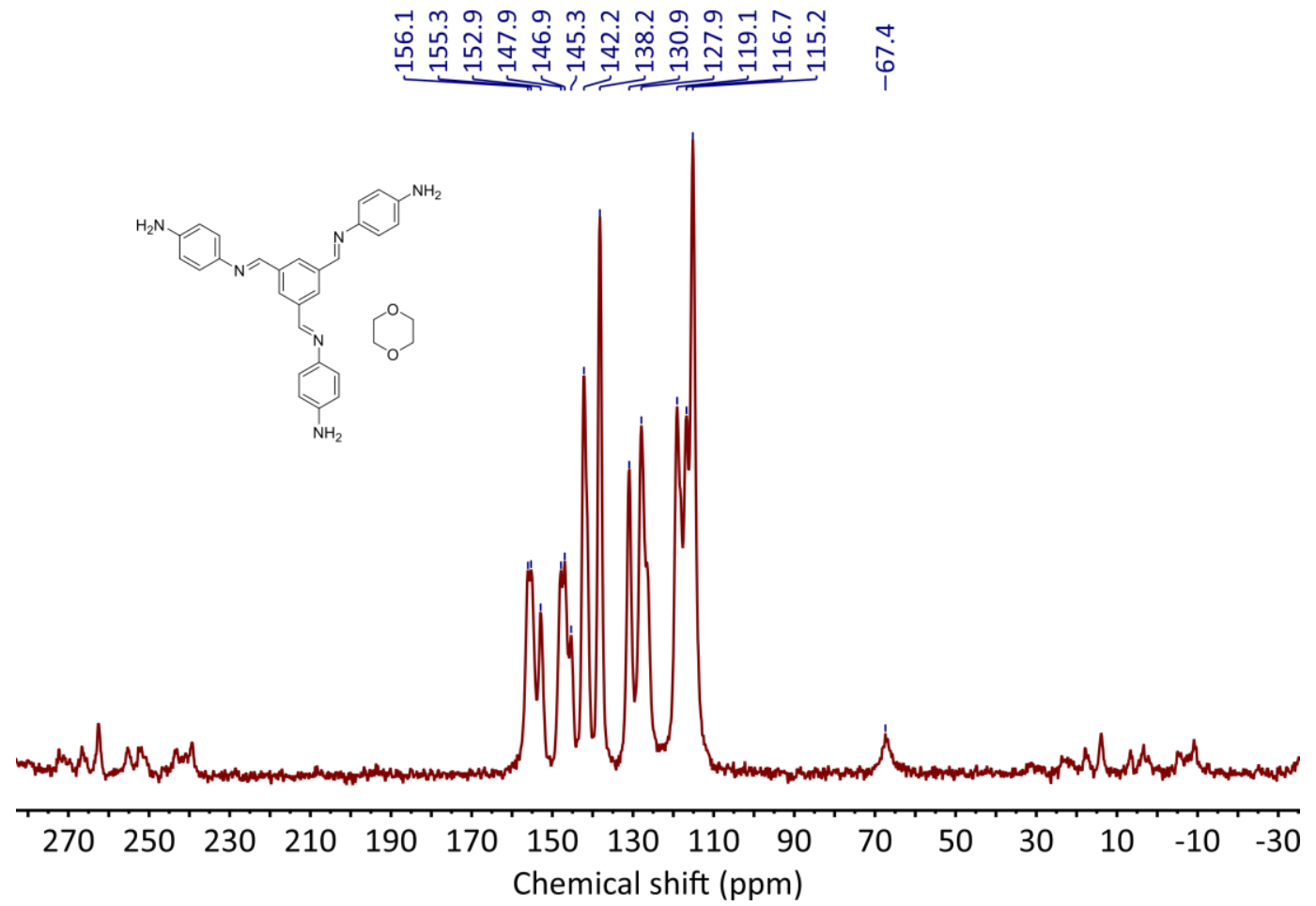

Figure S32. Measured ${ }^{13} \mathrm{C}$ ssNMR spectrum of 1.

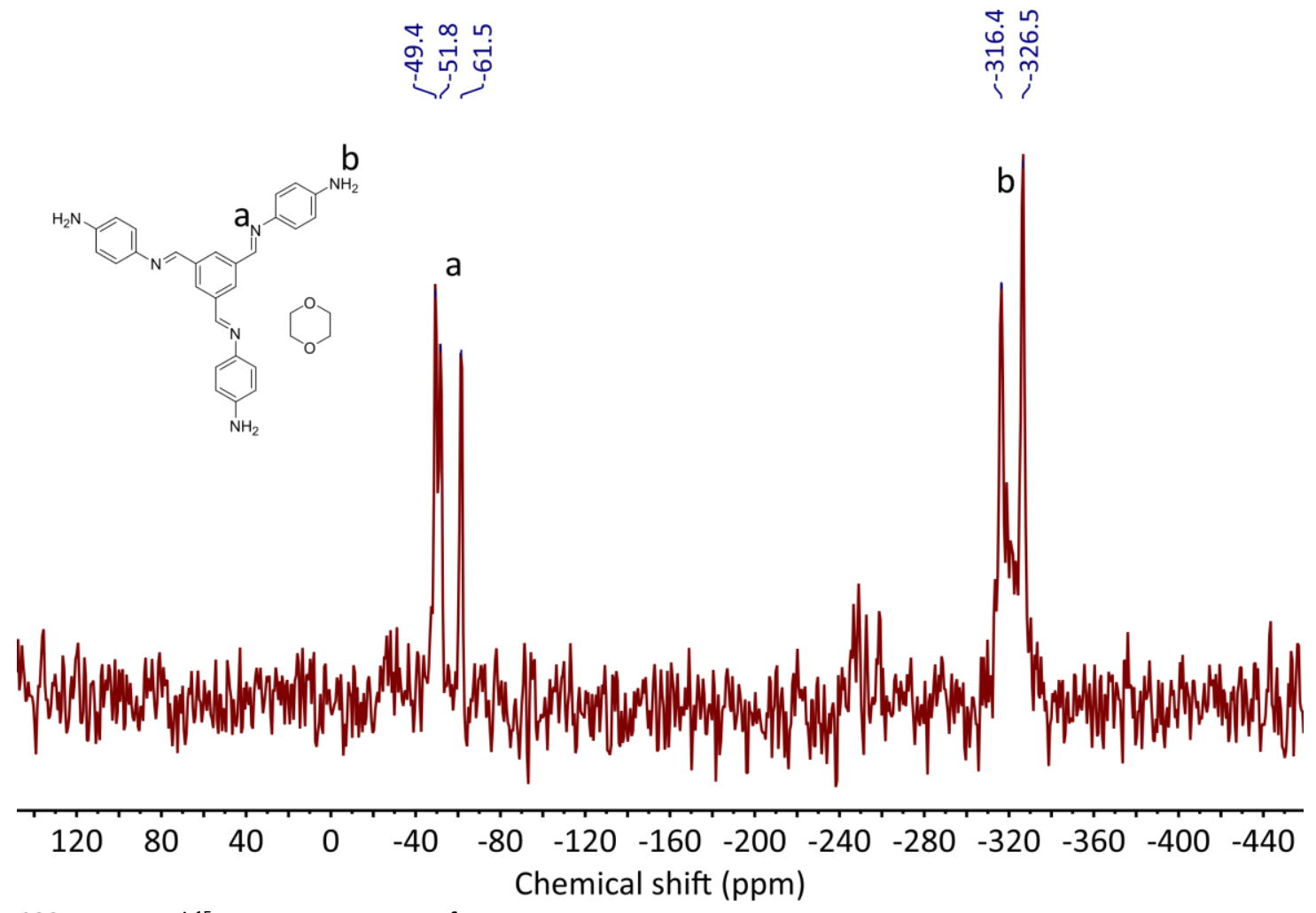

Figure S33. Measured ${ }^{15} \mathrm{~N}$ ssNMR spectrum of $\mathbf{1}$. 


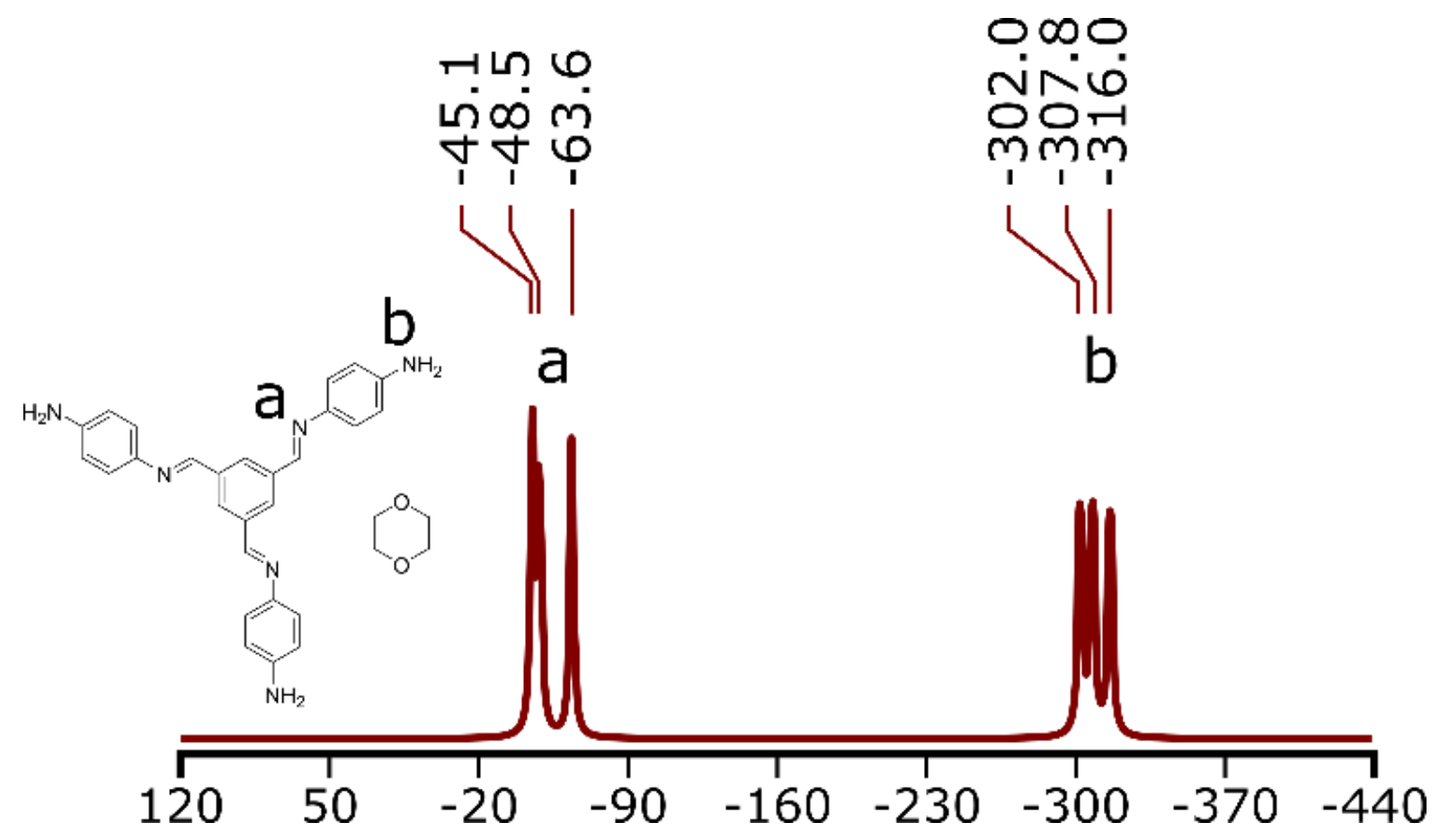

Figure S34. Calculated ${ }^{15} \mathrm{~N}$ ssNMR spectrum of 1.

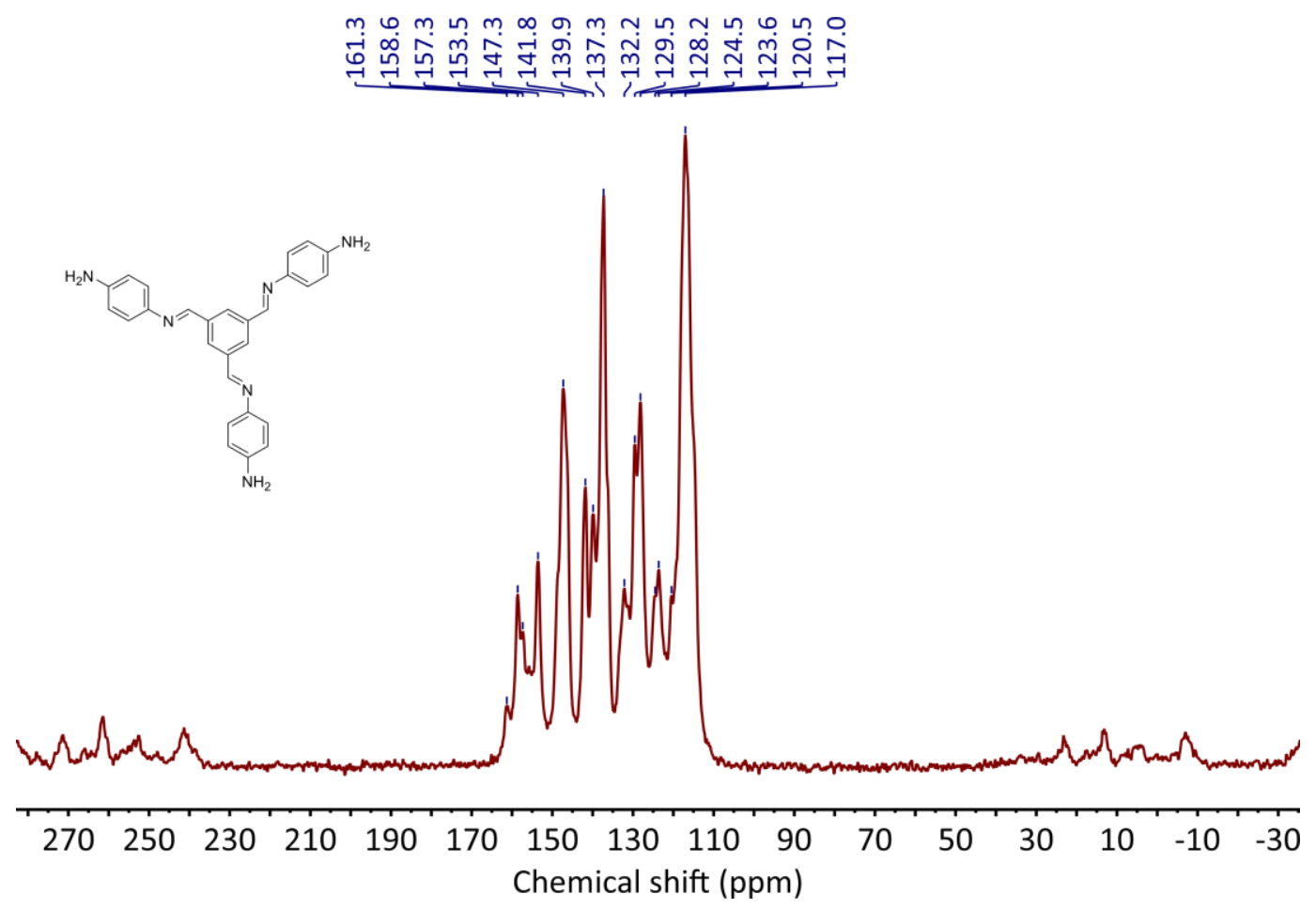

Figure S35. Measured ${ }^{13} \mathrm{C}$ ssNMR of the non-solvated 1'. 


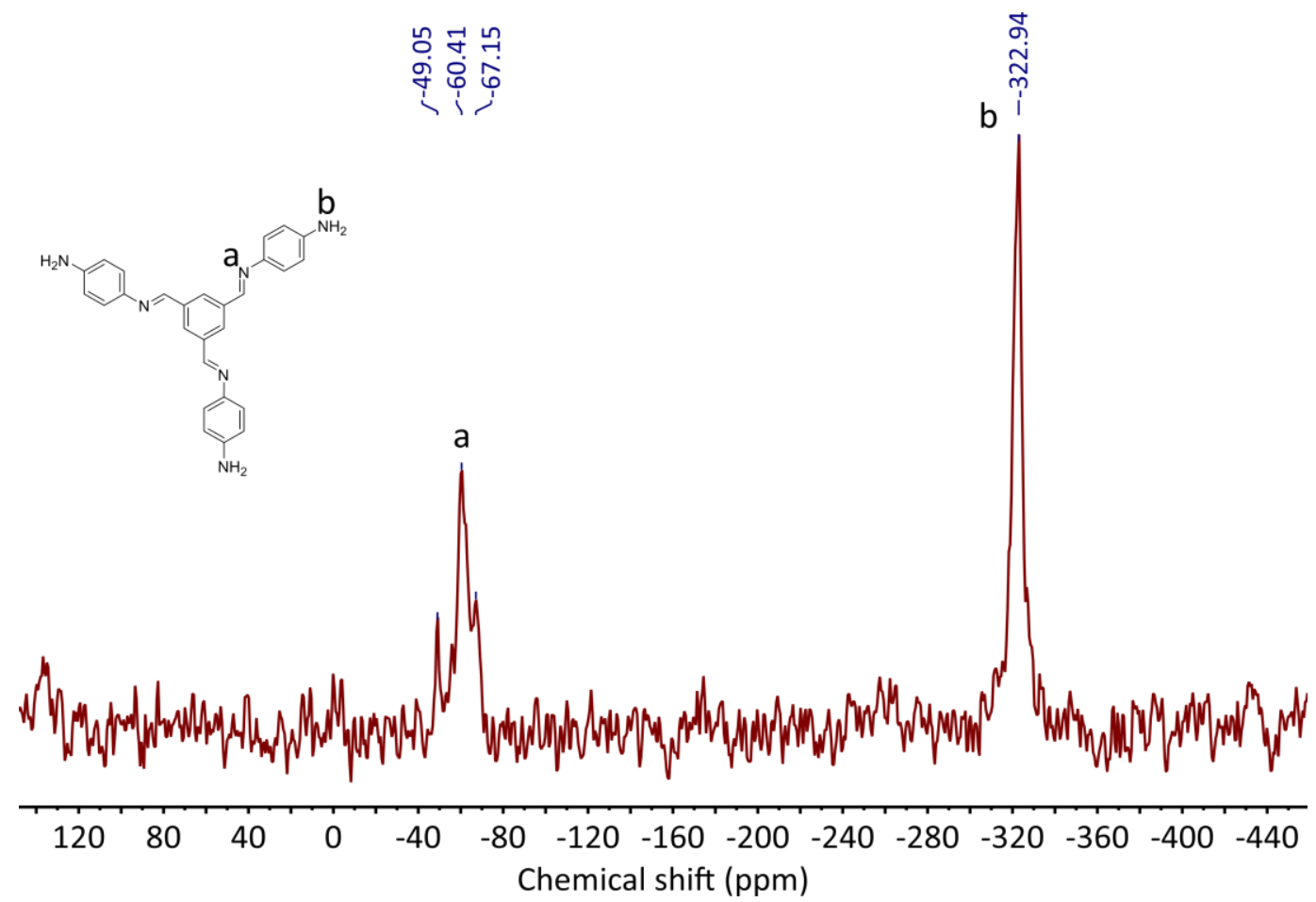

Figure S36. Measured ${ }^{15} \mathrm{~N}$ ssNMR spectrum of the non-solvated $\mathbf{1}^{\prime}$.

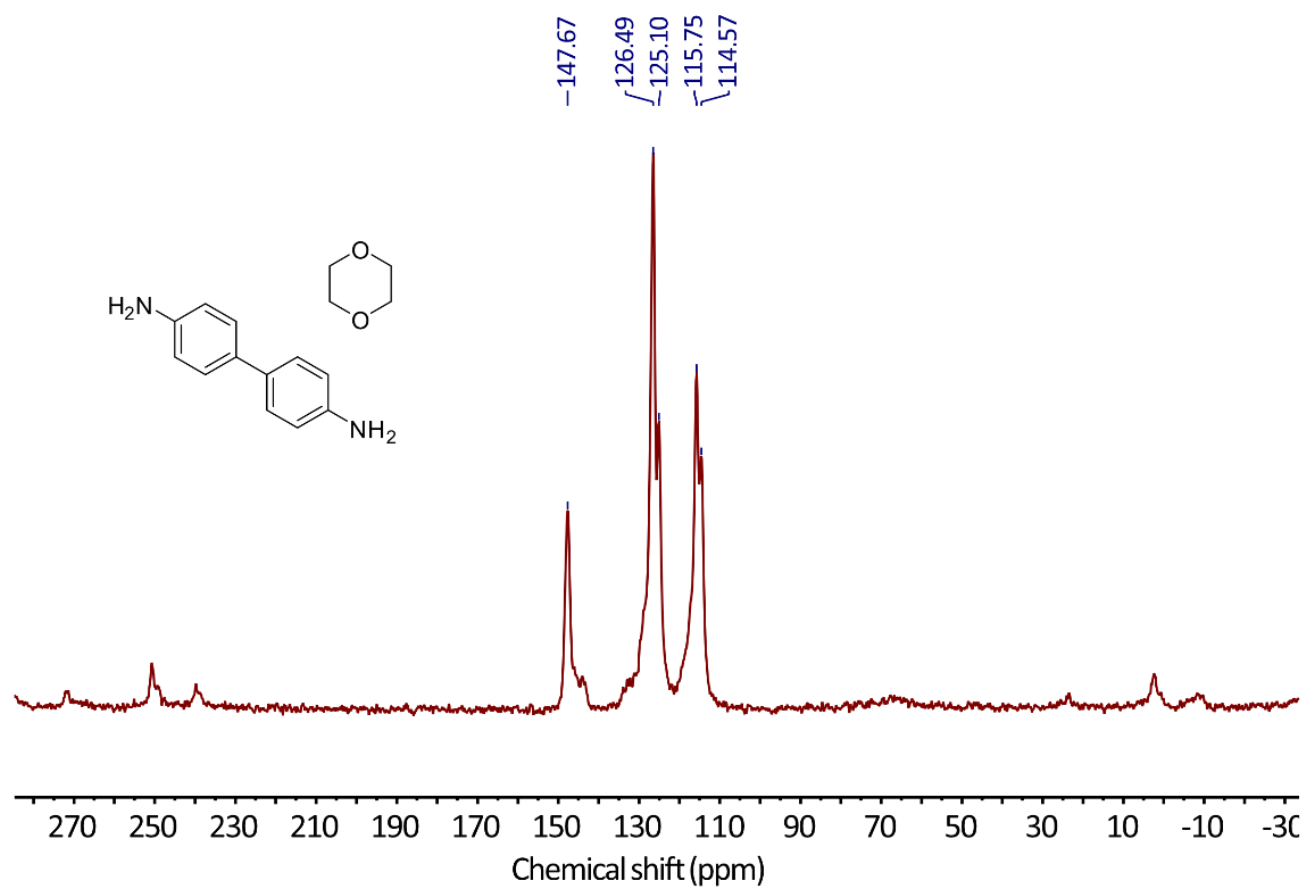

Figure S37. Measured ${ }^{13} \mathrm{C}$ ssNMR of intermediate 2. 


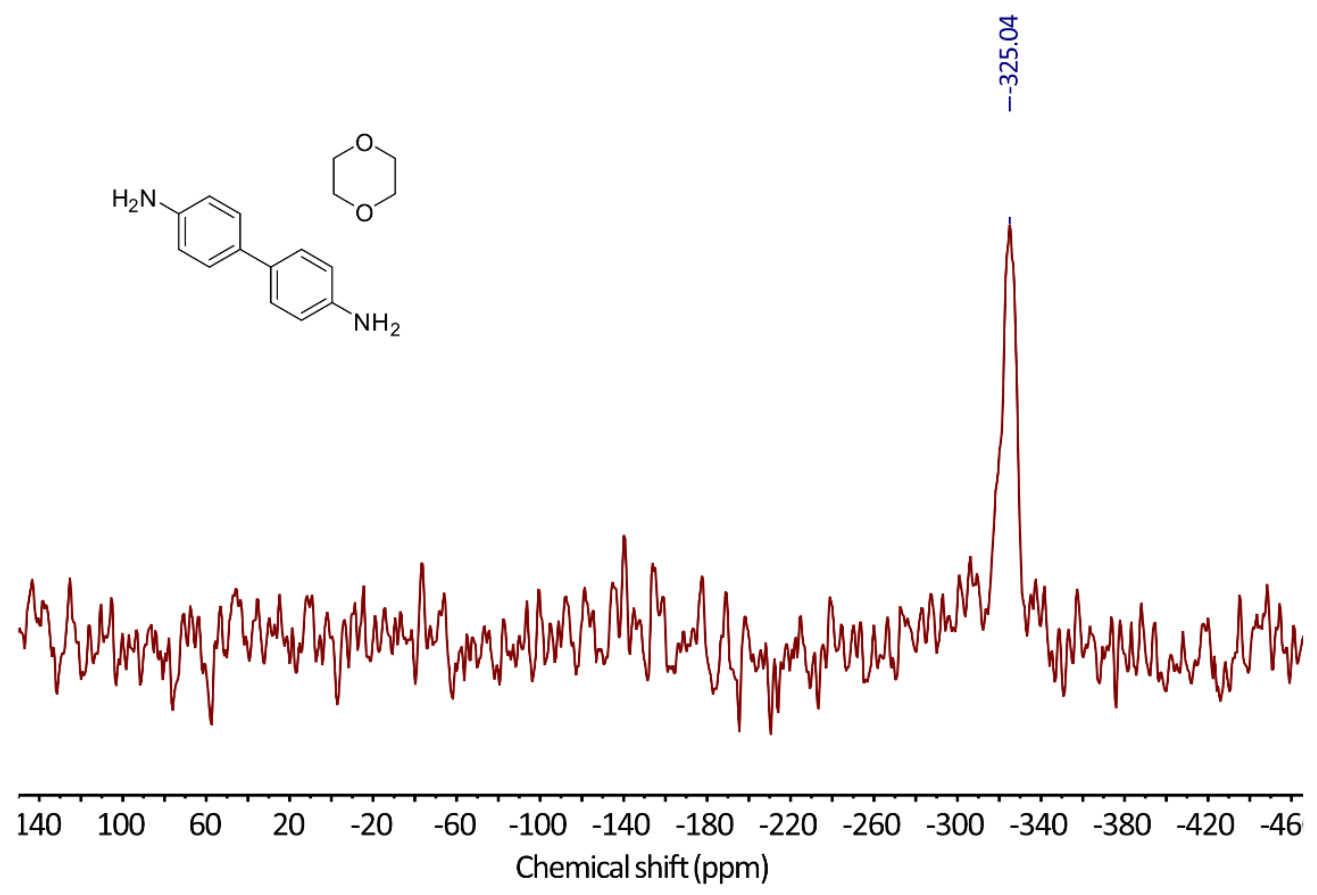

Figure S38. Measured ${ }^{15} \mathrm{~N}$ ssNMR of intermediate 2. 


\section{S7 Gas Sorption Experiments}

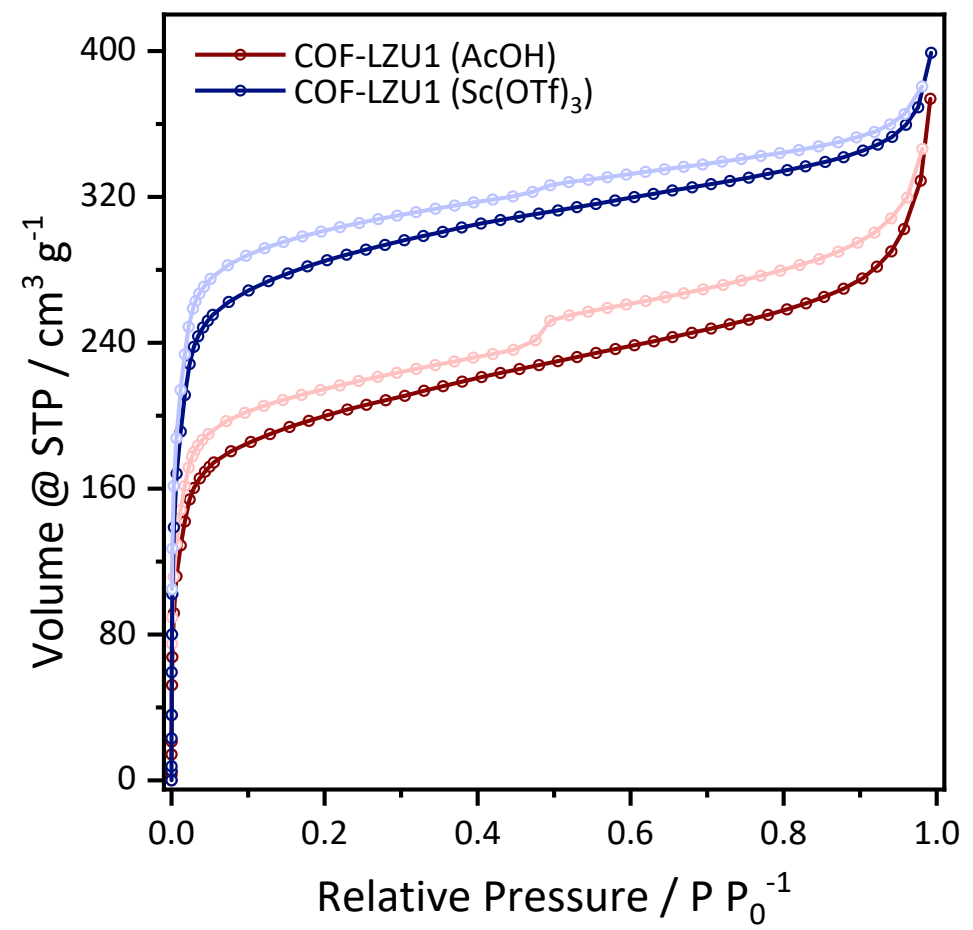

Figure S39. N2-isotherms of COF-LZU1 (AcOH, red curve), COF-LZU1 ( $\mathrm{Sc}(\mathrm{OTf})_{3}$, blue curve), measured at $77 \mathrm{~K}$. Darker colors represent adsorption, while lighter colors represent desorption.

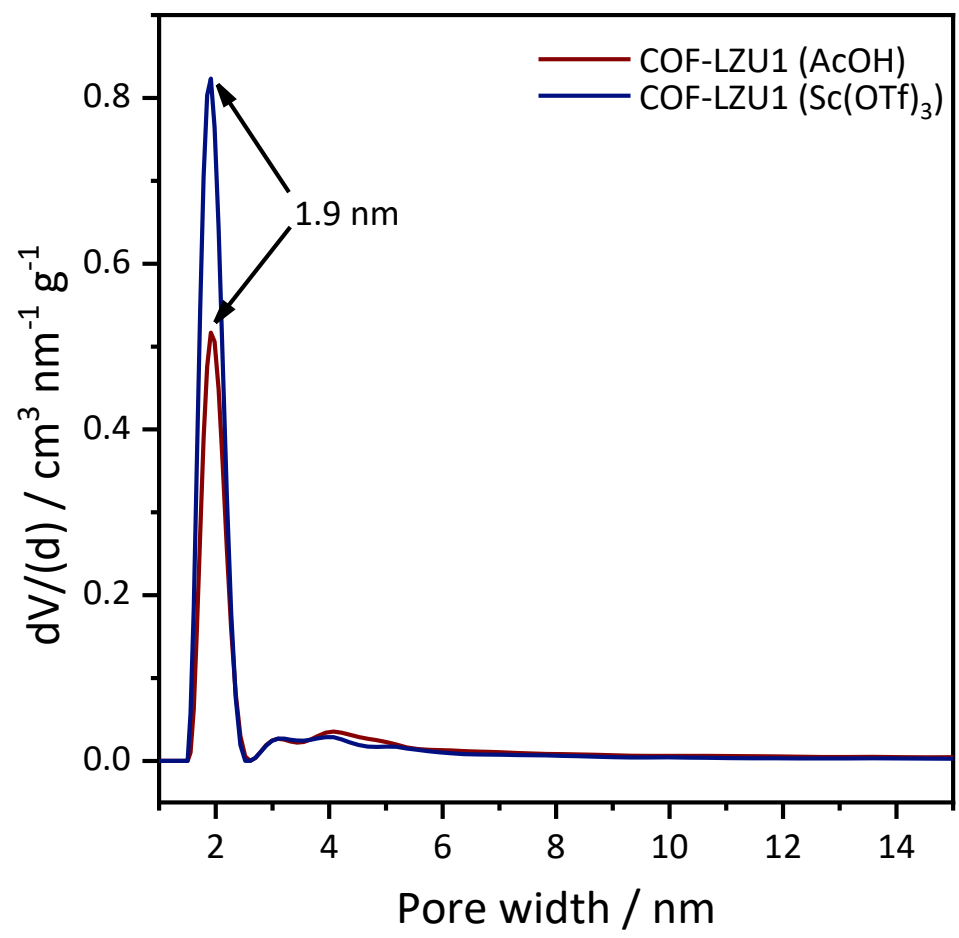

Figure S40. Pore size distributions of COF-LZU1 (AcOH), COF-LZU1 (Sc(OTf) $)_{3}$ ) derived from $\mathrm{N}_{2}$ sorption isotherms. 


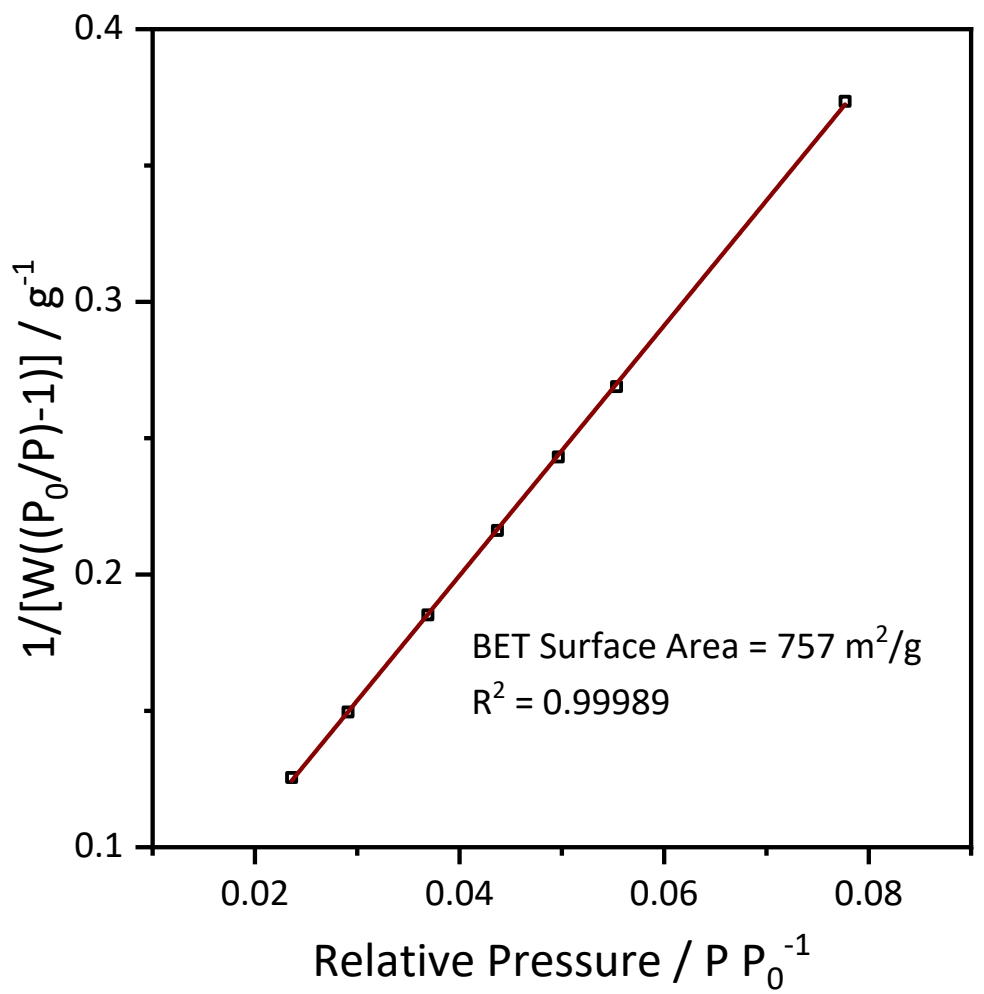

Figure S41. Multi-point BET surface area fit of COF-LZU1 (ACOH) derived from $\mathrm{N}_{2}$ sorption isotherm.

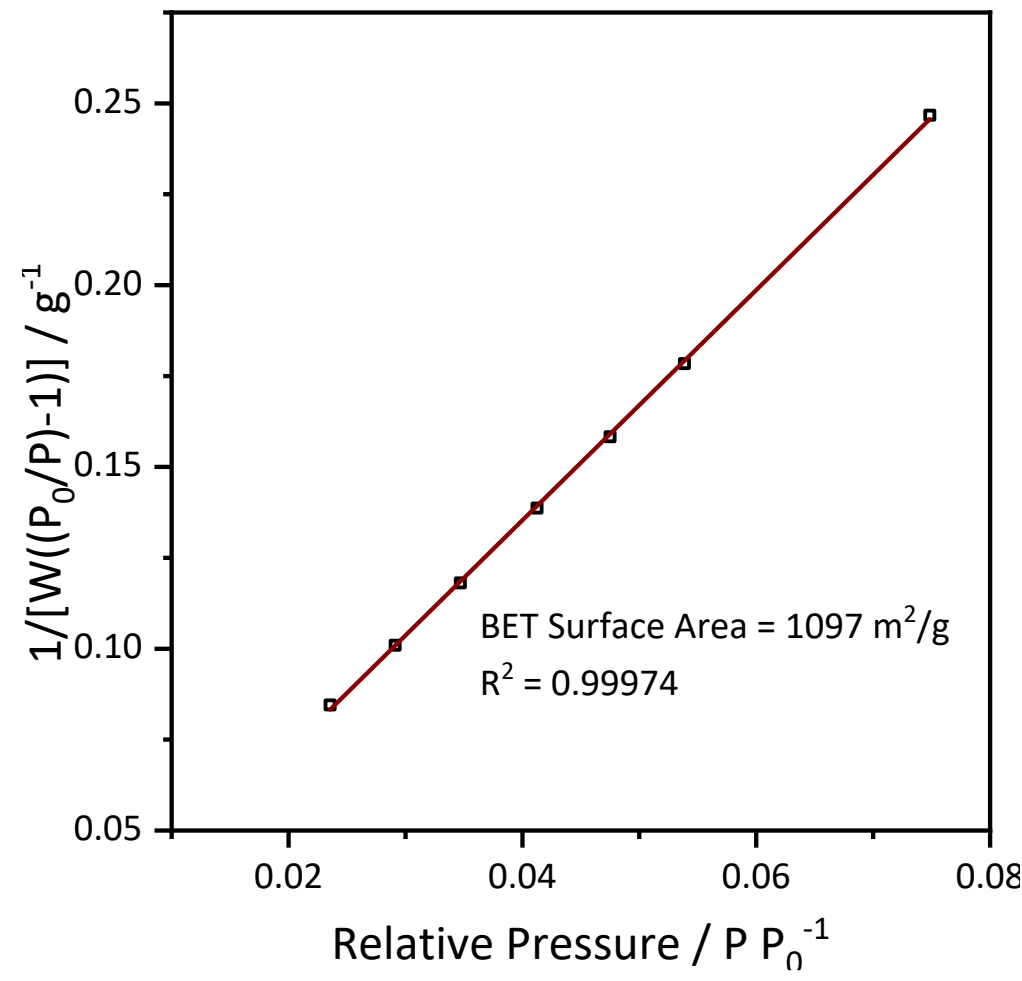

Figure S42. Multi-point BET surface area fit of COF-LZU1 ( $\left.\mathrm{Sc}(\mathrm{OTf})_{3}\right)$ derived from $\mathrm{N}_{2}$ sorption isotherm. 


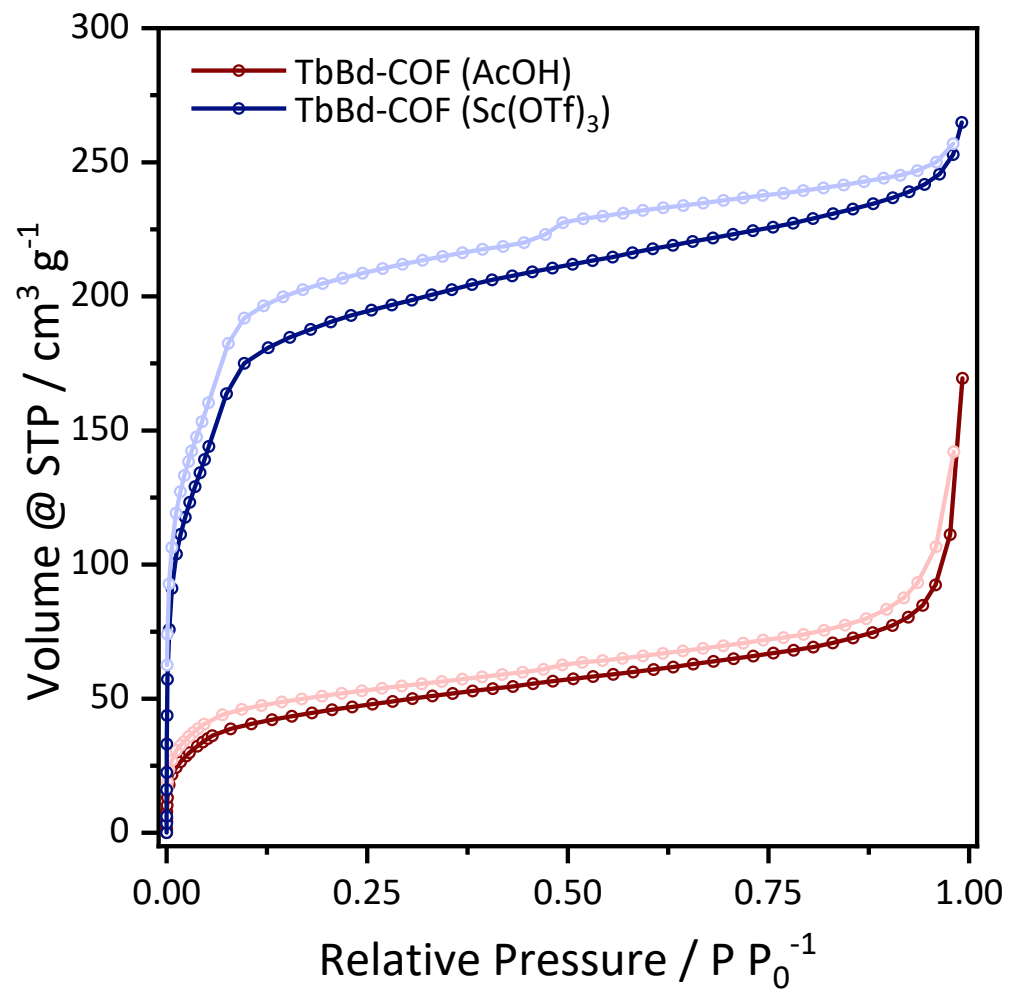

Figure S43. $\mathrm{N}_{2}$-Isotherms of TbBd-COF $(\mathrm{AcOH})$, TbBd-COF $\left(\mathrm{Sc}(\mathrm{OTf})_{3}\right)$, measured at $77 \mathrm{~K}$. Darker colors represent adsorption, while lighter colors represent desorption.

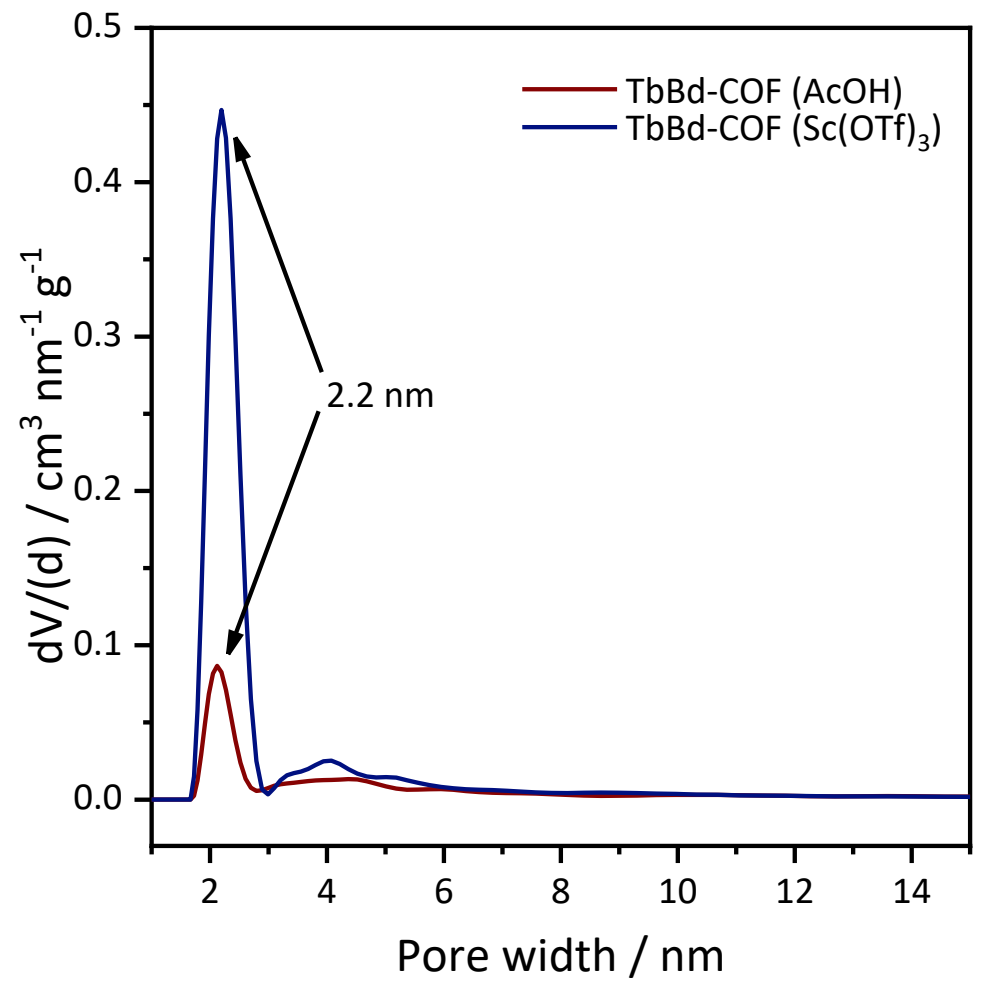

Figure S44. Pore size distributions of TbBd-COF $(\mathrm{AcOH})$, TbBd-COF $\left(\mathrm{Sc}(\mathrm{OTf})_{3}\right)$ derived from $\mathrm{N}_{2}$ sorption isotherms. 


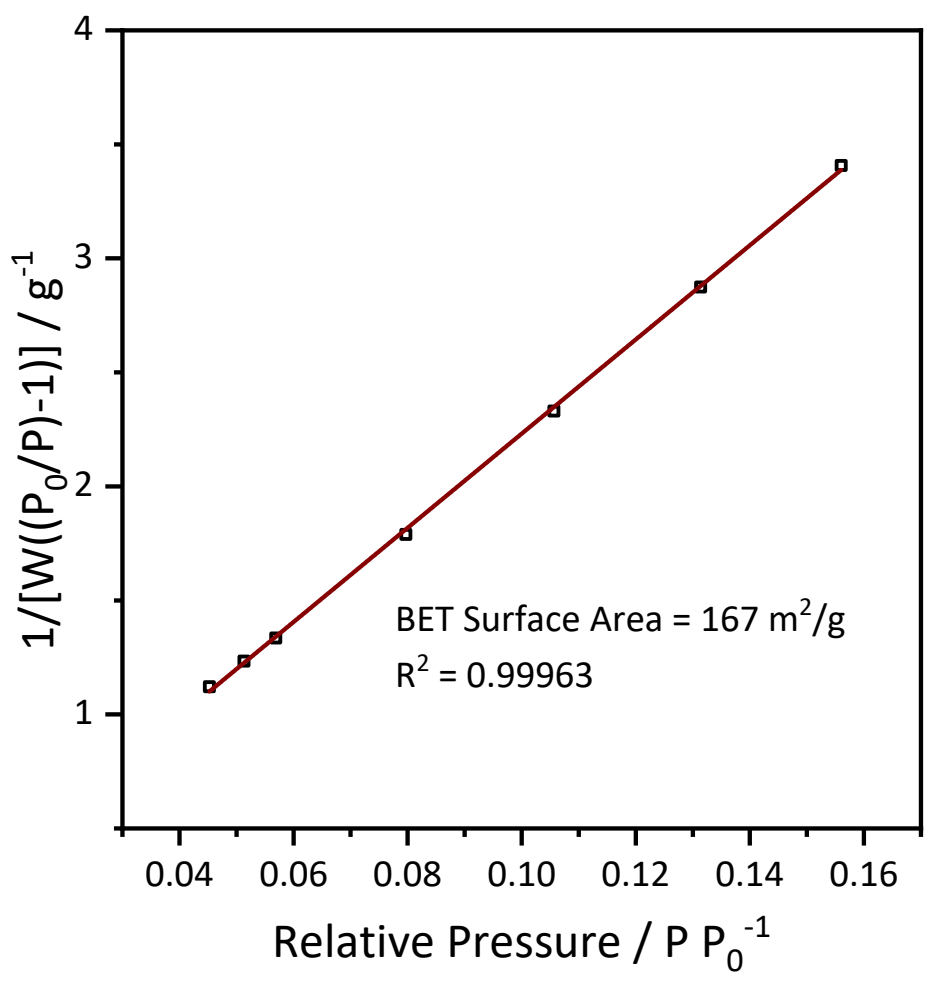

Figure S45. Multi-point BET surface area fit of TbBd-COF (AcOH) derived from $\mathrm{N}_{2}$ sorption isotherm.

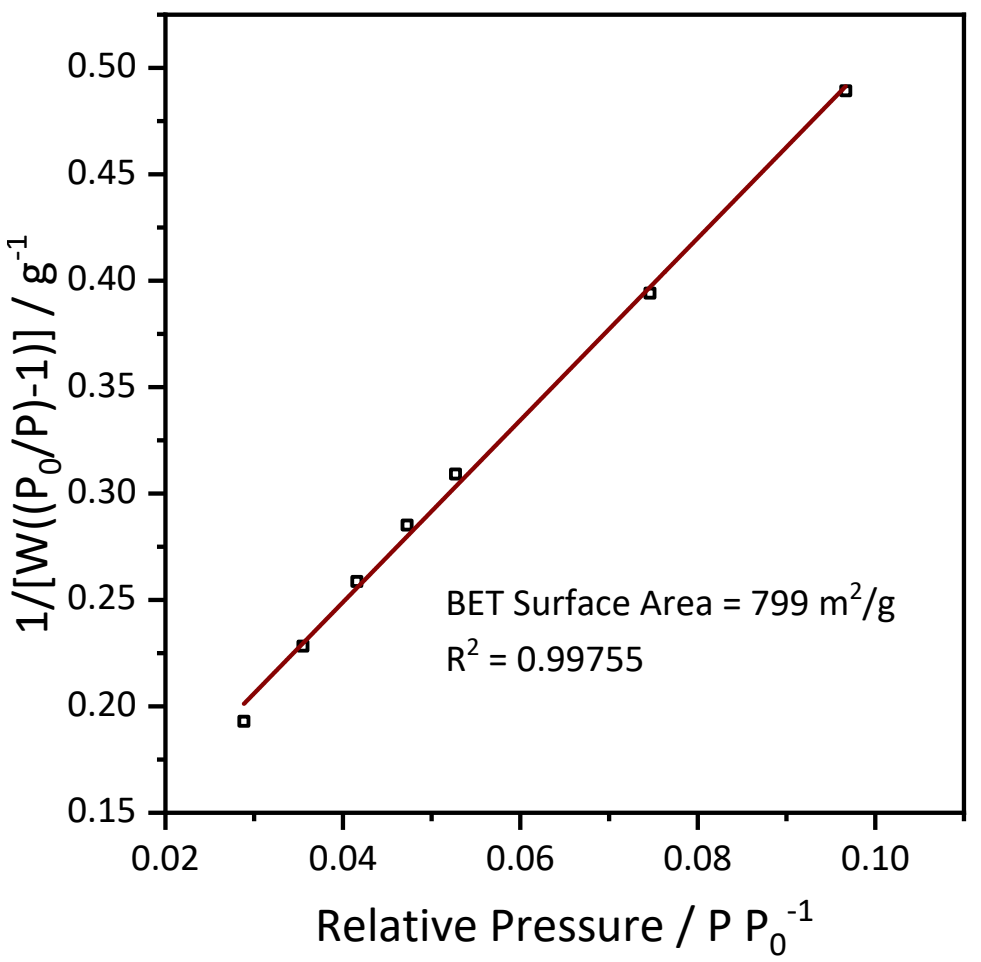

Figure S46. Multi-point BET surface area fit of TbBd-COF $\left(\mathrm{Sc}(\mathrm{OTf})_{3}\right)$ derived from $\mathrm{N}_{2}$ sorption isotherm. 


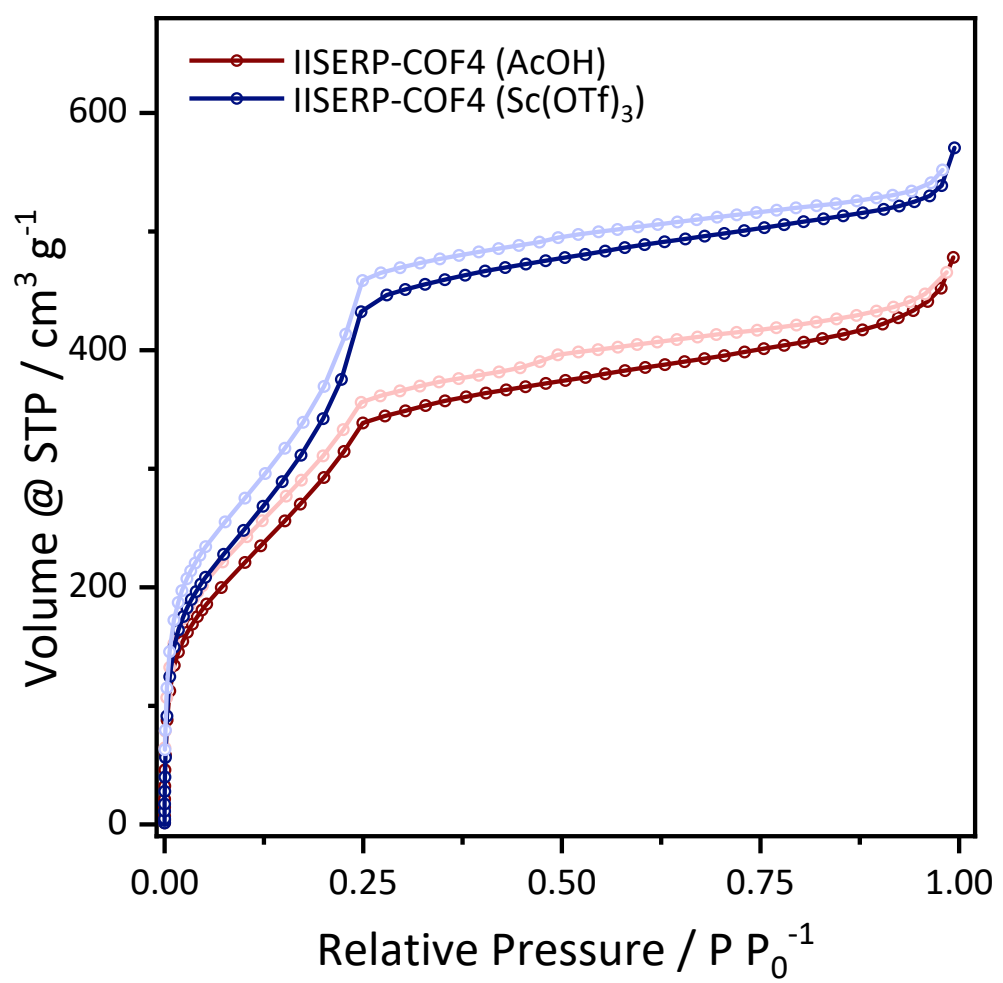

Figure S47. $\mathrm{N}_{2}$-Isotherms of IISERP-COF4 (red: AcOH), IISERP-COF4 (blue: Sc(OTf) $)_{3}$, measured at $77 \mathrm{~K}$. Darker colors represent adsorption, while lighter colors represent desorption.

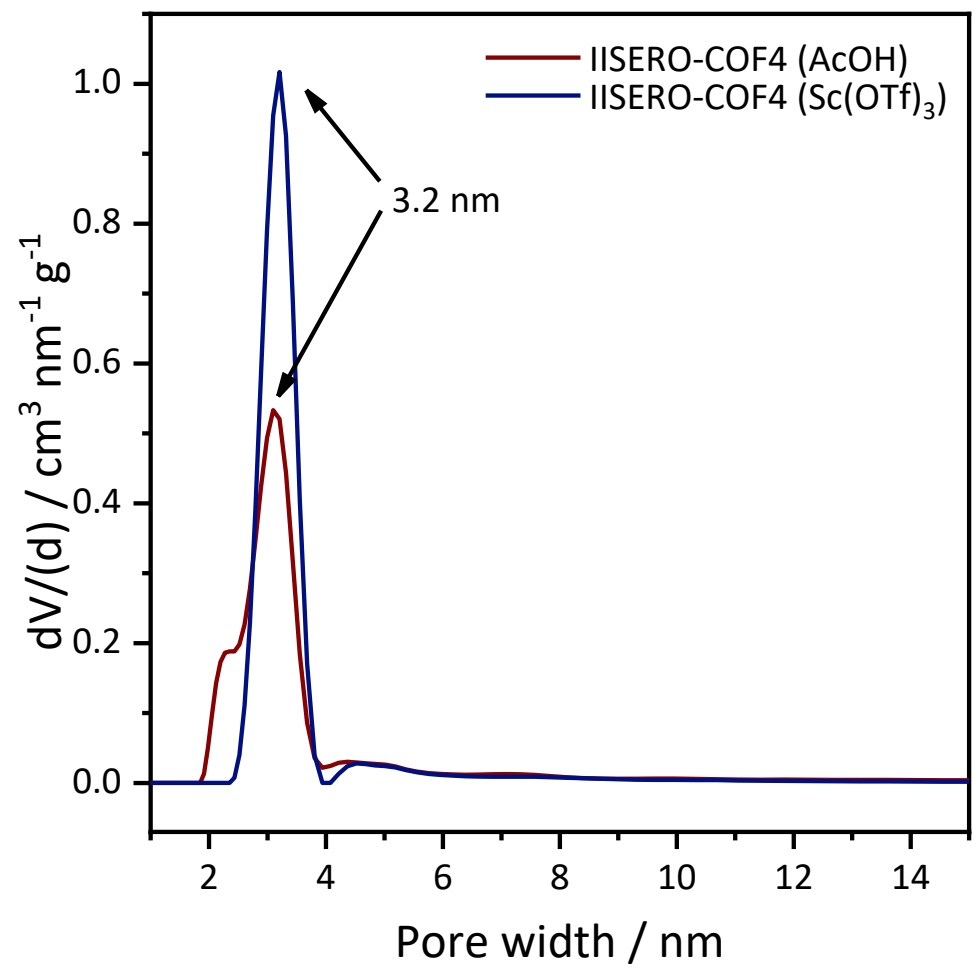

Figure S48. Pore size distributions of IISERP-COF4 (AcOH), IISERP-COF4 (Sc(OTf) $)_{3}$ ) derived from $\mathrm{N}_{2}$ sorption isotherms. 


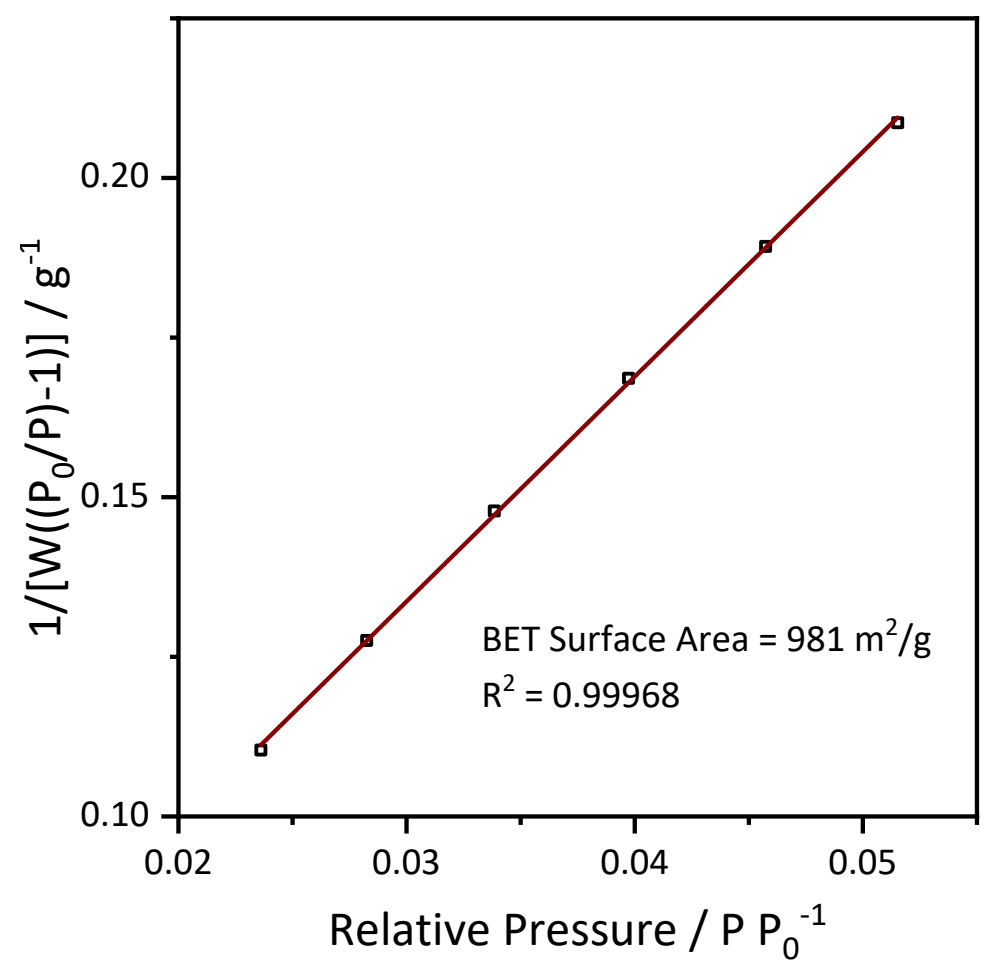

Figure S49. Multi-point BET surface area fit of IISERP-COF4 (AcOH) derived from $\mathrm{N}_{2}$ sorption isotherm.

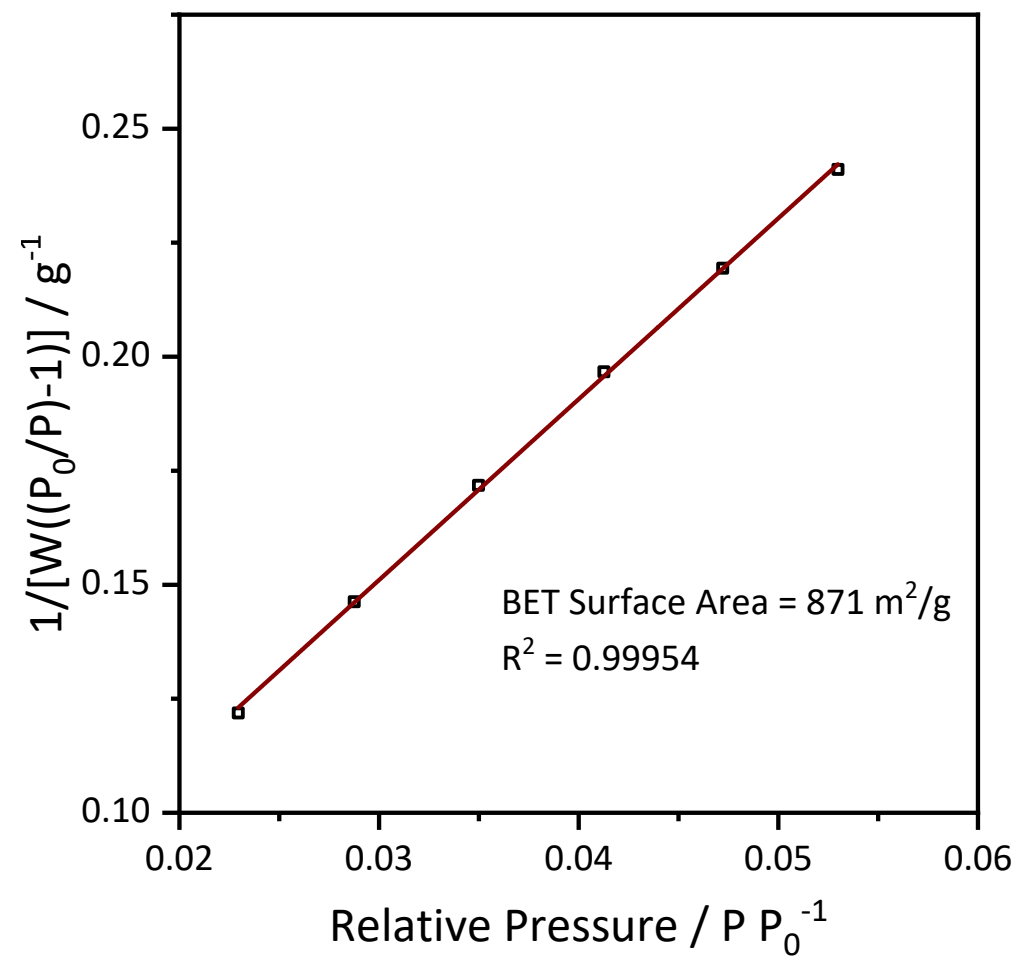

Figure S50. Multi-point BET surface area fit of IISERP-COF4 (Sc(OTf) $)_{3}$ ) derived from $\mathrm{N}_{2}$ sorption isotherm. 


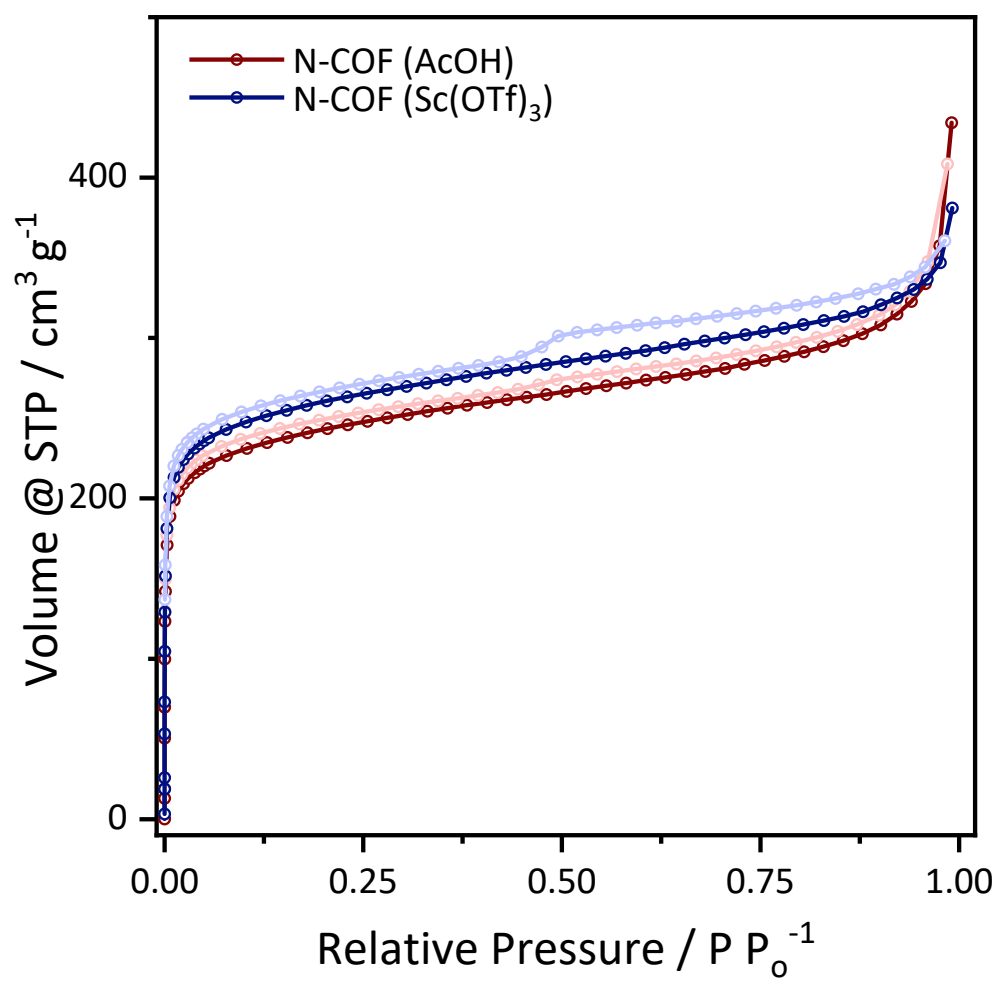

Figure S51. $\mathrm{N}_{2}$-Isotherms of N-COF $(\mathrm{AcOH}), \mathbf{N}-\mathrm{COF}\left(\mathrm{Sc}(\mathrm{OTf})_{3}\right)$, measured at $77 \mathrm{~K}$. Darker colors represent adsorption, while lighter colors represent desorption.

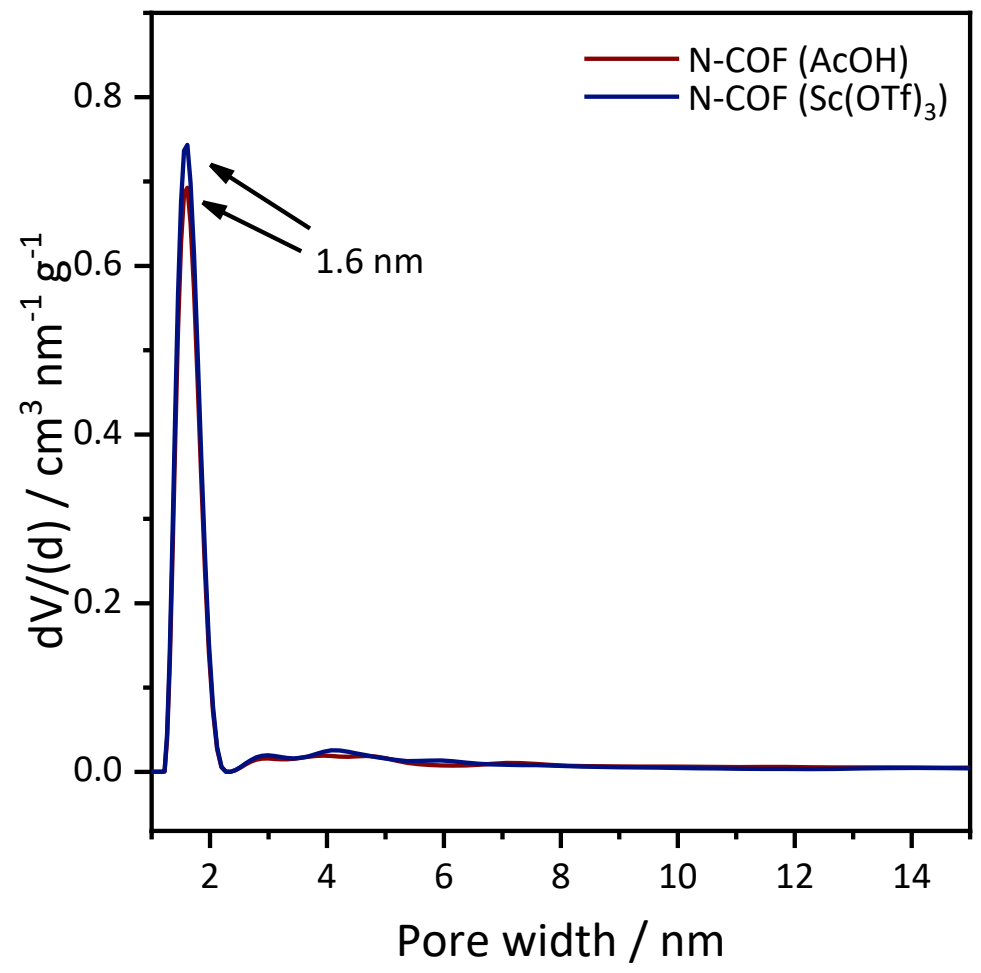

Figure S52. Pore size distributions of $\mathbf{N}-\mathrm{COF}(\mathrm{AcOH}), \mathbf{N}-\mathrm{COF}\left(\mathrm{Sc}(\mathrm{OTf})_{3}\right)$ derived from $\mathrm{N}_{2}$ sorption isotherms. 


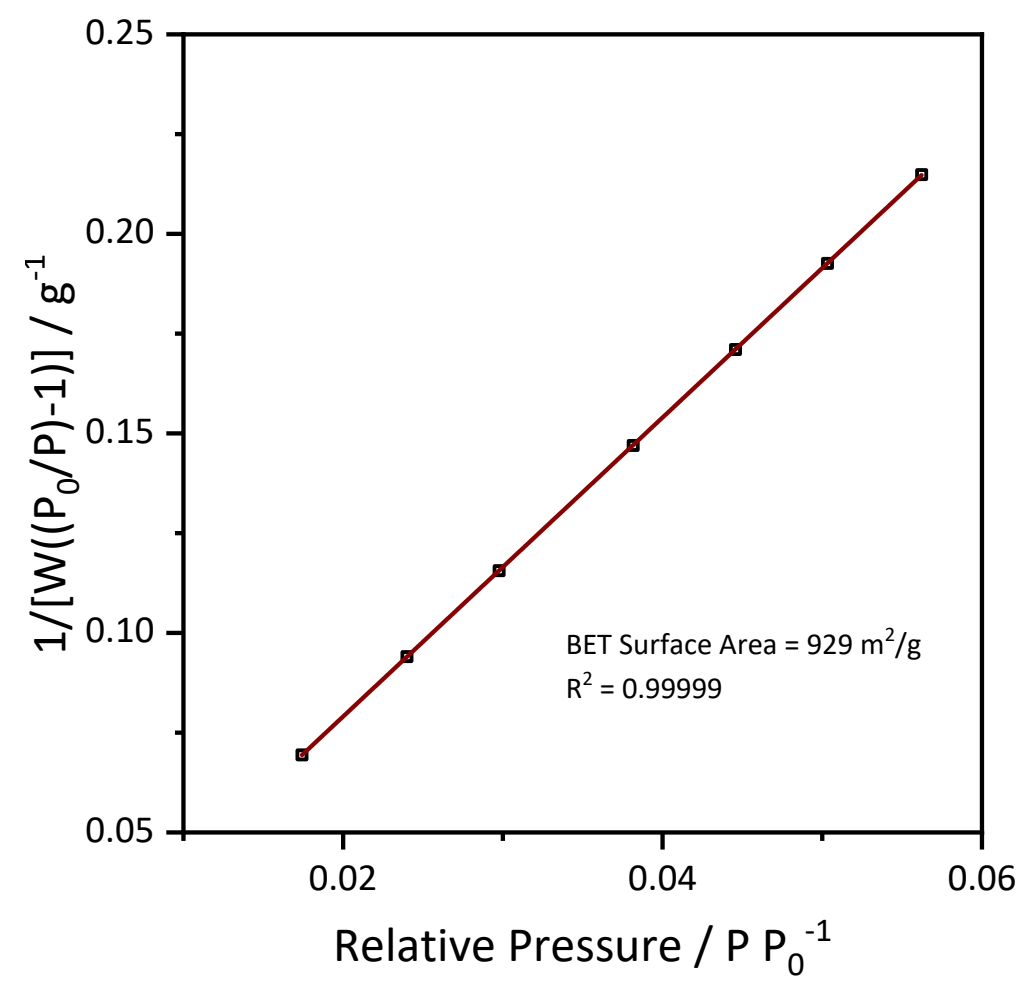

Figure S53. Multi-point BET surface area fit of $\mathbf{N}-\mathrm{COF}(\mathrm{AcOH})$ derived from $\mathrm{N}_{2}$ sorption isotherm.

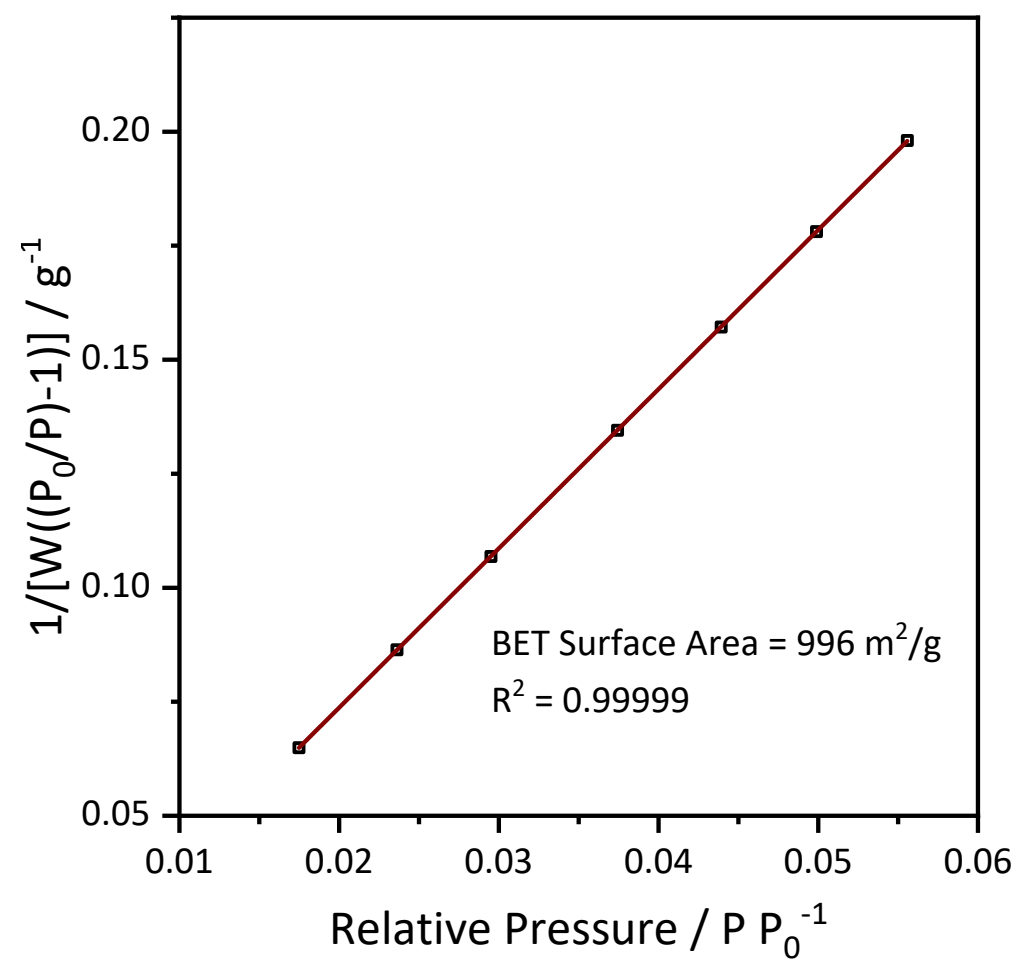

Figure S54. Multi-point BET surface area fit of $\mathrm{N}-\mathrm{COF}\left(\mathrm{Sc}(\mathrm{OTf})_{3}\right)$ derived from $\mathrm{N}_{2}$ sorption isotherm. 


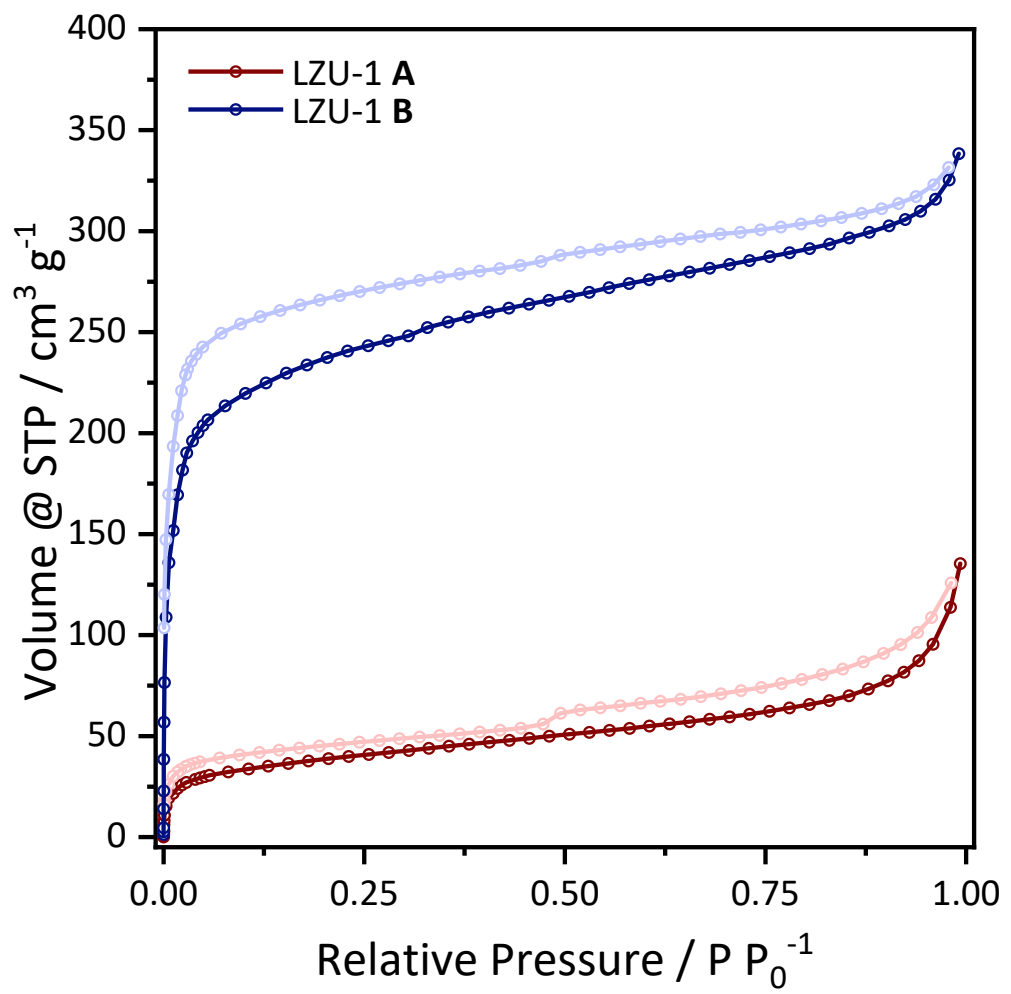

Figure S55. $\mathrm{N}_{2}$-Isotherms of COF-LZU1 with (A) mesitylene and (B) 1,4-dioxane as a liquid additive, measured at $77 \mathrm{~K}$. Darker colors represent adsorption, while lighter colors represent desorption.

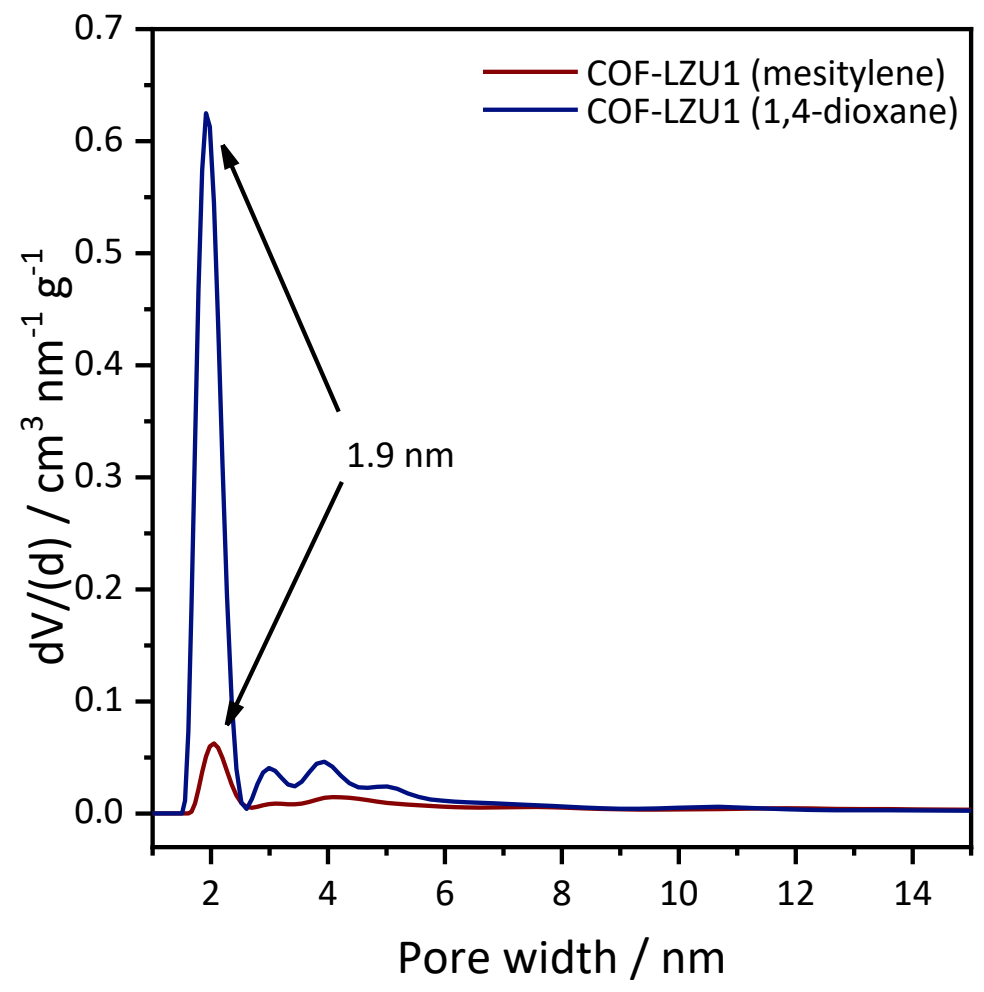

Figure S56. Pore size distribution of COF-LZU1 with mesitylene (red) and 1,4-dioxane (blue) derived from $\mathrm{N}_{2}$ sorption isotherms. 


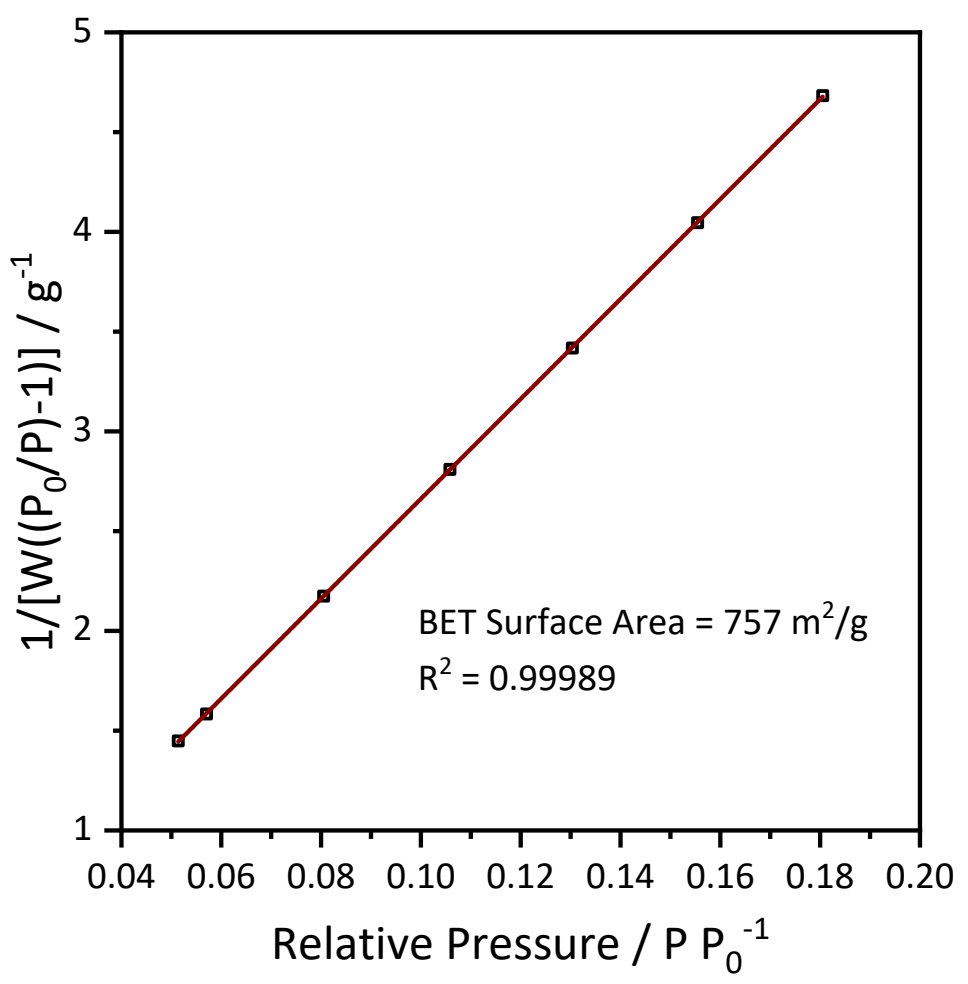

Figure S57. Multi-point BET surface area fit of COF-LZU1 (mesitylene) derived from $\mathrm{N}_{2}$ sorption isotherm.

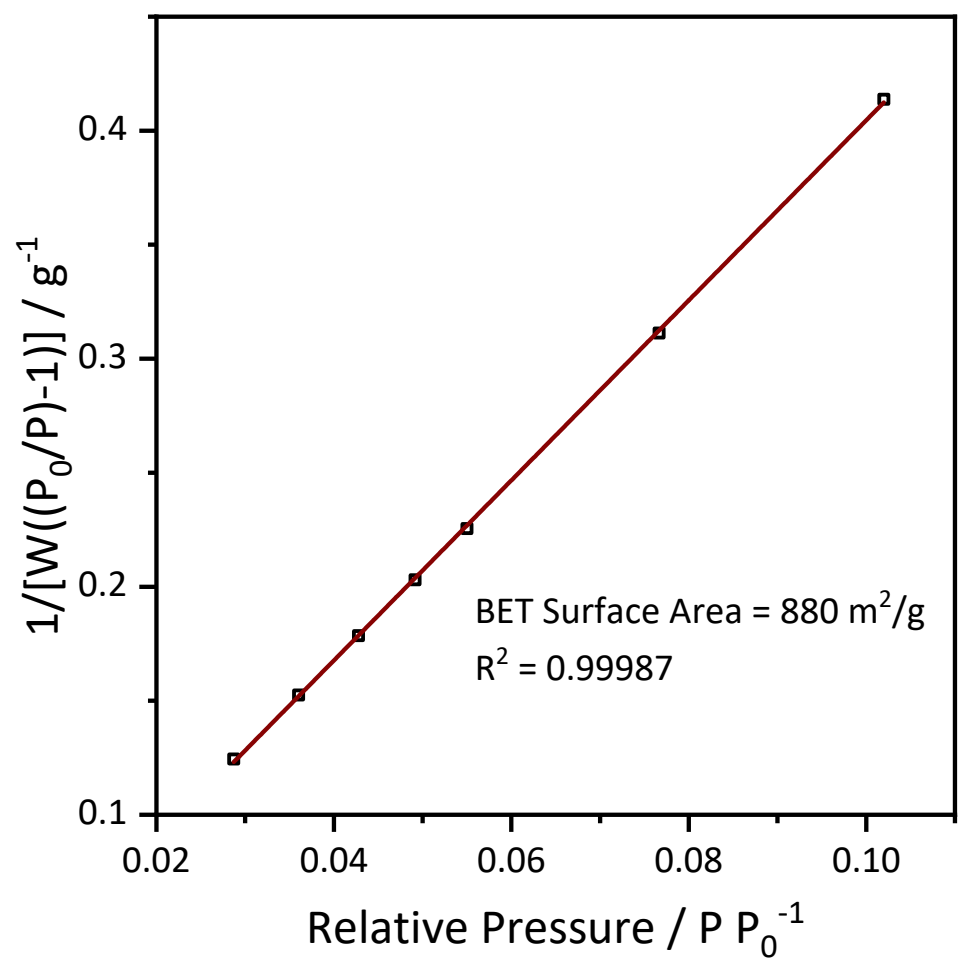

Figure S58. Multi-point BET surface area fit of COF-LZU1 (1,4-dioxane) derived from $\mathrm{N}_{2}$ sorption isotherm. 


\section{S8 Thermogravimetric Analysis}

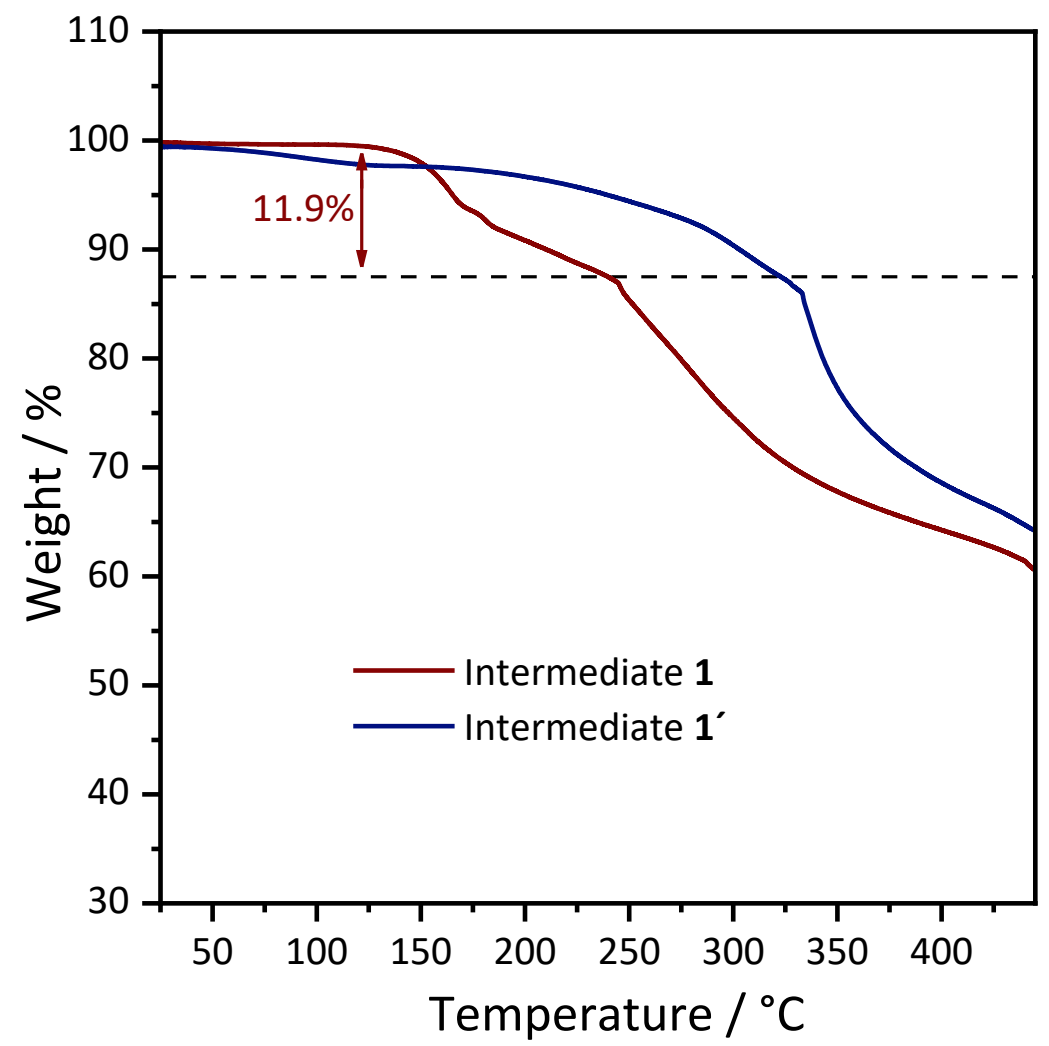

Figure S59. TGA curves for intermediate 1 and its non-solvated form $\mathbf{1}^{\prime}$. Measured mass loss of $11.9 \%$ starting at ca. $150{ }^{\circ} \mathrm{C}$ corresponds to desolvation process and release of 1,4 -dioxane $\left(\Delta \mathrm{m}_{\text {calc }}=17 \%\right)$. 


\section{S9 References}

[1] V. S. Vyas, F. Haase, L. Stegbauer, G. Savasci, F. Podjaski, C. Ochsenfeld, B. V. Lotsch, Nat. Commun. 2015, 6, 8508.

[2] I. Halasz, S. A. J. Kimber, P. J. Beldon, A. M. Belenguer, F. Adams, V. Honkimäki, R. C. Nightingale, R. E. Dinnebier, T. Friščić, Nat. Protoc. 2013, 8, 1718-1729.

[3] C. Prescher, V. B. Prakapenka, High Press. Res. 2015, 35, 223-230.

[4] A. P. Hammersley, ESRF Intern. Rep. 1998, ESRF98HA01, FIT2D V9.129 Reference Manual V3.1 (1998).

[5] E. J. Sonneveld, J. W. Visser, J. Appl. Crystallogr. 1975, 8, 1-7.

[6] S. J. Clark, M. D. Segall, C. J. Pickard, P. J. Hasnip, M. I. J. Probert, K. Refson, M. C. Payne, Zeitschrift fur Krist. 2005, 220, 567-570.

[7] T. Björkman, Comput. Phys. Commun. 2011, 182, 1183-1186.

[8] J. P. Perdew, K. Burke, M. Ernzerhof, Phys. Rev. Lett. 1996, 77, 3865-3868.

[9] S. Grimme, J. Comput. Chem. 2006, 27, 1787-1799.

[10] C. J. Pickard, F. Mauri, Phys. Rev. B - Condens. Matter Mater. Phys. 2001, 63, 24510112451013.

[11] S. Sturniolo, T. F. G. Green, R. M. Hanson, M. Zilka, K. Refson, P. Hodgkinson, S. P. Brown, J. R. Yates, Solid State Nucl. Magn. Reson. 2016, 78, 64-70.

[12] L. S. Germann, A. D. Katsenis, I. Huskić, P. A. Julien, K. Užarević, M. Etter, O. K. Farha, T. Friščić, R. E. Dinnebier, Cryst. Growth Des. 2020, 20, 49-54.

[13] L. S. Germann, M. Arhangelskis, M. Etter, R. E. Dinnebier, T. Friščić, Chem. Sci. 2020, DOI 10.1039/D0SC03629C.

[14] M. Lee, H. Kim, H. Rhee, J. Choo, Bull. Korean Chem. Soc. 2003, 24, 205-208. 
